Linköping Studies in Pedagogic Practices No. 29

Linköping Studies in Education and Social Sciences No. 10

\title{
Present absences
}

\section{Exploring the posthumanist entanglements of school absenteeism}

\author{
Linnea Bodén
}

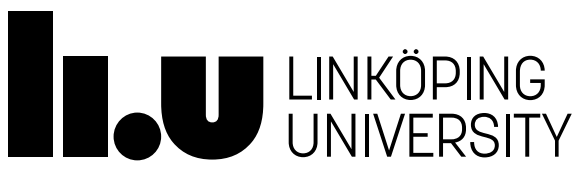

Faculty of Educational Sciences

Linköping 2016 
Linköping Studies in Pedagogic Practices No. 29

Linköping Studies in Education and Social Sciences No. 10

\section{Linnea Bodén}

\section{Present absences}

Exploring the posthumanist entanglements of school absenteeism

Faculty of Educational Sciences | Department of Social and Welfare Studies Pedagogic Practices

ISBN 978-91-7685-722-9

ISSN 1653-0101

Cover design: Linda Olofsson

Cover photo and embroidery: Linnea Bodén

(C) Linnea Bodén, 2016

Printed by LiU-tryck, Linköping 2016

Distributed by:

Department of Social and Welfare Studies

Linköping University

S-581 83 Linköping

SWEDEN 
Till Ian och Ellis

Till mormor 


\section{Acknowledgements}

This thesis is about entanglements. In a moment, I want you to close the book and look at the front cover: the backside of a cross-stich embroidery picturing a circuit card. I want you to look at the threads and the entangled 82482 stiches going up and down through the fabric. For about five years, this embroidery has been part of my writing. Each stich has become an entrance, and engagement, an entanglement into the thesis.

This thesis is about present absences and I want you to imagine the front side of the circuit card, always present in its absence. You can close the book now (but please open it again).

Thanks to the stiches, threads and needles for keeping my company through these years. I could not have done this without you. But more importantly, I could not have done this without all students, teachers and parents being part of the study. Thanks for so generously inviting and engaging with me. Thanks also to Skolwebben and Dexter for being the most interesting, strange and provocative research partners I could imagine.

Thank sincerest you to my supervisors! Thanks Eva Reimers for your careful readings, challenging questions and for always reminding me to have fun. Thanks to Ann-Marie Markström, who never stopped asking me 'What's the problem?!'. Thanks for your warm support, at all times. I have missed you in Norrköping. Thanks to Hillevi Lenz Taguchi. Despite the short time as a my supervisor, your brave ideas and feminist brainpower have been so important for this study. Thanks to the readers of my manuscript in different stages of the process. Magnus Dahlstedt, your encouraging comments during my first grading seminar were a necessary start. Thanks to Andreas Fejes, the half time reader. Together with Anna Bredström and Susanne Severinsson in the committee, your thoughtful reading helped me focusing the text on the essentials. Thank you Dorthe Staunæs! Your precise, careful and affirmative comments as the reader at my final seminar made all the difference to the thesis. Thanks to Tomas Saar, part of the committee. I truly appreciate the boosting e-mail you sent me after the seminar. And thanks again to Hillevi and Susanne, part of the committee. Your comments at this stage were crucial. 
This thesis would not be what it is without the creative, curious and open research environment of Educational practice (sic!) at Campus Norrköping, Linköping University. Thanks to all my dear colleagues for enabling this! Thanks to Eva Reimers and Jakob Cromdal for your on-going work to maintain and develop the positive culture. The 'working seminars' have been essential for my thinking. Thanks to Polly Björk-Willén and Tünde Puskás for organizing the seminars. A special thank you to Anna Ericson. With you as a department administrator, I have always felt confident in confusing times. Thanks also to Thomas Dahl, head of division at LEN (Learning, Aesthetics, Natural science), for finding ways to give me some extra time (=peace) during the last intense months of writing.

During these years, I have had the pleasure of being part of a number of interesting contexts, where I have learned a lot. Through the ERASMUS Programme Teaching Assignment, I had the honour of spending five weeks at the Institute of Education, University College London. Thanks Jessica Ringrose for your hospitality and for making these weeks a truly feminist, posthumanist and fabulous experience! 2012-2014 I was a member of the Board of the Faculty of Educational Sciences. I got an invaluable insight into the complex academic world. Thanks to the Dean at the time, Karin Mårdsjö Blume, for being a steady chairman that made this experience a joy. I also had the privilege to be part of organizing the Gender Lab, a collaboration between Linköping University and Stockholm University. I came to learn so much new and important things about gender equality and the academia. Thanks to the project leaders Cecilia Åsberg and Hillevi Lenz Taguchi for creating an important platform.

Thanks to all the amazing PhD students I have come to now, which some of you are already PhDs. Thanks to my colleagues in Norrköping: Anna Bylund! For all the crucial talks, laughs and tears. Thanks for the runs in the snow, thanks for the never-ending lunches. Your brilliance and friendship have been my boat with oars, sail, and engine (despite you being a bad painter). Linnéa Stenliden, thanks for being the perfect roommate and for always having a smile and a kind word to share. Thanks to Anders Albinsson, Daniel Björklund, Sara Dalgren, Katarina Elfström Pettersson, Martin Harling, Rizwan-Ul Huq, Linda Häll, Kirsten Stoewer, Lina Söderman Lago and Lasse Wallner. I am so glad to have come to know you all! Thanks to the great feminist 'Dissertation liberation army' at Linköping University: Sara Alhstedt, Veronica Ektröm, Karin Krifors, Jennie K Larsson, Sofia Lindtröm and Hanna Sjögren. Our conversations about life in academia have been important, fun and irreplaceable. Riikka Hohti, Simon Ceder, Camilla Andersen and Sofie Sauzet. Conversations with you - virtual and actual always expands my brain. Thanks for being great friends and brilliant scholars! Karin Gunnarsson, I am so glad for all the things we have shared during these years. Thanks for always being totally honest, totally kind-hearted and totally 
amazing. My dear friends at the 'extra office' in Gröndal: Jennie K Larsson, thanks for convincing me that an office in tumble-down building is a good idea. It is, with you as the best lunch date and talking partner ever. Thanks for the shared black metal fascination, even if we will never become 'true'. And Emilie Moberg, I am so glad that you came to join us. Thanks for always making me coffee, thanks for your generosity in your numerous readings of my texts and thanks for helping me to come up with the idea on how to organize the thesis. I also want to thank Rebecca Lawrence, who many years ago - when she was a $\mathrm{PhD}$ student at the Department of Sociology at Stockholm University supervised my Bachelor's thesis in Sociology. Thanks for standing up for my work, despite the critique from the department. It is not until recently, as a $\mathrm{PhD}$ student myself, I have realized what an amazing and brave thing you did. Thanks for encouraging me to continue the 'academic career'. I hope I will someday make that difference for a student.

The 'Stockholm gang', to old and new friends: Lena Aronsson, Klara Dolk, Christian Eidevald, Teresa Elkin Postila, Christine Eriksson, Karin Hultman, Kajsa Ohrlander, Anna Palmer and Hedda Schönbäck. You make me shine! Thanks to my language consultant Constance Ellwood, who have helped me with all parts of the thesis. Thanks for your thorough work and for the kind words during the last weeks of writing. Thanks to Susan Nordstrom for being a great and fantastic friend and thinker (please move closer!). And thanks to Sylvie Allendyke, for being my kindred spirit. In joy and in hard times, in music and in looks, in shoe size and ring size, in birthdays and in theorizing. Thanks for the Jesus \& Mary Chain gig, I will never forget it. xx

To my friends outside the academia: Cissi, thanks for being the coolest living thing on earth, for being a great great friend and my favourite pair of shorts. Thanks for fifteen years of rambling joy! Sara M, thanks for helping me with the chewing gum and surviving the 'högstadiet' with me and for still being one of my closest friends. Sara S, I always feel so good when I see you. You are wonderful, in all kinds of ways. Thanks to all the friends and our travels: Anna, Björn, Emil, Gabriella, Ida, Johannes, Kalle, Marcus, Matilda, Olle and Sanna. The stone castle, the horseback riding, the saucepan lids in the Basque Country; the PetroMax, the bacalhau, the surfing in Portugal; beer and food in Copenhagen. And all the ones I have not travelled with yet: Markus and Martina, so glad that we met! Linda J, Erik, Anders, Peter, Rasmus, Hanna and Patrik, Eva-Lo och Anders! A special thanks to Linda $\mathrm{O}$ for the front cover to the thesis.

To my dear dear family. Thanks to Rosanders, my beloved extra family. Thanks to Eva and Sten for the invaluable help and support during these years. Thanks for being the best farmor and farfar in the world! Thanks to Sofia, Jacob and John, I love you as my own siblings. Thanks also to Karin and Thomas, and welcome to the world Ludwig! To my Grummas-family, and especially to my 
mormor May. You are the most amazing person I have ever met and a true inspiration in everything I do. Thanks for reminding me to vyyyla and for loving me unconditionally. Not even fräk is enough to describe you! To Affe: I am so thankful for the love you give to my mother. And to Ingela: meeting you have made my father shine! Mamma, thanks for always being there for me. Thanks for your warmness and for making me laugh till I cry. Pappa, thanks for calling every Friday, thanks for your strength and humour. You will get through this! I love you mamma och pappa! My little brother Jonatan: thanks to Johanna for making my brother so so happy. And to you Jonatan, Brötchen. You are always close to me, even if you are always too far away. I can't describe how glad I am to have you in my life!

And finally, the three persons that are closes to my heart. Ellis, thanks for all the ideas and thoughts that made it into this thesis. We created them together, laying entangled and face-to-face (or maybe brain-to-brain), not asleep but almost. Thanks for your sparkling happiness! Ian, thanks for being the smartest and loveliest persons I know. Tack för att du påminner mig om att inget kan gå fel när en jobbat med något så länge. Thanks for the shoulder massage when I sat in front of the computer one of the last days of writing. And Olof. I am so grateful that you, not for a moment, have hesitated in encouraging me to take the job, go to London, or any other of my ideas. Thanks for all the times you didn't mentioned how tired you were of THE THESIS. Thanks for only mentioning it two or three times (at the most five...). Thanks for making everything everything work. Thanks for still making my heart beat faster. Lika litet som en hasselnöt, ja nästan litet som en ärta. 



\section{Contents}

INTRODUCING PRESENT ABSENCES 1

School absenteeism and digital registration 3

School absenteeism as an individual problem $\quad 5$

Software as a neutral and efficient tool 6

Autonomous humans and neutral materialities - a humanist composition 8

School absenteeism as a posthumanist phenomenon 9

$\begin{array}{ll}\text { Cutting together/apart the apparatuses of knowing } & 12\end{array}$

$\begin{array}{ll}\text { Aim and questions } & 13\end{array}$

Entrances, Entanglements, Engagements: guidance through the text 14

$\begin{array}{ll}\text { ENTRANCES } & 15\end{array}$

Entrancing a Swedish history of school absences and presences 16

Entrancing school absenteeism and digital registration 19

$\begin{array}{ll}\text { Research on school absenteeism } & 19\end{array}$

$\begin{array}{ll}\text { Research on digital registration } & 23\end{array}$

$\begin{array}{ll}\text { Concluding words on previous research } & 27\end{array}$

$\begin{array}{ll}\text { Entrances to the software and the schools } & 28\end{array}$

Digital software for school absence registration $\quad 28$

$\begin{array}{ll}\text { Three Swedish schools } & 31\end{array}$

In conclusion: entrances as a dislocation of referent? 32

$\begin{array}{ll}\text { ENTANGLEMENTS } & 33\end{array}$

Posthumanist approaches to researching school absenteeism $\quad 34$

Humans and nonhumans as entangled $\quad 35$

$\begin{array}{ll}\text { The agency of materialities } & 37\end{array}$

Theoretical entanglements with concepts $\quad 38$

Concepts cutting out the ontoepistemologies of school absenteeism 38

Concepts cutting out the 'how' of school absenteeism 40

Cutting together what was cut apart: entangling what and how 44

In conclusion: entanglements as a queer twist of time? 45 
$\begin{array}{ll}\text { Ethical engagements in research } & 47\end{array}$

$\begin{array}{ll}\text { Engagements with post-qualitative methodologies } & 48\end{array}$

Empirical engagements to explore practices $\quad 49$

Human and nonhuman conversations $\quad 53$

Emerging empirical productions $\quad 56$

$\begin{array}{ll}\text { Processes of analysis } & 60\end{array}$

Engagements with shimmery and gloomy glows $\quad 61$

$\begin{array}{ll}\text { Engagements with questions } & 62\end{array}$

Summaries of the research papers 63

I. 'Seeing red?' The agency of computer software in the production and management of students' school absences

II. The presence of school absenteeism. Exploring methodologies for researching the material-discursive practice of school absence registration 64

III. Dexter time. The space, time and matterings of school absence registration 65

IV. Going with the affective flows of digital school absence text messages $\quad 66$

Summary of the summaries 66

In conclusion: engagements through the waves and undertow? 67

DISCUSSING PRESENT ABSENCES

$\begin{array}{ll}\text { What becomes of the phenomenon of school absenteeism... } & 69\end{array}$

...in entanglements with digital technologies? $\quad 70$

...in the apparatuses of knowing? $\quad 72$

$\begin{array}{ll}\text { What is absent becomes present } & 74\end{array}$

$\begin{array}{ll}\text { Present absences and the potential of school absenteeing } & 75\end{array}$

$\begin{array}{ll}\text { SVENSK SAMMANFATTNING } & 78\end{array}$

$\begin{array}{ll}\text { Bakgrund och teoretisk situering } & 79\end{array}$

$\begin{array}{ll}\text { Syfte och frågeställningar } & 81\end{array}$

Empiriska engagemang $\quad 82$

$\begin{array}{ll}\text { Resultat och diskussion } & 83\end{array}$ 


\section{RESEARCH PAPERS INCLUDED IN THE THESIS}

I. Seeing red? The agency of computer software in the production and management of students' school absences

II. The presence of school absenteeism. Exploring methodologies for researching the material-discursive practice of school absence registration

III. Dexter time. The space, time and matterings of school absence registration

IV. Going with the affective flows of digital school absence text messages

\section{APPENDIX I}

Digital software for the registration of absences in the municipalities of Sweden

APPENDIX II

Interview guide, teachers

APPENDIX III

Interview guide, parents

APPENDIX IV

XIV

Interview guide, students 



\section{Introducing present absences}

When I was in Grade 7, I got a detention. I had gotten three 'dots' in the green book, and three 'dots' meant that you were reprimanded. The green book had a column next to each student's name, and 'dots' were placed there by our teacher when someone arrived late or was absent without approval. Rather than being asked to stay in the classroom after the lesson, to work on school-related tasks, my best friend Sara and I were assigned to remove stale chewing gum from the floor of the school hallway using a razorblade. I can still feel the sense, for a moment, of being one of the cool kids, one that breaks rules and 'has dots'. But mostly I remember the shame of crawling on the floor between the tables and benches where the $9^{\text {th }}$ graders were sitting. I had never thought of myself as a student who plays truant or has a problem with absences, and I don't think that any of my teachers or classmates would have described me in that way either. However, down there on the floor with the chewing gum, what became clear was that together with the green book, the 'dots' and the discursive understandings of how to handle absent students, my three late arrivals had become a problem. My absences had become present in and through the entanglements of practices and discourses on how to punish misbehaving students, emotions like shame and feeling cool, and materialities like chewing gum, dangerous razorblades, the green book and the 'dots'. The entanglements had produced the materialities as agential forces that needed to be acknowledged (Alaimo \& Hekman 2008; Coole \& Frost 2010) and school absenteeism emerged as a 'not-human-alone' activity, closely 
connected to the material tools by which the absences were registered and managed. Or, to borrow the words of Barad (2007), school absenteeism became a material-discursive phenomenon, in the entanglements of humans, nonhumans ${ }^{1}$, discourses, materialities and practices.

Since the event in the hallway, a major shift has taken place in relation to the registration of students' absences and presences in Swedish schools. What was then written, or 'dotted', in a green book is now digitally recorded and managed through various software ${ }^{2}$ programs such as Dexter, edWise, Fronter, InfoMentor, Hypernet, Ping Pong, SchoolSoft, Skola24, Skolwebben, Unikum, or Vklass. When I performed a review of the 290 municipalities of Sweden, to get an overview of how widespread the use of software for the registration of absences and presences was, the result was striking: all 290 municipalities were working with, or were ready to start working with, some type of software in public elementary schools (see Appendix I). ${ }^{3}$ It can thus be claimed that in recent years, the materialities surrounding the registration have transformed from books and 'dots', to software, computer screens, text messages and so on. School absenteeism has become 'digitalized'. But how has this affected the practices surrounding registration? And what entanglements and relations of humans, nonhumans, discourses and materialities become part of what is known as school absenteeism? How have absences become present through this? Accordingly, the challenge of this study is not to examine whether the software are important for the phenomenon of school absenteeism, but rather how they are important, and how they become important, in the relations between teachers, school management, students, parents, school facilities, schedules, and so on. This means that the main interest of the study is to explore how the phenomenon ${ }^{4}$ of school absenteeism is produced in entanglements of humans and nonhumans, when absences and presences are digitally registered.

In the methodological approach of empirical engagements I worked with two different types of software for the registration of absences and presences at three Swedish schools: the software Skolwebben at Kardinal School (in City 1), and the

${ }^{1}$ The words nonbuman and materialities are used interchangeably in the thesis, to refer to what in practices are separated from humans. These concepts are both referred to in the literature on posthumanism I am inspired by. I discuss them in the section of the thesis named Entanglements.

${ }^{2}$ I use the word software as an umbrella term for what is variously referred to as applications, web applications, administrative systems, platforms, portal services and so on, for the registration of school absences and presences. What links the types of software discussed in the thesis is that they are web based.

${ }^{3}$ Similar systems are used around the world (for example in Australia, Brazil, China, Denmark, England, Finland, Norway, and the U.S.).

${ }^{4}$ In this study, phenomenon is a theoretical concept introduced by Bohr and further developed by Barad (2003; 2007). I introduce this concept below, but in this first part of the introduction, use it in a colloquial sense. 
software Dexter at Sandö School and Björnäng School (both located in City 2). ${ }^{5}$ In four research papers I methodologically and theoretically explored the practices surrounding digital registration. Together with clocks, computer screens, concepts, doors, hallways, methodologies, parents, schedules, software, smartphones, students, teachers, theories, text messages and much more, present absences emerged and this is what the thesis is about.

\section{School absenteeism and digital registration}

Students' presences - that is, being present at the right lesson, at the right time could be described as one of the foundations of the Swedish educational system. The widespread use of software to ensure this presence can be understood in the light of an on-going intertwining of education and digital technologies ${ }^{6}$ (see for example Hansson 2013; Selwyn 2011; Stenliden 2014), and in the light of what has been referred to as "digital educational governance" (Williamson 2016). But the digital technologies could also be understood as facilitating Swedish schooling policy. The Swedish Education Act (SFS 2010:800) states that all children must attend school the year they turn seven ${ }^{7}$ and continue their education until they finish Grade 9 (usually they have turned sixteen by that time) (SFS 2010:800, Chapter 7, 2\$, 10\$, 12ई). Compulsory schooling is accompanied by a demand for compulsory school attendance, that states that a student shall participate in schooling unless s/he is ill or has been granted leave (SFS 2010:800, Chapter 7, 17\$). Responsibility is shared between the municipality and the parents/ caregivers; parents have to make sure that children participate in schooling, and the municipality has to make sure that all children fulfil the demand for compulsory school attendance (Skolverket 2010). School absenteeism is an offense, and parents can be penalized with a fine if their child is absent without good reason (SFS 2010:800, Chapter 7, 23 \$).

This policy might make how both the absences and the presences of students should be defined seem obvious. Nonetheless, it has been shown that a number of different concepts and definitions are used to describe school absenteeism, both in research and in everyday language (Reid 2010). This has been described as

\footnotetext{
${ }^{5}$ The names of the schools are pseudonyms, as well as the names of the participating students, teachers and parents. However, the names of the software, Skolwebben and Dexter, are not. Because of the widespread use of both Skolwebben and Dexter, using the actual names should not compromise confidentiality.

${ }^{6}$ Digital technologies are software, hardware and information systems used in institutions to generate and gather data (see Lynch 2015).

${ }^{7}$ Under certain circumstances, this can be extended to the year the child turns eight (SFS 2010:800, Chapter 7, 10ฐ, 11ฐ).
} 
problematic since it has led to a "lack of consensus regarding definition, assessment, and treatment" (Kearney 2003, 57). Whether an absence is described in terms of 'lurking', 'hiding' or as something unauthorized - understandings associated with the concept of truancy (Gentle-Genitty et al. 2015) - or in terms of anxiety or an irrational fear of going to school - understandings associated with the concept of school phobia (Chitiyo \& Wheeler 2006) - produces different connotations. In Sweden the terms 'hallway ramblers' (students that go to school without attending lessons) and 'home sitters' (students that do not attend school at all) (Ekstrand 2015; see also Strandell 2009), show additional understandings of absences and presences. It is crucial, in this context, to see that there are in fact many ways of being present or absent in school settings, and that teachers and students negotiate the importance, impact and consequences of various forms of presences and absences in situated contexts every day. Absences can occur when students do not attend school at all and when they attend the school but not the lessons (Strandell 2009), and when they attend the lessons without performing the assigned tasks, referred to as "absences in class" (Jonasson 2011). Defining absences and presences is thus difficult. Furthermore, definitions of school absences/presences affect understandings of how an absence emerges, how farreaching it is, and its effects (Jonasson 2011; Gottfried 2009; Reid 2006).

However, when it comes to the digital registration of absences and presences, definitions are precise: either a student is in the classroom in the right lesson and at the right time, or $\mathrm{s} /$ he has a valid reason for not being there, or $\mathrm{s} / \mathrm{he}$ is regarded as being absent. When absences meet the binary of digital registration either you are present or absent - they are defined as 'bodily'. This means that nothing other than the physical presence of an identifiable human body in the classroom is regarded as presence. It could be claimed that digital registration produces a change in definitions of school absenteeism: from very vague, to very precise. But despite an intense focus on how students' absences and presences should be managed and recorded, and the far-reaching use of software to accomplish this, school absenteeism has rarely been thought of in the light of such comprehensive digital registration. This points to an under-researched, almost neglected, area within educational research on school absenteeism: the actual digital tools that thousands of schools engaged with in everyday encounters with absenteeism and the practices this produce in educational settings. Two different, but related, discourses can be theorized as contributing to this: notions of the responsible (e.g., blameable) individual student, and notions of digital technologies as neutral and effective. These discourses are unfolded in the following section. 


\section{School absenteeism as an individual problem}

School absenteeism, non-attendance and truancy have been described as problems existing worldwide (Gentle-Genitty et al. 2015), and as having substantial cost implications not only for the individual learner but also for the wider society (Maynard 2014; Strand 2013). According to a survey performed as part of the PISA study in 2012, 21\% of the Swedish students had skipped class once or a couple of times during the two weeks preceding the PISA test. This is close to the average number for the OECD (18\%). More remarkable is the fact $56 \%$ of Swedish students answered that they had arrived late to a lesson sometime during the last two weeks. This number is significantly higher than the $35 \%$ that is the average number for the OECD (OECD 2013). The OECD report describes this as an acute problem, but highlights at the same time explanations for late arrivals, such as public transport that does not match the start of the school day. However, when these results reached the Minster of Education in office at the time, Jan Björklund, he addressed Swedish teachers, stating: "Lock the classroom door!" (Hennel 2013, my translation). Even if this is understood as a political move, in the epoch of PISA results, it highlights something crucial in relation to students' unexcused absences or late arrivals: the individual student is the one to be 'locked out', responsible but also blameable. The statement can be seen as an example of what happens when individualist notions and explanations of school absenteeism are taken to the extreme. But it points to something that recurs in public debate, research and policy: explanations for school absenteeism are to be found 'within' the individual student - not in the educational setting, not in the public transport system, and not in any other materialities that offer possibilities of being on time or late, present or absent. The student is seen as an autonomous individual, separated from the educational surroundings.

Research on school absenteeism has problematized individualistic notions and highlighted the way the focus on the individual impedes discussions of the complexities of school absenteeism (Corville-Smith et al. 1998; Ekstrand 2015; Sutphen, Ford \& Flaherty 2010; see also Skolverket 2008; 2010). Nevertheless, individual-centred understandings of students' absences and presences dominate research on school absenteeism. Characteristics related to the individual student's psychological or psychosocial problems, his or her (lack of) abilities or knowledge, and the effects of poorly motivated home environments (Huck 2011; Karlberg \& Sundell, 2004; Kearney \& Bensaheb 2006; Kozina 2015; Reid 2015; Sommer 1985; Sheppard 2007; Sundell, El-Khouri \& Månsson 2005; Veenstra et al. 2010) have become recurring explanations for absences.

Traces of the individualistic understandings of school absenteeism are to be found in the Swedish Education Act and I highlight two formulations that are important in understanding the practices of digital registration. From 1 July 2012, 
a new writing of the Swedish Education Act stated that Swedish schools were obliged to report students' unexcused absences in the report cards for each semester (SFS 2011:506). ${ }^{8}$ The statutory requirement that absenteeism should be reported to parents on the same day as the absence takes place (SFS 2010:800, Chapter $7,17 \S$ ) is yet another political decision that has put a focus on schools' management of students' absences. It can be claimed that both these requirements are discursively informed by understandings of school absences as primarily related to the individual student. The 'punishment' of the individual student (having the absences registered in the report card or relayed to a parent) can be understood as justified since the absences are connected foremost to the behaviours of the student. This also points to how absenteeism is expected to be handled by the home.

Studies and reports conducted in the educational sciences and social work have stressed that when responsibility for absence is understood as located within the individual and/or family, the role of the educational system becomes difficult to address (Strand 2013; Skolverket 2008; 2010). A conclusion that can be drawn from this is that, when absenteeism is reduced to something individual and easily identifiable, both explanations and actions can fail to reduce students' absences. Nevertheless, that absences and presences are easy to define and distinguish becomes the rationale that motivates the work with digital software. The software is produced as an invisible, but nevertheless important, tool to display, summarize and structure what is already 'obvious': the student is either absent or present.

\section{Software as a neutral and efficient tool}

The charting, controlling and registering offered by the digital devices can be understood as facilitating the terms of the Education Act. The requirement for notes on absences in the report cards means that a thorough check of each student's absences and presences must take place and that no mistakes can be made in this reporting, since this has major implications for students. Furthermore, the requirement to inform parents on the same day of an unauthorized absence, requires that the process - from the discovery of an absence, to registering it, to informing the parents - is speedy. It could be claimed that the combination of these requirements has created a market for accurate, swift and effective ways to manage the registration of students' absences and presences in Sweden. Together with the text message service that sends automated messages (or e-mails) from the software to parents when a student arrives late or is absent without permission, the various software programs have

8 The requirement (SFS 2010:800, Chapter 6, 129) has recently been removed from the Education Act. However, by the time of the empirical engagements of this study (2012-2013), it was a writing that in different ways affected the practices surrounding school absenteeism. 
become a solution to statutory demands. But it could also be claimed that the digitalisation of the registration, and the tools that help facilitate this, have become part of the rationale that have formed the policy, i.e., that the swift and frequent control the tools offer has enabled the statutory writings.

Collaboration between schools and families have been described as a key aspect of school attendance and absenteeism (Carroll 1986; Skolverket 2008; 2010), and both the software and the contact with parents through text messages have become a way to maintain these relations. Early research on school absenteeism conducted within the field of education emphasized that, despite an increased focus on control, disciplinary actions and registration, such actions are not an effective intervention to reduce absenteeism (Fraser 1987; Jönsson 1990). However, current research focusing on registration is with few exceptions conducted in the field of computer science. These studies highlight the software as a means for a more accurate management of school absenteeism that limits 'human errors', and promote the real-time information to parents on students' absences and presences as one of the benefits of registration (see for example Ervasti, Isomursu \& Kinnula 2009; Isomursu et al. 2011; López Fernández et al. 2013; More \& Nayak 2013). The software is thus inevitably interwoven with expectations of an improved handling of school absenteeism. Williamson (2016, 3f.) points out that "[c]ontemporary education is increasingly organized through a densely networked apparatus of computer code, algorithms, database infrastructures, architectures, servers, platforms and packages", but that the actual software, systems and technologies often become hidden. The focus of research on software in education is on its technological aspects (sometimes with an interest in usability), rather than on how technologies effect and affect everyday procedures in schools: the research becomes a 'black-boxing' that hides the "social processes, technological histories, power plays and beliefs" (Lee 2009, 17) that have shaped the technology. This is also true of the studies on the digital registration of absences and presences. Even though researchers in recent times have paid more attention to the effects of digital technologies in education ${ }^{9}$, the limited number of educational studies focusing on digital registration points to something crucial: the software is often forgotten or unnoticed since it is primarily understood in terms of a neutral tool to facilitate a more efficient and modern educational setting (Ozga 2016). Sørensen (2009) describes how the practices produced and performed in relation to new technology in education are often overlooked, even when a great amount of time and financial resources have been invested in that technology. One explanation for this may be that software is seen as a 'tool'. This concept of tool implies a neutral and passive device used by

\footnotetext{
${ }^{9}$ See for example the special issue on "Digital Education Governance", edited by Willamson (2016) in European Educational Research Journal.
} 
humans to achieve certain goals. In relation to the digital registration of absences and presences, teachers, parents and students are expected to use the software to streamline and improve the management of absence administration and to get trustworthy information on absences and presences; the software is understood as the most efficient tool to achieve this.

\section{Autonomous humans and neutral materialities - a humanist composition}

Above, I have described prevailing dominant notions of the individual student's responsibility for school absenteeism and notions of neutral and effective digital technologies as related to each other. I would claim that both of these strands of thought depart from the same ontological ground: assumptions within humanism and humanistic ideologies. Wolfe (2010, xiv-xv) states that within humanism " the human' is achieved by escaping or repressing not just its animal origins in nature, the biological, and the evolutionary, but more generally by transcending the bonds of materiality and embodiment altogether". Definitions of autonomy and independence have become synonymous with the concept of the human, to the extent that it is next to self-evident that in relation to school absenteeism, individual students are both the ones responsible and the ones to blame, whereas the software becomes a tool to record the absences and presences. When putting the human at the centre, questions focus on how the world can be arranged to support different dimensions of human life, and materialities are understood as instruments for human well-being (Sørensen 2009). These notions thus derive from an anthropocentric tradition, where anthropocentrism is the perception that humankind holds the central position in the universe (Braidotti 2013) and that humans and nonhumans are easily separated categories (Lenz Taguchi 2010). This inevitably eradicates the possibility of understanding how nonhumans - such as software - are part of practices that are foremost understood as human. However, as highlighted by Star (1995) digital software and computers have the capacity to encode only certain aspects of the world - they thus exclude other aspects - which means that computers become productive of simplifications and invisible choices in different practices. Software is thus far from a passive materiality. Furthermore, as humans have become understood as interwoven with surrounding technologies in the critique of the dominant anthropocentrism, notions of independent humans have become difficult to uphold (Åsberg, Koobak \& Johnson 2011a).

By focusing this study on the practices performed and produced around school absenteeism and that involve the interactions of multiple agents, I wish to open up a questioning of the discourses of the independent and responsible student and of technologies as neutral. This makes possible a theorizing of digital technologies as powerful in the entanglements of humans and nonhumans. To 
explore how school absenteeism might be thought of in new ways that question some of the dominant understandings of students' absences and presences, I introduce a posthumanist approach.

\section{School absenteeism as a posthumanist phenomenon}

Within this study, a posthumanist approach offers a way of emphasizing the productive and agential force of materialities, when researching school absenteeism. It is a way of acknowledging how the 'dots' in the example opening this thesis become agentic, and of opening up to the agency of computer software. Registrations of school absences are inevitably connected to discourses of control and surveillance: students need to be on time or otherwise a text message will be sent to their parents, teachers need to do the registration and sometimes fill in for a colleague when there has been a change in the schedule or otherwise the lesson will be colored red on the computer screen, and parents need to remember to notify their children's absences or they will get a text message. A posthumanist approach becomes a way of acknowledging how materialities are crucial in producing and maintaining discourses of control. An interdependence of materialities and discourses is emphasized, which means that there is no rejection of the discursive within a posthumanist approach but rather a repositioning that focuses on intra-actions ${ }^{10}$ of discourses and materialities: "the discursive as always-already material, and the material as always already a discursive construction" (Jackson \& Mazzei 2012, 115). The conjunctive term material-discursive (Barad 2003; 2007) becomes a way of linguistically enacting this ontological prerequisite. Accordingly, the posthumanist approach put to work in this study can be described as a continuation of a Foucauldian theorizing (Foucault 1981; 1995; 2000) on the productive potential of power, discourses and materialities (Hekman 2010; Lykke 2010a). But a posthumanist approach also enables a shift of focus in relation to digital registration: from having the discourses of control and surveillance at the centre of attention to inspiring a production of knowledge that recognizes materialities and nonhumans and extends human relations to include what has previously been understood as peripheral and as a passive background.

When materialities are theorized as intra-acting with humans and as important as humans in the production of various practices, the digital software can no longer be understood as a neutral object that acts in the hands of humans. Thus, agency is not something ascribed only to humans, but emerges in relations

\footnotetext{
${ }^{10}$ The concept of intra-action is distinguished from the more commonly known interaction, which presupposes the existence of independent entities prior to entanglement, and a pregiven split between them. Instead, intra-actions points to the way distinct entities do not proceed but emerge through entanglements (Barad 2007). This is discussed further in Entanglements.
} 
between multiple situated human, and nonhuman, agents (Barad 2007), where agency and agents refer to the capacity to produce and reproduce various practices. This means that both humans and nonhumans are performative agents. Influenced by Butler's $(1990 ; 1993)$ theorizing of performativity as well as the writings of Haraway (1989; 1991), Barad (2003, 808) introduces a posthumanist understanding of performativity ${ }^{11}$ that

incorporates important material and discursive, social and scientific, human and nonhuman, and natural and cultural factors. A posthumanist account calls into question the givenness of the differential categories of 'human' and 'nonhuman,' examining the practices through which these differential boundaries are stabilized and destabilized.

Hence, a posthumanist approach to performativity does not only include human expressions or actions in the materializations and production of a specific phenomenon, but also emphasizes that human and nonhuman agency always presupposes each other (Barad 2003; 2007). This challenges the separation between the human 'users' and the nonhuman 'to-be-used' of digital software, as the technologies are understood as an important and agential co-producer of school absenteeism. Accordingly, Barad (2003; 2007) emphasizes that the point is not to show the independent agency of materialities, but rather that agency is produced in entanglements of humans and nonhumans, not as an attribute but as on-going refigurations of the world. Theorizing nonhumans as agential coproducers of the world in its becomings (Barad 2003, 803) can be seen as a posthumanist continuation of the feminist critique of humanistic notions of who or what to include when researching practices foremost associated with humans. This points to how the focus moves from the human at the centre - where this human often refers to a very specific (hu)Man: "masculine, white, urbanized, speaking a standard language, heterosexually inscribed in a reproductive unit and a full citizen" (Braidotti 2013, 65). What is put to work in this study is thus not a 'gender perspective' (even if gendered discourses are also theorized as affecting school absenteeism) but a feminist imperative that zooms in on what has previously been understood as marginal and non-agentic in different (educational) settings (Braidotti 2013; Haraway 1997; Åsberg, Koobak \& Johnson 2011b; compare also with Sjögren 2016). Making matter come to matter "is a feminist project whether or not there are any women or people or any other macroscopic beings in sight" (Barad interviewed in Dolphijn \& van der Tuin 2012, 59).

11 See also Colebrook (2014a) for a discussion of the differences between a Butlerian and a posthumanist performativity. 
Including the 'peripheral' as a feminist practice is crucial also in the field of educational research (Jackson \& Mazzei 2012; Jones \& Jenkins 2008; Lenz Taguchi 2012; Pedersen 2014; Renold \& Ivinson 2014; Taylor \& Hughes 2016; Taylor \& Ivinson 2013) where it becomes necessary to pay close attention to the changes both human and nonhuman performative agents enable in specific educational practices (Lenz Taguchi 2010). ${ }^{12}$ Within this study, a focus on practices is central, where practices are defined as the concrete acts occurring in the entanglements of humans and nonhumans that have the potential to change - or produce - a phenomenon like school absenteeism. However, a challenge of working with a posthumanist approach when researching school absenteeism is that practices that occur among students, teachers and parents become almost by default human-centred. Pedersen $(2014,84)$ asks if it is possible to reach beyond a human-centred way of understanding the world and, as humans, engage in research that is not anthropocentric. Her answer is both challenging and important for this study. She claims that it is central to separate the anthropogen (practices that derive from human activities) from the anthropocentric. Even if the starting point is that the practices researched are foremost associated with humans, they do not necessarily need to be treated as centred on human actions. Rather, the researcher needs to approach these practices as if materialities and humans are equally important, to be able to produce new knowledge (Pedersen 2014). This means that the definitions, distinctions and decisions on what to include and what to exclude in the processes of research affect school absenteeism itself. School absenteeism is thus in this study engaged with as a Baradian phenomenon" 13 a concept that puts emphasis on how "theorizing and experimenting are not about intervening (from outside) but about intra-acting from within, and as part of, the phenomena produced" (Barad 2007, 56, italics in original). Accordingly, what might be thought of as a production of knowledge on school absenteeism will always and at the same time be a production of the same phenomenon. This idea that the processes of research are crucial to how the phenomenon of school absenteeism is understood is developed below.

${ }^{12}$ For recent examples of posthumanist research in education, see for example Taylor and Hughes' (2016) edited volume Posthuman Research Practices in Education, Snaza and Weaver's (2015) edited volume Posthumanism and Educational Research and the special issue of Cultural studies $\Leftrightarrow$ Critical Methodologies on "New Empiricisms and New Materialisms" edited by St. Pierre, Mazzei \& Jackson (2016). A number of recent $\mathrm{PhD}$ theses have put a posthumanist approach to work in productive ways in relation to educational research: Andersen (2015) on race in early childhood settings, Brøgger (2015) on the Bologna Process, Ceder (2015) on educational relationality, Gunnarsson (2015) on health promotion in schools, Hohti (2016) on classroom matters, Sauzet (2015) on interprofessionalism in higher education and Sjögren (2016) on notions of sustainability in educational practices.

13

How this concept is put to work in this study is discussed further in Entanglements. 


\section{Cutting together/apart the apparatuses of knowing}

Regarding the processes of research as central to how school absenteeism is enacted highlights that this study - like all scientific engagements - "is actually a production of reality with very specific material consequences for the agents involved" (Lenz Taguchi \& Palmer 2013, 671). Research is thus, in the words of Barad $(2007,148)$, an arrangement of apparatuses that "enact what matters and what is excluded from mattering". Hence, "[a]pparatuses are not passive observing instruments; on the contrary, they are productive of (and part of) phenomena" (Barad 2007, 142). This means both that different versions of school absenteeism emerge depending on how it is researched and that practices of knowing (epistemologies) are inseparable from practices of being (ontologies). Barad (2003; 2007) introduced the conjunctive concept ontoepistemology to highlight the way research is always "the study of practices of knowing in being" (Barad 2007, 185).

Theorizing school absenteeism through the premises of an ontoepistemology acknowledges that the processes of research always shape, reshape, create and recreate school absenteeism in specific ways. The theoretical approaches and concepts engaged with in this study, the methodologies put to work, the software and schools involved, the previous research discussed, as well as myself as a researcher, are all inevitably entangled with how the phenomenon is produced. I have theorized the entanglements of all these different components as the apparatuses of knowing of this study (see also Lenz Taguchi 2010; Lenz Taguchi \& Palmer 2013). This opens up understandings of how knowledge is produced, as well as how knowledge produces realities. Accordingly, this study takes a perspective in which school absenteeism does not exist in and of itself but is continuously produced through the apparatuses of knowing.

To be able to research school absenteeism in the myriad of entanglements constituting the apparatuses of knowing, it is necessary to produce artificial and provisional separations between the 'object' of inquiry, the researcher, theories and methodologies to sort out the entanglements. The process of separating what is researched from how it is researched is theorized by Barad (2003; 2007) as enactments of agential cuts. Such cuts enact a local resolution within the phenomenon (Barad 2003, 815) and are made, not by autonomous research individuals, but by the larger material and discursive arrangement of which they are a part. Agential cuts both bring things together and take them apart (Barad 2007, 381). Practices, humans and materialities are connected through the cuts since some things within the research process are produced as belonging together. At the same time the cuts are divisive by emphasizing the importance of some things but not others (the things deselected). It is a 'double sided' movement that sets boundaries by making both connections to and distinctions between other phenomenon (Sauzet 2015, 140). This means that different cuts 
materialize different phenomena (Barad 2007, 178) as well as different versions of the thing studied. As the practices and entanglements within the apparatuses of knowing change through specific cuts, so does the reality that is part of producing school absenteeism. For this study this means that school absenteeism needs to be theorized as shifting and flowing since multiple versions - multiple realties - emerge in the production of the cuts. Hence, how the cuts are enacted is crucial to what is produced as absences and presences.

This study wishes to challenge notions of the 'nature' of both the digital technologies and the humans engaging with those technologies. What is central is to open up to apparatuses of knowing that allow that agential cuts produce new realties and new versions of school absenteeism. A specific way of relating to school absenteeism - a specific ontoepistemology of school absenteeism - is thus put to work in the study: school absenteeism as a phenomenon that emerges in/of the practices performed and produced in relation to the digital registration. ${ }^{14}$ The study therefore has two intertwined objectives that are impossible to separate: to look at the practices surrounding digital registration and at how these practices produce the phenomenon of school absenteeism.

\section{Aim and questions}

The aim of the study is to explore how school absenteeism as a materialdiscursive phenomenon is produced in the practices of humans and nonhumans, when absences and presences are registered and managed through digital technologies.

With the objective of producing theoretically as well as empirically grounded knowledge on school absenteeism, the following questions were formed:

- How is the phenomenon of school absenteeism produced when absences and presences are registered digitally?

- How does the phenomenon of school absenteeism emerge when both human and nonhuman entanglements are included in the apparatuses of knowing?

\footnotetext{
${ }^{14}$ I outline the relations between these concepts further in Entanglements.
} 


\section{Entrances, Entanglements, Engagements: guidance through the text}

This comprehensive summary - the 'kappa' [the coat] - is the first part of a compilation thesis. The aim of this text is to link the aim and questions of the study to the knowledge produced through the four research papers (included at the end of the thesis). In the papers, I research how school absenteeism is produced in three Swedish schools working with digital technologies for registering absences and presences. The 'kappa' discusses how this empirical work was conducted. The theoretical and methodological positioning and decisions made throughout the study could thus be described as giving insight into the apparatuses of knowing that are part of producing the analytical findings ${ }^{15}$ presented in the four research papers.

Deciding where a theoretical discussion ends and where a methodological discussion begins, where discussions of a framework become explorations of previous research on school absenteeism, where explanations of software become analysis and so on has been a dilemma, but also a productive force, because, and this is essential, all of these different parts are equally important in the production of the phenomenon. All of this $i$ the phenomenon of school absenteeism. I have thus decided to counteract the separation that impedes connections and in which background, previous research, theory, methodology, and so on are presented in different chapters. Instead the remainder of the 'kappa' is presented in three sections that play out the productiveness of entanglements. What is included and excluded - cut out or cut in - from these sections is enacted in close relation to the aim and research questions of the study. How these agential cuts are enacted is addressed in each section of the 'kappa'.

The first section provides Entrances into the Swedish history of school absences and presences, into previous studies on school absenteeism and digital registrations, into two different software systems and into three schools. The second section discusses Entanglements as a posthumanist approach to researching school absenteeism, as well as the relations between the different posthumanist concepts that have been put to work throughout the study. The third section contains Engagements with the ethics of doing research within a posthumanist approach, engagements with methodologies, empirical engagements and processes of analysis. Summaries of the four research papers are also included in this section. The 'kappa' concludes with a discussion - Discussing present absences that focuses on how the phenomenon of school absenteeism has been produced within this study and that introduces the concept of school absenteeing.

${ }^{15}$ A discussion of the concept of analytical findings is presented in the section of the thesis named Engagements. 


\section{Entrances}

The door it opened just a crack, but love was shrewd and bold.

I let love in - Nick Cave ${ }^{16}$

... a nonplace, and nontime, a dislocation of referent, a fracture, a rupture, a disjuncture, an opening (Barad 2010, 262).

This section enters doors, just a crack and much more. The double connation of the word entrance, meaning both 'an opening' and 'to enchant', points to how the historical overview, the previous research, and the descriptions of the software and the schools that are the focus of this part of the thesis are not neutral representations in terms of a background or a framework. A background is always more than a background, it is an important knowledge-producing apparatus, and what is stressed as mattering in this part of thesis inevitably affects the production of the phenomenon of school absenteeism.

Entrances into the phenomenon of school absenteeism at the same time shape, enchant and transform knowledge on absences and presences. Accordingly, this part of the thesis is a way to start exploring how the phenomenon of school absenteeism is and has been enacted: what matters and what is excluded from mattering. Theorizing what is discussed in this part as

${ }^{16}$ Lyrics: Cave (1994) 
productive entrances that do something with how the phenomenon is enacted is also a way of emphasizing the responsibility for acknowledging what is cut out of and what is cut into the phenomenon of school absenteeism. To entrance theoretical as well as empirical parts of the phenomenon, three topic areas are introduced. First, I frame a historical outline of the phenomenon of school absenteeism in the Swedish context. This is followed by a discussion of previous research on school absenteeism, and on digital registration, which subsequently folds into an entrance to the two types of software and the three schools involved in this study. Entrances concludes with a discussion of the entanglements of the different entrances, to invite thinking on openings without closures.

\section{Entrancing a Swedish history of school absences and presences}

Outlined in this section is a flowing entrance through 174 years of school absences and presences in Sweden, from 1842 when the first efforts were made to make schooling compulsory to the digital registrations of the present time. Or put another way, this section provides an entrance into the historical and discursive notions and practices that are part of producing school absenteeism as it is enacted in Swedish schools today. Even though it ranges over a number of years, it is still a short journey. To be able to stay close to the aim and questions of this study, the broader and more general strands of the history of Swedish schooling have been agentially cut out of - excluded from - this entrance. What is agentially cut in - included - are the parts that relate specifically to absences, presences and their registration.

\section{In the early days of Swedish schooling}

In accordance with the first statute for schooling ('folkskolestadga'), Swedish schooling became compulsory in 1842: all children had to start school by the age of nine and every parish had to have at least one school with a trained teacher (Sjöberg 1996). Sandin (1986) shows how historically the establishment of schools was closely connected to a wish to keep children away from the streets and to give them a proper and 'moral' upbringing. However, compulsory schooling had no requirements in terms of enrolment or attendance (Sjöberg 1996). A problem in the early days of Swedish schooling was thus the irregularity of attendance and the high number of student absences. Absence rates of more than $40 \%$ were not unusual during the 1870 s and 1880 s (Sjöberg 1996, 252). ${ }^{17}$

${ }^{17}$ As a comparison, during the 1870 s in the UK local school boards were empowered to enforce compulsory school attendance for children aged 5 to 13 (Gillie 2008). In the US compulsory attendance laws were introduced in Massachusetts in 1852, and after Mississippi passed the law in 1918 attendance became compulsory in all states (Rauscher 2014). 
In 1882, a new 'folkskolestadga' was introduced, which stated that all children aged seven had to enrol in schooling for seven years (this could sometimes be shortened to six years) (Larsson 2011). Increasingly strict attendance requirements made parents responsible; they were warned if their children did not attend. In the following statute, 1897, illness was defined as a valid reason for school absences while the teacher, and not solely the school council, became responsible for the management of students' presences (Sjöberg 1996). During this time, schools were obliged to record students' absences and presences, but there were no policies on how this should be done. Thus, registration varied in different parts of Sweden. In one canonry, registration was organized in a dairy where children's 'uteblifande' [old Swedish word for absences] was recorded and comments were made about the nature of the absences: whether they were authorized or not, and whether they were due to illness. The information formed the basis for a catalogue ('examenskatalogen'), in which information about each student's absences and presences during the school year was recorded. What was written in the catalogue was transferred to the 'enrolment book' that followed students throughout their schooling (Sjöberg 1996, 37).

\section{Toward a comprehensive schooling}

A new curriculum was adopted in 1919. In relation to the previous periods, presences in schools had increased substantially, mainly as a consequence of the possibility of halftime studies (Sjöberg 1996, 252). Nonetheless, school absenteeism was a normalized behaviour as children were kept at home during periods of cultivation and harvest (Sjöberg 1996; Richardson 2010). Students where torn between school and home: while the school was able to invoke compulsory attendance, the home could invoke the need for labour. Labour was sometimes also used as an excuse for students to play truant (Landahl 2006, 46). ${ }^{18}$

As Swedish society became more industrialized the need for children to help the family decreased and was no longer a legitimate reason for school absence. In 1950, the government passed a resolution for nine years of compulsory education. Foremost, this meant that all students were entitled to an equivalent education. During this period, 'illness certificates' sent from home to school,

\footnotetext{
18 Similar patterns were also evident in UK during the early $20^{\text {th }}$ century. Children, especially of the working classes, were needed at home to help parents in their daily duties (Auerbach 2012). In the United States, other issues related to absences and presences came into focus when compulsory attendance statutes were passed in the early $20^{\text {th }}$ century. Transfers between different schools were common but also between different school systems with conflicting attendance control systems, resulting in an undermining of compulsory attendance laws as it became difficult to track and enforce school attendance (Gross 2014).
} 
became a problem as false certificates were seen as the new way to play truant (Landahl 2006). In 1962, 'grundskolan' [the Swedish comprehensive school] replaced all the former models of schooling: nine years of compulsory education, for children aged 7-16 years (Halldén 2008; Qvarsebo 2006; Richardson 2010). At this point, the first Comprehensive School curriculum, Lgr-62, was introduced. Conversations between teachers and parents were particularly emphasized, since parents were regarded as a way to make sure that norms taught at school were maintained at home, making attendance rates easier to uphold. A special book was initiated to record absences and presences for each student; it was sent home to parents once a month (Qvarsebo 2006).

\section{Approaching a shift in Swedish educational politics}

During the late 1960s reports of students' lack of motivation, poor discipline, and dissatisfaction with schooling along with a high level of absenteeism forced the government to, in 1970, appoint a commission to investigate why comprehensive schools were failing to provide a positive learning environment. The findings of the commission, SIA (Skolans inre arbete [SOU 1974:53]), suggested for example that students should be able to choose between different activities at school (Morawski 2010, 184 ff.). This was reinforced in the curriculum from 1980 (Lgr80) and schools were expected to offer more individualized and adaptable content (Assarsson 2007, 22). As a result of this, schedules were reorganized, classrooms were at times left empty as students were relocated to other places in the school (Dovemark 2004, 200 ff.), and students in different classes no longer had common break times (Landahl 2006, 84). These changes made attendance more difficult to control. The curriculum (Lgr-80, 26) clearly stated that presence at school was compulsory and that parents were obliged to immediately notify the school if a student was to be absent, and as far as possible, in advance. Further the curriculum stated that the school had to control and register students' attendances and facilitate a system for speedy contact with the home.

A major shift occurred in educational politics in Sweden in 1991, described in terms of a shift from education as a "public good" to a "private good" (Englund 1993). The responsibilities for schooling shifted from the state to the municipalities and new possibilities were opened up for private schools to emerge. In line with market-oriented principles, the possibility of choosing between different schools required of parents to take part in shaping the educational patterns of their children (see for example Dahlstedt 2007; Englund 1995; Larsson, Löfdahl, \& Pérez Prieto 2010; Lindblad et al. 2002). Competition among students arose over getting a place at the best schools (Dahlstedt 2007; see also Kallstenius 2010). And at the same time, competition among schools over students became crucial as each student was, and still is, accompanied by an amount of money (a school voucher), paid by the home municipality of the student. As a school with low absence rates has been viewed as more likely to 
contribute to improved educational results (Jonasson 2011), the competition among students and schools can be described as reflected in the work on attendance control and absenteeism. Absenteeism became a problem not only for the individual student, and for the family, but also for the school that might fail to attract students (Bodén 2013).

When the 1994 curriculum, Lpo-94, replaced the former curriculum, the section on absences and presences had been removed. In the Education Act from this period absences were only mentioned in relation to student insurance matters (SFS 1985:1100, Chapter 12b, BJ). In the current curriculum from 2011, Lpo-11, neither absences nor presences are mentioned. However, the current Education Act (SFS 2010:800) explicitly addresses absences, presences and how absenteeism information shall be communicated to parents. The immediate and frequent control that digital registration enables can be understood as playing a role in this requirement.

\section{Winding up, entering the next}

What this entrance into the history of school absenteeism and its registration shows is how absences and presences; registrations of students in relation to time, space and place; and procedures for contact with the home concerning attendance or absenteeism have been an integral part of the history of Swedish schooling. Different times have dealt with different issues related to absenteeism, producing it in different ways: sometimes as acceptable because children have to help parents at home, at other times as lies, and recently as a problem not only for students but for the image of the successful school. Accordingly, societal tendencies, educational politics and technological developments affect both the registration of absences and presences and the relations with parents. How school absenteeism and digital registration have been theorized and described in previous research is discussed in the following section.

\section{Entrancing school absenteeism and digital registration}

This study is located within research on school absenteeism and on digital technologies for absence registration, and in this section both these areas are discussed. In the introduction to the thesis, discourses of responsible students and neutral technologies were highlighted as central to how the phenomenon of school absenteeism is produced as well as how it has been seen in previous research. In the following section, I elaborate on the discussion of studies offered in the introduction.

\section{Research on school absenteeism}

A majority of the research on school absenteeism consists of quantitative studies with a focus on causes for, results of and interventions to handle absenteeism 
(Ekstrand 2015; Jonasson 2011; Reid 2005; Sutphen, Ford \& Flaherty. 2010). In this entrance I focus on studies that primarily address the causes of absenteeism. This focus can be theorized as a performative and agential cut that affects how school absenteeism is described. Yet, as per my review of a large number of previous studies, it seems that whether a study focuses on results or interventions, it is always causes that are addressed, searched for and discussed. Causes of absences are viewed as affecting both the consequences of the absenteeism and also what interventions to stage. In acknowledging what this cut has cut out and what it has cut in, it thus appears if it is more inclusive than exclusive.

\section{School absenteeism as a multi-faceted phenomenon}

While early research on school absenteeism predominantly focused on individual factors (see for example Tyerman 1968), according to Reid (2010) school-related explanations have been given more attention in recent research (see also Dahl 2016). However, a review of the recommendations and results within 155 research reports on absenteeism from a number of different countries published during the $21^{\text {st }}$ century, shows that most studies continue to focus on individual factors (Ekstrand 2015). Although several studies (see for example Reid 1999; 2014; 2015; Corville-Smith et al. 1998; Weinberg \& Weinberg 1992) highlight the importance of understanding school absenteeism as a complex, multi-faceted or 'multifactorial' problem consisting of a combination of background factors (such as family relations, socioeconomic variables, residential areas, and gender; see for example Arthur 2015), 'personality' (such as school phobia, learning disabilities, poor school performance; see Sutphen, Ford \& Flaherty 2010) and school context (see Sälzer et al. 2012), I would - like Corville-Smith et al. (1998) and Sutphen, Ford and Flaherty (2010) - argue that research on school absenteeism tends to focus on only one of these many aspects at a time. With the intention of not (re)producing this separation, that according to Sutphen, Ford and Flaherty (2010) has significant impacts on truancy interventions, I weave together in the following studies focusing on individual factors, background factors (that have somewhat also an individual focus) and studies focusing on structural or school related explanations.

In 1990, the review Skolk - en forskningsresumé [Truancy - a summary of research] (Jönsson 1990) was published; it has been described as a milestone in Swedish research on school absenteeism (Ekstrand 2015, 462). The review presents 47 different Swedish studies, conducted between 1953 and 1988, with the aim of summarizing what "the research can tell us about truancy" (Jönsson 1990, 3, my translation). When the results from the different studies are summarized, the review shows that truancy is primarily occurring in secondary schools and is primarily an urban problem, that gender is not decisive in truancy behaviour, and that truants often had a childhood filled with troubles, come from less study 
motivated environment, do worse in school, often exhibit deviant behaviour, often have abuse problems and are more worried and anxious than other students (Jönsson 1990). A survey of international research articles on absenteeism interventions, published between the years 1990-2007 (Sutphen, Ford \& Flaherty 2010), has similarities to Jönsson's review. This survey shows how research on the causes of absenteeism have been divided into four different areas: individual factors (such as school phobia, learning disabilities, poor school performance); family (low income, single parents, lack of parental involvement in school); the school (difficult relationships with teachers, dissatisfaction with organization of teaching, bullying) and the social environment (school located in a 'problem area') (Sutphen, Ford \& Flaherty 2010). Reid (1999) as well as Strand and Granlund (2014) follow a similar pattern when claiming that absenteeism is caused by individual, social and/or school factors.

In two widespread Swedish reports ${ }^{19}$ on school absenteeism (Karlberg \& Sundell 2004; Sundell, El-Khouri \& Månsson 2005) the focus is primarily on individual causes. In both reports, absenteeism is seen as a marker of anti-social behaviour rather than as a healthy protest against the school, with school-related factors also considered important for certain groups of students by Sundell, ElKhouri and Månsson (2005). Both of these reports are based on surveys of the drug habits among youth in Stockholm. They could be described as part of a common strand within research on school absenteeism: larger scale studies focusing on identifying at-risk groups (Ekstrand 2015). Other examples are Maynard et al. (2012) with data from a national survey of drug use and health in the United States, and Harakeh et al. (2012) focusing on Dutch adolescents.

In contrast to the knowledge produced within the studies on risk groups, Havik, Bru and Ertesvåg (2015) highlight how research focusing on clinical or family approaches limits the knowledge enabled on the role of structural and school related factors. In a survey of 5,465 Norwegian students from the $6^{\text {th }}$ to $10^{\text {th }}$ grades, their conclusion is "that the role of school factors must always be taken into account in connection with unexcused school non-attendance" (Havik, Bru \& Ertesvåg 2015, 221). In a similar study, using data from a large-scale survey, the Longitudinal Study of Young People in England (LSYPE), Attwood and Croll (2015) show how disliking school was given as a main reason for absenteeism. In a report on long-term truancy, Skolverket [The Swedish National Agency for Education] report that when the directors of all Swedish municipalities were asked, social and psychosocial problems or weak support

\footnotetext{
${ }^{19}$ In order to be able to produce knowledge on the Swedish context, where not much research on school absenteeism has been performed, evaluations and inquiries by government agencies like Skolverket (The Swedish National Agency for Education) and Socialstyrelsen (The National Board of Health and Welfare) are included.
} 
from home were described as common causes of absenteeism (Skolverket 2008, 10). And when complaints from parents and students were reviewed, shortcomings in treatment by schools were highlighted as a main reason for absences (Skolverket 2008, 62).

A subsequent study by Skolverket (2010) interviewed students who had been long-term truants. The report emphasize that absenteeism is a complex web of individual, home and school-related explanations. Southwell $(2006,96)$ highlights a similar point when claiming that absenteeism needs to be understood as "an educational phenomenon prompted by diverse factors related to individuals' unmet special educational needs". A similar perspective is highlighted by Strand (2013). In a study on truancy from the perspectives of both the students and the school, Strand (2013) problematizes the dichotomy between individual and structural factors. One of the conclusions from the study is the important role of the school in transforming risk factors that draw students from the school, to instead enable a positive school climate that draws students back. Interest and effort on behalf of the school is thus necessary. Stigsdotter Ekberg (2010) nevertheless describes how schools tend to show a lack of interest in attracting truanting students, and Lauchlan (2003) points out that school intervention programmes often fail to reduce absenteeism.

\section{The production of a specific version of school absenteeism}

This entrance into previous research on school absenteeism highlights how the research apparatus (theory, research questions, methodologies and research participants - mainly human in the research discussed here -) produce what is understood as school absenteeism within the studies discussed. When registry or survey data, produced by municipalities or school staff, are used as the basis for the analysis, individual-based models of explanation (Karlberg \& Sundell 2004; Sundell, El-Khouri \& Månsson 2005) that refer to antisocial behaviour and explanations relating to students or their families appear to dominate. When students or parents are asked, problems and challenges within the school seem to be the explanation given (Skolverket 2010; Jönsson 1990; Strand 2013). When 'the truants' themselves are asked, shortcomings in teaching practices are given as the major reason for school absenteeism (Southwell 2006). A similar result is shown in Ekstrand's review: school management, teachers and health-team members seem to blame the home, individual attitudes towards the school, drug abuse, and social and cultural class. Students and parents find explanations in the educational structure and treatment by the school (Ekstrand 2015, 463). Different versions of the phenomenon seem to emerge depending on who or what is entangled within the research. What is cut out of or cut in to the phenomenon thus produces different realities related to school absenteeism.

The majority of research has been conducted in the field of psychology (Ekstrand 2015), with consequences for the knowledge produced: a focus on 
individual factors, psychological shortcomings, and individualist versions of the phenomenon of school absenteeism. This is echoed outside the research field: in statutory texts and in political and public debate, as shown in the introduction to the thesis. My claim that this individualist (read: anthropocentric?) focus in research makes it more difficult to embrace the complexities of school absenteeism is supported by Ekstrand's (2015) assertion that more research in the field needs to focus on schoolwork, schools and communities. This would make possible apparatuses of knowing that enable new versions of school absenteeism to emerge. This takes us to the next section, a discussion of the knowledge previously produced on the digital registration of students' absences and presences.

\section{Research on digital registration}

Digital software to manage registrations and keep records of actions and activities appears in a wide range of areas: border control and the social sorting of migrants and travellers (Dijstelbloem \& Broeders 2015); registers of the activities of jobseekers (Larsson 2015); government functions such as building plans, vehicle registration, criminal and crime information (Rao 2013); patient administration in hospitals (Thakare \& Khire 2014; Winthereik, van der Ploeg \& Berg 2007); control systems to record those who enter/exit doors at workplaces (Dahyabhai \& Mehta 2014) and so on. Until recently, interest in the digitalization of the educational setting has been limited (Williamson 2016).

In the early days of digitalization there were concerns that, because of automation, computers would outcompete humans (Bowker \& Star 2015). However, in recent studies it is the benefits of the automation of registration to reduce administration and increase efficiency that is valued. This is evident in research on software for the registration of students' absences and presences in schools, where the focus is the possibility of avoiding 'human error' and the benefits of swift and frequent control. The significance of digital technology in education is usually discussed in terms of supporting teaching and learning, but in fact the majority of digital technologies in schools are used for managerial or administrative purposes (Selwyn 2011; see also Hansson 2013; Williamson 2016). The software for registration of students' absences and presences can be theorized as part of what Griffith and André-Bechley (2008) describe as the "formalised, technically developed, and rationalised procedures that regulate the everyday operations of institutions" (cited in Selwyn 2011, 473). Thus, the purpose of this entrance is to introduce the major trends within previous research focusing on the digital registration of absences and presences in schools, and two areas of interest are cut out for consideration: studies focusing foremost on educational questions and those focusing on technological aspects. 


\section{Electronic registration to improve school attendance}

There is a limited number of educational studies focusing on aspects of the digital registration of absences and presences. This can be theorized as in line with the 'invisibility' (other than technological aspects) of digital technologies in educational settings (see Lee 2009; Sørensen 2009; Williamson 2016). Still, there are a handful of studies focusing on software similar to those I engaged with, and I discuss these studies below.

In 1989, a project on the digital registration of school absences was initiated in western Holland (Visscher \& Bos 1993). The aim of the project was to investigate "whether the computer could help schools to reduce absenteeism" (Visscher \& Bos 1993, 297). Two reasons are highlighted as likely to contribute to a reduction of absenteeism. First, the handling of registration becomes systematic as it produces an 'absence-list' of students and, if carried out correctly, enables the detection of absent students. And second, registration enables the production of statistical measures, which can help reduce absenteeism on a general level. However, the results of the study show that the introduction of a system did not result in a significant reduction in absenteeism (Visscher \& Bos 1993, 307). The authors stress that one explanation might be that rather than detecting and tackling the reasons and causes of absenteeism, registration becomes a matter of the treatment of symptoms and effects can often be solely the punishment of students (Visscher \& Bos 1993, 308).

With an overall aim of advancing "an understanding of the impact of electronic registration on school attendance at secondary level in England and Wales", Lewis $(2009,5)$ explores school staff members' notions and experiences of the digital registration of absences. ${ }^{20}$ The participants in the study considered the digital tools for the registration of each and every lesson to be valuable in maximizing student attendance. As students are tracked throughout the day and know that all absences and late arrivals will be registered, and as relevant people can be alerted to address a problem with almost no delay, "prompt action brings the best chance of a positive outcome by preventing the behaviour from becoming entrenched" as explained by Lewis $(2009,57)$. A main conclusion from the study is that electronic registration can make a valuable contribution to increasing school presences, but only together with other initiatives. What is highlighted is thus that the electronic registration could be "a very useful tool in maximizing attendance but that it had to be used as part of an integrated approach by schools' pastoral care teams and the Education Welfare Service"

${ }^{20}$ Lewis's (2009) study is a Master thesis which in some ways limits both the depth and the breadth of the study. This also applies to Enarsson's (2016) Master thesis, discussed below. However, because of the limited number of educational studies on digital registration, I have found these studies helpful for situating my thesis in the education context. 
(Lewis 2009, 63). However, teachers felt that log-in times sometimes made their work more difficult and explained that time was sometimes taken at the start of a lesson. Similar experiences are also highlighted by Visscher \& Bos (1993, 307) who report on behalf of teachers that increased work in the form of registration and handling is the strongest negative effect.

The results of an online survey with 151 Swedish teachers show that teachers have a mainly positive attitude to digital attendance registration systems (Enarsson 2016). The teachers reported that the system enables an accessible overview of absences and presences and eases contact with parents. However, $68 \%$ of the teachers answered that they did not believe that the systems had decreased absenteeism (Enarsson 2016, 21). Technological failure and the time spent on the registration are given as some of the disadvantages of the system. Enarsson (2016, 26) explains that the design of the system affects what functionalities and registrations are enabled - what can be registered and what cannot - and that this in turn produces an infrastructure for the practices in schools. However, few of the teachers address the binary of registration - if a student is not bodily present, s/he must be absent - as a problem, and few problematize the concepts of absences and presences (Enarsson 2016, 27).

In a study on two Australian secondary schools, Selwyn (2016) discusses how school leaders and managers described the information collected through the digital registration of absences and presences as being of little benefit. Foremost it became 'summary level data'. The numbers collected through registration that lead to claims that absence rates have declined from $5 \%$ to $4 \%$ becomes a way to produce a picture of a successful school, and one participant in the study depicts the data reports as being conducted for superficial reasons (Selwyn 2016, 57). This sheds new light on what Visscher and Bos (1993) described as one of the benefits of the system - to produce statistical measures - and can also be related to how Swedish schools, as described in the historical overview, use statistical measures to produce a picture of a successful school with low absence rates.

\section{With a focus on technological efficiency and development}

If educational studies of digital tools for the registrations of absences and presences are limited, studies in the field of computer sciences focusing on how to make the system more efficient and limit 'human errors' are more common. However, most of the technologies discussed in these studies differ from the software engaged with in this thesis, namely, Dexter and Skolwebben (discussed further in the next section). The focus rather is primarily on the automated digital registration of students, using Bluetooth, face scanning, QR codes and so on. I return to this below.

Finland stands out with several publications in the area of digital registration in schools. In 2008, a study of automated attendance supervision, based on Near Field Communication (NFC) technology, was arranged at a primary school in 
Finland (Ervasti, Isomursu \& Kinnula 2009). During the trial, the students (6-8 years old) registered their arrival and departure from school with a contactless smart card, touching a smart card reader device or an NFC-enabled mobile phone. The main benefits of the system were, according to the authors, that teachers did not need to mark the students' absences or delays, which left more time for teaching. The system was described as facilitating teachers' work by offering technologies that gathered information about students' attendance or possible lateness and enabled real-time information on students' attendances for parents. Similar results are shown in a later study by the same authors, building on an analysis of the same trial (Isomursu et al. 2011). As with the previous study, the focus is primarily on the adoption of new technology and how/whether this creates value for the users. Both these studies describe the system in positive terms, focusing on the gain of more time for teaching. A third study (More \& Nayak 2013) that departs from the same material arrives at similar conclusion: monitoring students' attendance manually requires time and effort, which is taken away from teaching. Furthermore, the security of the school is described as improved as it is easy to get an overview of which students are in which classroom (More \& Nayak 2013, 575).

Several studies have investigated automated attendance recording in relation to higher education. A project using NFC-technology was carried out in Spain at the Universidad Pontificia de Salamanca, Campus Madrid, between 2011-2012, (López Fernández et al. 2013), showing that the technology resulted in greater control on behalf of the educational institution and took some of the administrative burdens and obligations off the teachers. An increase in actual teaching time is described as one of the benefits of the system, in line with the Finnish studies in primary schools. In a study focusing on attendance at Mumbai University, the capabilities of Bluetooth Smart technology was investigated (Lodha et al. 2015). In a similar way as in the Finnish studies, manual registration is described as time-consuming and as valuable lecture time misspent. Manual registration is described as sometimes inaccurate and prone to human errors. Accordingly, Bluetooth technology is emphasized as a means of making registration more efficient and effective (Lodha et al. 2015; see also Bhalla et al. 2013; Gavade et al. 2015). In line with this, a review of various automated systems for managing students' absences and presences describes these 'computerized attendance systems' as eliminating human involvement, data entry mistakes and repetitive work (Patel \& Priya 2014). To help avoid these kinds of problems, Masalha and Hirzallah (2014) suggest the students scan QR codes with their smartphones as they enter lectures, marking their presence, and Patel and Priya (2014) suggest that devices for face recognition be installed in lecture halls.

When summarizing these studies, it is clear that they do engage with educational practices, but mainly from the point of view of how to make the 
systems more efficient. Put another way, they are concerned with how the system should be designed to streamline the lessons, improve teachers' work and increase parents' insights into the actions of their children. Accordingly, the automatization of attendance technologies is presented as almost indisputable. Interestingly, Patel and Priya $(2014,111)$ discuss the development of a desktop application from 2008, that is very similar to the functions within Dexter and Skolwebben:

all the list of registered students in a particular course will be displayed when the lecturer start the application. The attendance registration is done by clicking a check box next to the name of the students that are present, and then a register button is clicked to mark their presence.

The authors describe how the human involvement in this 'old' type of registration is likely to cause data entry mistakes and - again - to take time from teaching (Patel and Priya 2014; see also Sospeter, Sinde \& Kaijage 2015). Even if the registration is digitalized and done on a computer screen in this system - as in Dexter and Skolwebben - the practice of doing the registration manually is old and out-dated. It can thus be claimed that the rapid technological development the previous studies demonstrate becomes part of producing Dexter and Skolwebben not only as tools to help facilitate a more efficient management of student documentation (see for example IST n.d.), but as tools that from a technological perspective are already old-fashioned. The more automatized the process is, the more efficient and trustworthy the system seems to be.

\section{Concluding words on previous research}

The entrances to previous research highlighted a number of cuts that have affected how the phenomenon of school absenteeism is produced in this study. When the different studies focusing on school absenteeism are cut together, a specific individualist version of the phenomenon of school absenteeism emerges, even though some other studies have pointed out the necessity of looking outside the realms of individual failures and despite some studies addressing how practices in the educational setting are affected. When the different studies focusing on digital registration are cut together, a version emerges wherein technological efficiency and development become the major theme. However, a cut that seems to cut apart, but cut together rarely is the cut between school absenteeism and digital registration. Although Enarsson (2016) asks how understandings of absences and presences are affected by the binary options within the software, this question is hardly recognized by the teachers in her study. The phenomenon of school absenteeism has been enhanced in a specific way such that school absenteeism and digital registration are usually enacted as 
neither belonging together nor affecting each other. It thus seems that to be able to recognize the entanglements of school absenteeism and digital registration, it becomes necessary to explore ways - theories as well as methodologies - to cut them together again. This is devolved further in the next sections of the thesis, Entanglements and Engagements. But before this, let's enter the software and the schools of the study.

\section{Entrances to the software and the schools}

This entrance explores the setting of the study: with what and where I engaged empirically. It starts with an introduction to the two forms of software that are part of the study, as details and descriptions of the functionalities of the software are needed to understand the practices that are produced around the registration of school absences and presences. Following this, I introduce the three schools in which the empirical engagements took place. Even though the empirical material I engage with is produced in three different schools, my focus has not been on what distinguishes the schools from each other. What has been important is rather a careful engagement with the various practices that appear in each of the settings to create knowledge on how these practices produce the phenomenon of school absenteeism.

\section{Digital software for school absence registration}

For registering absences and presences, the schools I worked with use two different platforms that in some aspects differ from each other.

\section{Skolwebben at Kardinal School}

The software used at Kardinal School is called Skolwebben and is one of a group of "portal services targeting primary schools, preschools, upper secondary schools and adult education" (edWise n.d., my translation), named edWise (owned by Tieto Sweden AB). Six municipalities in Sweden work with software named Skolwebben (see Appendix I) ${ }^{21}$ and in the municipality where Kardinal School is located, the system has been in use since 2006. Skolwebben is described as software/a portal for administrative work in school and for communication between teachers, students and parents (Tieto n.d.). The portal holds information about students' absences, grades, tests as well as online 'rooms' for communication. Both Skolwebben and edWise are described by Tieto (n.d.) as a digital learning portal that helps teachers to plan, implement and evaluate via the

21 Despite sharing the same name, not all of the software called Skolwebben is connected to edWise. Some is connected to InfoMentor and some is 'independent', connected to neither edWise nor InfoMentor (see Appendix I for a discussion of this). 
Web, "to make life easier for everyone in the school - regardless of the type of school" [my translation]. For students, Skolwebben is described as a tool to communicate with teachers and other students, share information, view schedules and manage materials to complete school assignments. For parents it is described as a tool for greater transparency in the school activities of their children and an opportunity to become more involved. To $\log$ in, teachers either use their BankID, a certificate or a text message service, students use a login name and a password, and parents use their BankID. This means that teachers, students and parents can access the webpages. If a student is sick, the parents can report the absence by texting a number connected to the software or by using an app on a smartphone, also connected to the software.

The section of the portal I studied at Kardinal School is the page called 'Absence'. Since I was not part of the actual process of registration at Kardinal School, I focus in the following on how the registered absences were displayed in the software after the registration had been done. When a teacher logs in, an interactive picture of a schedule is shown on the page, and differently colored fields representing the lesson indicate whether a student was present or absent. Blue signals that the lesson has not yet been registered (either because the teacher had forgotten to register it or because the lesson had not yet taken place), green signals that the student was present at the lesson, yellow that the student was missing but that the absence was valid, and red that the student had been absent and the absence was unexcused. However, red also indicates tardiness, leaving the lesson early without a valid reason, or neglecting to bring the required school materials. The teacher could also make a note about the reason for the absence.

The two classes I visited at Kardinal School were in Grades 5 and 6, which at the time of the visit meant that they did not yet get grades. ${ }^{22}$ No text message service was connected to the software at the time of my visit and no automated email service was activated, which meant that parents needed to $\log$ in to Skolwebben to take part in absence registrations.

\section{Dexter at Sandö School and Björnäng School}

Dexter is the software in use at Sandö School and at Björnäng School. Dexter was introduced in the municipality of City 2 in 2005, and by the time of the study all but one of the 7-9 grade schools in City 2 worked with Dexter. It is described as an administrative system for managing student data in the municipality and is a web application of software called Extens (IST n.d.). Extens and Dexter are owned by IST (IT-specialisten för skola och barnomsorg/IT for Education).

\footnotetext{
22 Only from the autumn of 2012, were the students in Grade 6 graded. My visits were conducted during the winter of 2010. See the part of the thesis called Engagements.
} 
Dexter includes class lists, grades, schedules, attendance data and much more, and the data in Dexter are automatically transferred to Extens, where information about grades and so on is registered (IST n.d.). Sixty municipalities in Sweden work with Dexter (see Appendix I).

The section of the application I studied at Sandö and Björnäng Schools is also named 'Absence'. At these two schools I took part in the registration and had access to the pages displaying the registered information. When logging in to Dexter, and accessing the 'Absence' page, the teachers are met by a list of the day's lessons. If all students are present, they can choose to register the lesson just by ticking a box. If some students are missing, they can choose to register one absence/presence at a time. There are a number of options on what to fill in in relation to individual students. The teachers can choose between the following categories: present, reported absence, other school activities, left the lesson, approved leave, unexcused absence, late arrival and health care visit. Reported absence, other school activities, approved leave and health care visit are regarded as excused absences, while left the lesson, unexcused absence and late arrival are regarded as unexcused absences. All of those unexcused absences are counted as 'bodily absences'; that is, as a student physically not being at the lesson. Since all absences registered in Dexter are transferred automatically into the computer system for grading (Extens), the only registration allowed is 'bodily absence'. The teacher can make a note about someone being present without participating, but what is written in the notes is not transferred to the grading system.

To display the absences of a student, the teacher can choose a list view in which all absences for an individual student are displayed, a percentage view showing the total time absent from lessons, or a graphic display of all students in a class. The absences of an individual student can also be displayed as a colored weekly schedule, in the same way as in Skolwebben, where green means 'present', red 'unexcused absence', yellow 'excused absence', grey that the lesson has not taken place yet or that the teacher has not registered it, and white that the lesson has been cancelled.

Teachers and school staff are able to $\log$ in to the system to report student absences and presences, to write student reports, and to e-mail students and parents. School staff are the only ones who interact with the system directly. At the time of the study, neither students nor parents were able to log in to the system, even though a try-out (that was not developed further) with parents being able to log in had been performed at Sandö School before I started working with the school. However, a text messaging and an e-mail service were connected to Dexter and when a teacher registered an unexcused absence or a student's late arrival for class, parents received a text message and/or an email. Messages were sent as soon as the registration was complete, at half-hour intervals - day and 
night - but only at the first registration; that is, parents did not receive more than one message a day.

\section{Three Swedish schools}

As shown in Appendix $I$, the digital registration of absences is being used, or is about to be introduced, in public schools in all 290 municipalities in Sweden. I have engaged with three schools, in two different towns, to produce knowledge on practices in relation to digital registration.

\section{City 1 - Kardinal School}

Kardinal School is located in a middle-class neighbourhood in a large Swedish city (City 1) and has about 800 students, from preschool to the $9^{\text {th }}$ grade. In December 2010, I spent one day at the school, following two groups of students in $5^{\text {th }}$ and $6^{\text {th }}$ grade during their lessons. I asked students about their thoughts on absence and asked one of their teachers about absenteeism and systems for recording absences. The purpose of this first engagement was primarily to explore practices surrounding school absenteeism and to help me open up new questions about school absenteeism. Both students and teachers described Kardinal School as having no problems in relation to school absenteeism, but teachers also stated that they had well-functioning safety nets if a student needed help in relation to this. In conversations with both students and teachers my impression was that there were barely any unexcused absences or late arrivals to classes. Despite this, it became clear that discussions about absences occurred daily since teachers, every day and for every lesson, registered absences and presences in Skolwebben. The digital technologies seemed to be an important a part of everyday life at this school as well as the means by which both students and teachers (and parents) came into contact with questions about school absences and presences. This brief, but very productive meeting, had a big impact on the study, in terms of arousing my interest in digital registration.

\section{City 2 - Sandö School and Björnäng School}

Sandö School is located in countryside dotted with villas, 15 miles outside the urban area of the municipality. At the time of the study, the school had about 360 students from fourth to $9^{\text {th }}$ grade. Both teachers and students described Sandö School as a school with a very low level of absenteeism. Some teachers had access to a personal laptop that they sometimes brought to class to register the presences and absences during lessons, and some had access to an app on their smartphones where the registration could also be done. The teachers who had access to a laptop or the app usually did the registration during the lesson, while the students were engaged in independent work. Otherwise registrations were done between classes, in the teacher's office. 
In conversations with teachers at Björnäng School, it was repeatedly stated that working with absenteeism was especially important at this school because the school was located in 'that kind of area'. This statement seemed to be an integral part of the identity of the school, making it unnecessary to point out directly that the school was located outside the urban centre, in a multi-ethnic area with mainly leasehold flats. Björnäng School had, at the time of the study, about 220 students in $7^{\text {th }}$ to $9^{\text {th }}$ grade. The school worked with the principle of one studentone laptop. This principle also applied to the teachers, which meant that teachers had their own laptops that they usually brought to classes to do the registrations.

\section{In conclusion: entrances as a dislocation of referent?}

The entrances explored here can be theorized as the beginning steps in producing the phenomenon of school absenteeism in this study, where "this 'beginning', like all beginnings, is always already threaded through with anticipation of where it is going but will never simply reach and of a past that has yet to come" (Barad 2010, 244). When the referent is dislocated - when a background is never only a background but a mixture of previous research, of historicities, of definitions, of software, of schools - a small crack in the door will let all these things in. Call the entrances a bold love (and with this I mean that sometimes mismatched things are drawn to each other and assembled), or call it something else. But when these entrances are temporarily cut together, research on school absenteeism is produced in certain ways in relation to research on digital registrations and vice versa (humans as error makers? technology as a solution? individuals as responsible?), and the software of this study, Skolwebben and Dexter, is produced together with the historicities of absences and presences throughout Swedish schooling. Not as an in-advance, pre-given conclusion, but as an ongoing process of making some things matter, and of excluding other things from mattering.

The entanglements of the different entrances calls for "a radical reworking of the traditional notion of causality" (Barad 2007, 33, italics in original). What I have tried to do with the entrances is thus to engage in a thinking on the phenomenon of school absenteeism as going somewhere that it will 'never simply reach', a thinking that is in a constant process of becomings in entanglements of research, histories, and the software and schools of this study: openings without closures. 


\section{Entanglements}

We met through a queer twist of time.

Valerie - Frida Hyvönen ${ }^{23}$

Entanglements are not intertwinings of separate entities but rather irreducible relations of responsibility. There is no fixed dividing line between 'self and 'other', 'past' and 'present' and 'future', 'here' and 'now', 'cause' and 'effect' (Barad 2012a, 46).

In this section I outline the theoretical entanglements when putting a posthumanist approach to work researching school absenteeism. This theoretical approach becomes a way of focusing on the practices of both human and nonhuman performative agents in relation to the registration of absences and presences. And more importantly, it becomes a way of emphasizing that when researching the digital registration of absences and presences, the dividing line between humans and nonhumans, past and present, causes and effects needs to be problematized. The naming of the section emphasizes that what is unfolded below is entanglements, and not "independent objects with independently determinate boundaries and properties" to borrow the words of Barad (2007, 33).

\footnotetext{
${ }^{23}$ Lyrics: Hyvönen (2005)
} 
Entanglements are explored in two sub-sections. In the first, I focus on posthumanist approaches to researching school absenteeism. What is emphasized is how this approach entangles humans and nonhumans, and opens up the agency of materialities. In the second sub-section, I focus on specific posthumanist concepts that have been agentially cut out and have become part of producing the phenomenon of school absenteeism in this study. The emphasis in this discussion is on how concepts have become productive in relation to the phenomenon of school absenteeism, as well as on how the phenomenon of school absenteeism has affected these posthumanist concepts. The sub-section concludes with a discussion that highlights the importance of engaging with entanglements in all their queer twists and turns.

\section{Posthumanist approaches to researching school absenteeism}

The aims and questions of this study have been produced in close connection with the specific ontological and epistemological underpinnings of a posthumanist approach in order to enable the recognition of school absenteeism as a 'not-human-alone' phenomenon. The process of choosing what to 'name' this theoretical approach has been dynamic. Alternative names might have been a material feminist approach (Alaimo \& Hekman 2008), a (feminist) relational materialist approach (Law 1999), agential realism (Barad 1999; 2003; 2007), new materialism(s) (Braidotti 2000; Coole \& Frost 2010; Dolphijn \& van der Tuin 2012; Hird 2009), new empiricism (Clough 2009) or post-constructionism (Lykke 2010b). These theoretical movements are diverse but united in their "insistence on the significance of materiality in social and cultural practices" (MacLure 2013a, 659). They have all in diverse ways influenced my work and become important at different stages of the process. I have decided on a posthumanist approach, not only as an umbrella term to lodge these different theoretical takes, but to emphasize that what is central for this study is an approach that challenges humanistic notions and assumptions about school absenteeism, where "the figure of 'Man' (sic) naturally stands at the centre of things" (Badmington 2004, 1345). Moreover, a posthumanist approach is always already feminist in its foregrounding of marginalized and 'passive' materialities and in its challenging of the hu(Man) as the founding principle (Lenz Taguchi forthcoming).

Within this study, a posthumanist approach offers a way of introducing and inspiring a production of knowledge that acknowledges materialities in the production of school absenteeism, to include aspects of the phenomenon that have previously been understood as peripheral (Hultman 2011). Thus, when school absenteeism is engaged with in a posthumanist approach, concepts like 'the human', 'the nonhuman' and 'materialities' need to be scrutinized and problematized. This is developed further in the following section, where the 
ontological and epistemological underpinnings of a posthumanist approach are unfolded and related to the phenomenon of school absenteeism.

\section{Humans and nonhumans as entangled}

The term posthumanism appears to have worked its way into the humanities and social sciences in the middle of the 1990s (Braidotti 2013; Wolfe 2010). Today, feminist theorists, perhaps foremost Haraway (1988; 1989; 1991; 1997), are acknowledged as principal points of reference for how posthumanism is understood (Alaimo \& Hekman 2008; Barad 2007; Åsberg, Hultman \& Lee 2012). As the term suggests, the reinterpretations of humans, materialities and agencies that the prefix 'post' evokes are related to assumptions within humanism and humanistic ideologies, where anthropocentrism - the perception that humankind holds the central position in the universe (see for example Braidotti 2013) - is the ontological departure. Posthumanism is not a turning away from humans or human actions, but rather a perspective that opens up a critique of the human as a coherent, rational, autonomous and universal category that can be defined once and for all (Braidotti 2013). It is not 'post' in terms of a coming after or going beyond, but rather in offering a continuing exploration of the human (Edwards 2010; Lykke 2010b). Posthumanism can be described as distributing, dislodging and disaggregating anthropocentric notions, as the focus is moved from the 'Man' in the centre to include what has been understood as marginal or of less/no importance (Braidotti 2013; Colebrook 2014a). To focus on school absenteeism within a posthumanist approach is thus not to turn away from absent or present students, but to zoom in on how these absences and presences always emerge together with various nonhumans.

The writings of Barad (2003; 2007) have profoundly influenced the posthumanist approach $I$ have engaged with in this study. Drawing on the writings of foremost Bohr (1963; 1998), Foucault (1981; 1995; 2000), Haraway (1988; 1989; 1991; 1997) and Butler (1990; 1993), Barad (2003; 2007) entangles the philosophies of feminist theorizing with quantum physics. With insight from both feminism and the natural sciences, posthumanism for Barad (2007, 32) becomes a way to

signal the crucial recognition that nonhumans play an important role in naturalcultural practices, including everyday social practices, scientific practices, and practices that do not include humans.

Barad (ibid) continues: 
'posthumanism' marks a refusal to take the distinction between 'human' and 'nonhuman' for granted, and to found analyses on this presumably fixed and inherent set of categories.

Thus, a posthumanist approach inevitably opens up questions about the relations between humans and nonhumans, and how these relations could be defined. The concept of the nonhuman is commonly used to describe agencies and forces that are not associated with human beings (see for example Alaimo \& Hekman 2008; Barad 2007; Hultman 2011; Tuana 2008). This concept can be understood as problematic in relation to the underpinnings of the approach engaged with in this study. First, it indicates that humans and nonhumans are two distinct and easily separable categories. And second, it indicates that everything attributed to the nonhuman within the study (computer technologies, school schedules, hallways and so on) is reducible to one comprehensive category. The separation becomes even more difficult as humans to a great extent already consist of nonhuman entities (bacteria, pacemakers, residues and effects of the surrounding environment and so on; see Åsberg, Koobak \& Johnson 2011a). However, I have decided to work with the concept of the nonhuman in the study to emphasize that differences between humans and nonhumans are often actualized in ways that affect how school absenteeism is produced.

For this thesis, a posthumanist approach offers new ways of understanding "how students and teachers are constituted by focusing on the materialities of bodies, things and spaces within education" (Taylor \& Ivinson 2013, 665). One of the benefits a posthumanist approach is thus that it opens up to the productive potential of digital technologies in relation to school absenteeism. However, this could also be viewed as one of the challenges of the study because posthumanism has also been associated with technological accomplishments (Whatmore 2004), in which the merging of humans and new technologies becomes a way to enhance, improve and extend human capabilities (Weaver 2010). The focus for these associations is however the posthuman - notice my emphasis on man and the difference from the concept of posthumanism - as configurations of humans in seamless relations with intelligent machines (Hayles 1999; 2003). The posthuman might seem close to the approaches engaged with in this study, in which the technologies of the software for registrations of absences and presences are theorized as equally important as humans in the production of the phenomenon of school absenteeism. But, the fascination with the technological, linear and progressive development and enhancement of the posthuman body expressed by for example Hayles (1999; 2003), Weaver (2010) and Fukuyama (2002) - could rather be described as an intensification of anthropocentric notions as it involves a re-centring of the human (Badmington 2004; Braun 2004; 
Wolfe 2010). These understandings of the posthuman can thus be seen as almost the opposite of the posthumanism discussed in this thesis.

\section{The agency of materialities}

When researching school absenteeism from within a posthumanist approach, agency is not ascribed solely to humans but interest is also directed at how materialities become part of producing what takes place in the educational setting. The point is not to show the independent agency of materialities, but rather that agency is produced in entanglements of humans and nonhumans (Barad 2007). Agency is however not democratically distributed across these entanglements. There will always be power imbalances, but to research those hierarchies, the specifics of the present entanglements need to be carefully examined (Dolphijn \& van der Tuin 2012). This examination needs to be related to the premises of the study. When engaging in practices related to the registration of absences through digital technologies, materialities like clocks, keyboards, doors or schedules ('concrete' materialities) as well as digital software, binary codes or text messages ('invisible' or 'abstract' materialities) have been - and still are - produced as nonagentic and passive 'things' whose raison d'être is to be used by humans. In this sense the concept of materialities has similar connotations as the concept of the nonhuman within this study. I use these concepts interchangeably in the thesis, to refer to what, in practices related to school absenteeism, are separated from humans. Thus, the concepts of the nonhuman and of materialities become a way to describe a hierarchy in which materialities/nonhumans both theoretically and empirically are distinguished from humans.

A focus on materialism is not a new perspective since some of the ideas engaged with in a posthumanist approach can be historically traced to the thinking of Nietzsche, Heidegger and Marx (Pedersen 2014). What distinguishes posthumanist approaches from Marxist-influenced theorizing is a "keen interest in engagements with matter" (Hird 2009, 330, italics in original) whereas Marxistinflected materialisms understand economic and material conditions as the organizational structure of humanity (Taylor \& Ivinson 2013). This leads to a rereading of materialism, away from its Marxist definitions (Dolphijn \& van der Tuin 2012). The material engagements that are discussed in this thesis are hence an ontoepistemological concern with the agency of materialities in the production of the phenomenon of school absenteeism.

Entanglements of humans and nonhumans/materialities and a questioning of the boundaries of these categorizations, as well as an interest in the agency of nonhumans/materialities can be described as the central ontological underpinnings of the posthumanist approach put to work in this study. In the following I outline the specific posthumanist concepts that have been engaged with. 


\section{Theoretical entanglements with concepts}

The objective of this section is to focus on the concepts central to the study. I outline my aim with the concepts, and how they have been put to work, with an emphasis on the ways in which they affect the production of the phenomenon of school absenteeism. I also outline how the particularities - the material conditions - of the phenomenon of school absenteeism affect the concepts. The exploration begins with the concepts that form the ontological - or rather the ontoepistemological - departure for the study, and continue with an exploration of the specific concepts that are put to work to enable a close examination of how the phenomenon of school absenteeism is produced. Barad (2010, 253) describes concepts as the "indeterminate outside of the appropriate material conditions needed to make them intelligible". Thus, concepts are always specific material arrangements that emerge through the relations of theories, methodologies and research questions. To be able to zoom in on what work the different concepts have done in the thesis, I enact a temporary - and quite violent - agential cut between concepts helping me focus on the 'what' of school absenteeism, and concepts helping me focus on the 'how'.

\section{Concepts cutting out the ontoepistemologies of school absenteeism}

Barad's contribution to developing a philosophy that takes account of both human and nonhuman agency and of materialities in the production of a phenomenon is named an agential realism, a theoretical framework that emphasize the integral nature of epistemological, ontological and ethical responsibilities. ${ }^{24}$ With inspiration from this framework, three concepts have emerged as the basis for how I have engaged with the practices related to the registration of students' school absences and presences: school absenteeism as a phenomenon, produced in, as well as producing, practices. These concepts can be described as the principal conceptual agents in the study; i.e., the concepts that create orientations for thinking (Colebrook 2014b; Lenz Taguchi forthcoming) on school absenteeism.

\section{Phenomena, practices and productions}

A phenomenon can be defined as a situation (often remarkable) that is observed to exist or happen, or a fact whose cause or explanation is in question (Oxford Dictionary of English $3^{\text {rd }}$ Edition); this is a description that might apply to the phenomenon of school absenteeism. As the previous part of the thesis highlights, school absenteeism is often described as something deviant or remarkable, associated with problematic behaviours associated with young students. However,

${ }^{24}$ Ethics are discussed further in Engagements. 
it is not this general description of a phenomenon that is put to work in this thesis. Barad (2007, 140, italics in original) describes phenomena as

produced through complex agential intra-actions of multiple materialdiscursive practices or apparatuses of bodily production, where apparatuses are not mere observing instruments but boundary-drawing practices - specific material (re)configurations of the world - which come to matter.

As an extension of Bohr's quantum physics, Barad (2007) describes phenomena as the inseparability of 'the object' (in this study school absenteeism and the practices created in the digital registration of absence and presence) from 'the measuring agencies' (in this study the computer software, but also the theoretical and methodological premises), and claims that what is studied cannot be separated from the myriad of performative agents intra-acting with the object, just as it cannot be separated from how and together with what it is studied. Phenomena are thus the "ontological inseparability of objects and apparatuses" (Barad 2007,128 , italics in original). In relation to school absenteeism this means that the research focus also has to include the specific material configurations of the practices related to school absences and presences. The phenomenon is not produced in a vacuum but in these concrete material practices. Practices are thus the occasions that in entanglements render a phenomenon such as school absenteeism intelligible and/or challenging, but also the specific actions that arise as a result of the phenomenon. Human practices are not the only practices that matter, but neither is a phenomenon independent of human practices (Barad 2007, 206). Practices include both what takes place at the different schools of this study (what could be referred to as educational practices) and what takes places when producing knowledge on the phenomenon (what could be referred to as scientific practices). Within this study, school absenteeism is regarded as a phenomenon that is produced - that is, shaped and reshaped in different practices - rather than existing in and of itself. Production could in this sense be understood as nonlinear and non-deterministic flows that entangle practices of researching school absenteeism with how the phenomenon is produced; it entangles practices of being and practices of knowing in an ontoepistemology. And this is what constitutes realities.

As expressed by Barad (2007), in (social) science the concept of 'reality' often provokes a sense of discomfort because of its positivist associations. Nevertheless, Barad $(2007,205)$ claims that "we' cannot afford not to talk about 'it"'. As she unfolds her understandings of the concept, it becomes clear that reality is neither independent of human practices nor a social/discursive construction, since humans are neither pure cause nor pure effect, but part of reality in its becoming (Barad 2003). Following this, productions of reality always 
emerge in the mangle of the object of inquiry and the measuring agencies, as well as of the theoretical and methodological apparatuses of knowing. Thus, reality does exist, but what produces it are always phenomena, as specific material configurations of the world (Barad 2007, 206). Since reality is always produced, the potential of producing other or new realities is always present, which means that it is appropriate to theorize it as multiple realities, where no one reality is truer than another. In relation to school absenteeism this means that students' absences and presences do exist, but not as independent practices outside the way they are enacted in entanglements. The research thus has to include the specific material configurations of the practices related to school absenteeism, and acknowledge that the absences and presences could always be otherwise.

Phenomena, practices and production could be described as co-producers of the ontoepistemology of this study. My ambition in engaging with these concepts is to open up a theorizing on how the phenomenon of school absenteeism is produced in and through the entanglements of educational and scientific practices, that may or may not include humans (compare with Barad 2003, 817). To enable this, I have temporarily cut apart these three concepts from the other concepts of the study, producing an apparatus of knowing that forces them to answer the question of 'what' is the phenomenon of school absenteeism. In what follows, I outline the concepts that have been agentially cut out to explore 'how' school absenteeism as a phenomenon is produced in practices of humans and nonhumans.

\section{Concepts cutting out the 'how' of school absenteeism}

In the entanglements of the research interest of the study and the "materiality of the field" (Childers 2013), three concepts have emerged as my most assertive companions in the processes of analysis: intra-action, spacetimematterings and assemblages. These concepts have temporarily and agentially been cut out, not by me as an autonomous research individual, but by the larger material and discursive arrangement of which they are a part (compare with Barad 2007), to enable a focus on 'how' school absenteeism as a material-discursive phenomenon is produced. To open up to complexity has been the guiding principle when the concepts were chosen/chose me. It inevitably follows that what has been produced is diverse, rather than coherent, apparatuses of knowing. Concepts that at the first glance seem to originate from different theoretical traditions have collided within the phenomenon of school absenteeism, and affected both the phenomenon and each other.

In the following section, I introduce the concepts with a special focus on how they have been put to work in this study. The ambition for these three concepts has been to enable a close examination of the particular ways in which school absenteeism is produced in human and nonhuman entanglements. The 
concepts have helped me to direct my gaze towards this 'how', which has made different aspects of the phenomenon of school absenteeism come to life.

\section{Intra-actions: entanglements producing practices}

To research how the phenomenon of school absenteeism is produced in practices, a careful examination of the material-discursive entanglements that form the phenomenon needs to be undertaken. This means that $I$ have attuned to these entanglements as intra-actions. Intra-action is a concept that recognizes that there are no independent or distinct components in the production of a phenomenon. Rather, it is through intra-actions that the boundaries and properties of the different components become defined (Barad 2003, 815). The concept highlights the fact that that neither humans nor nonhumans act on their own, since all actions and agencies are produced in entangled becomings (Lenz Taguchi 2010). Hence, the concept of intra-action is distinguished from the more commonly known interaction, which presupposes the existence of independent entities and a pre-given split between them (Barad 2003). Interaction furthermore often describes an inter-personal relationship (Jackson \& Mazzei 2012), whereas intra-action involves matter as an active performative agent in all relations.

When focusing on intra-actions, humans cannot be separated from the surrounding materialities/nonhumans in the production of the phenomenon of school absenteeism. This means that students, teachers and parents do not have specific 'roles' in the production of school absenteeism, and neither do computer software systems, clocks, schedules or classrooms. The agential parts of the production of the phenomenon emerge through entanglements. The concept of intra-action thus becomes a way of zooming in on the entanglements, to figure out how the specific practices of humans and nonhumans and the intra-actions among them produce school absenteeism, without taking the functions of either humans or nonhumans for granted. Accordingly, the practices surrounding school absenteeism are always an entanglement, and not a human-alone responsibility. By focusing on school absenteeism in intra-actions, enables an emphasis on how each component of the phenomenon becomes agentic in relation to other components. This questions a logic in which both humans and nonhumans are coded with pre-determined notions of their respective properties when it comes to school absenteeism. The concept of intra-action thus opens up a production of knowledge that departs from notions of students' individual shortcomings, and instead emphasizes that there would not be a phenomenon of school absenteeism without nonhuman agents intra-acting with students, teachers and parents. The concept becomes a way of highlighting how things that might 
seem unimportant are vital for exploring school absenteeism. ${ }^{25}$ How intra-actions produce absences and late arrivals, but also presences, is developed in the following section.

\section{Spacetimematterings: time, space, place and matter}

The concept of intra-actions becomes a way to unfold how school absenteeism is produced in entanglements; this section focuses on how it becomes possible to produce knowledge on the intra-actions that are specific to school absenteeism.

Time undoubtedly becomes the centre of attention when theorizing the phenomenon of school absenteeism. However, as the concept of intra-action has shown, no component of a phenomenon is isolated, and neither is time. It is not enough to be on time anywhere in the school area; it is presence in the classroom at the right time that matters. And furthermore, to be regarded as present, a student needs to be registered as present in the digital software. The complex intra-actions of being at the right place, at the right time, with the right educational belongings (for example, the right school books or sharpened pencils) and getting the right registration in the software, structure both bodies and materialities as well as produce absences and presences. As a continuation of the work of Massey (1994; 1999; 2005) on the entanglements of space and time, I have turned to the agential realist concept of spacetimematterings (Barad 2007) to explore this further.

Educational practices can be understood as specific configurations of space and time that are continually remade (McGregor 2003), which can open up insight into the spatial and temporal dimensions underpinning educational processes (Gulson \& Symes 2007). However, in a posthumanist approach the ordering of time and space in education is not an ordering by human subjects but rather material gatherings that interrupt and affect notions of space and place. Specific intra-actions among space, time and matter thus become crucial for the production of school absenteeism ${ }^{26}$. Spacetimematterings become a way of underlining the inseparability of space, time and matter (Barad 2007), and of exploring how the intra-actions of school absenteeism do not happen in space or on time but are of spacetimematter (compare with Juelskjær 2013). This means that neither time nor space nor matter is static but always in processes of becoming, and that the "intra-actions themselves matter to the making/marking of space and time” (Barad 2007, 180). And, as outlined above, digital technologies need to be understood as an agential part of this.

25 The concept of intra-action has become more than an analytical companion. In empirical engagements with educational practices, the concept has also become part of producing a methodology of intraviews that zoom in on the agency of materialities in the process of empirical production. This is developed further in the next part of the thesis, Engagements.

This is developed further in Research paper III (Bodén 2016). 
Within this study, the aim of engaging with the concept of spacetimemattering is to invite a co-producer of knowledge, one that enables me to research how the software and other materialities become powerful performative agents that in spacetimematterings produce presences, unexcused absences, and late arrivals. The concept also becomes a way of shedding new light on the notions of the 'bodily' presence of students. Furthermore, it shows how the software blurs the boundaries between time, space and matter which affects relations between homes and schools, relations often emphasized as crucial to key aspects of school attendance and school absenteeism (Skolverket 2008; 2010, see also Markström 2013). When it comes to school absenteeism, relations between homes and schools could be described as both intense and emotional. This can also be said of other practices related to school absenteeism, and takes us to the next section, that introduces the final concept that has been put to work to explore 'how': assemblages.

\section{Assemblages: desires, energies and affects}

The concepts of intra-actions and spacetimematterings open up a complex analysis of how school absenteeism is produced in entanglements of humans and nonhumans, and time and space. However, the practices surrounding school absenteeism are also produced in multifaceted entanglements of desires and affects, analysis of which neither of these two concepts fully enables. I have thus engaged with the Deleuzio-Guattarian concept of the assemblage (Deleuze \& Guattari 1987) through educational and posthumanist researchers (like Coleman \& Ringrose 2013; Hickey-Moody 2013; Jackson \& Mazzei 2012; Kofoed \& Ringrose 2012; Lenz Taguchi 2012; 2013; MacLure 2013a; Renold \& Ivinson 2014; Ringrose 2011; St. Pierre 2004; Tamboukou 2008; Youdell 2011), to open up yet another property of the phenomenon.

According to Youdell $(2011,14)$ the concept of the assemblage enables conceptualization and thus study of the intricacies of the educational terrain - the relations of "economy and politics, policy, organizational arrangements, knowledge, subjectivity, pedagogy, everyday practices and feelings". An assemblage can be described as a "contextual arrangement in which heterogeneous times, spaces, bodies and modes of operation are connected" (Hickey-Moody 2013, 94). All assemblages are compositions of energies and desires, where desire is addressed as a force that in complex ways flows between - as well as through - humans and nonhumans, assemblages and bodies (Ringrose 2011). The work this concept does in the thesis is to open up the possibility of theorizing desires and energies (see further Deleuze \& Guattari 1983 ) in relation to the phenomenon of school absenteeism. The concept of the assemblage thus enables a production of knowledge in which the digital registration of absences and presences becomes an embodied, material, affective practice, rather than a neutral, impersonal, and automated action. Accordingly, a 
theorizing of affect is closely connected to how the concept of the assemblage is put to work in the study; affective assemblages decentre the location of feelings and emotions and enable a theorizing of how affect belongs neither to a specific body, nor to a specific technological tool, nor to a specific place/space, but emerges in entanglements within the assemblage (Mulcahy 2012). Affective assemblages become a way of researching multiple entanglements of affect, where what might be perceived as passive digital materialities produce affective and emotive engagements in relation to school absenteeism.

To conclude this section on concepts engaging in the questions of 'how' school absenteeism is produced in practices, it needs to be stressed that the Deleuzio-Guttarian concept of the assemblage has been cut together with the Baradian/agential realist concepts of intra-action and spacetimematterings. Recently, some critique has been articulated in relation to whether Barad's and Deleuze's work can be used together. For example, Hein (2016) claims that even if Barad's and Deleuze's work are regularly presented alongside each other (as both belonging to the framework of new materialism or posthumanism), they put to work different ontologies and their understandings of matter deviate. However, if 'the real' in posthumanism is already understood as multiple and encompassing diverging versions of the real, multiple ontologies are then not only operating on the same plane of thinking, as Deleuze would claim, but also produce new versions of the real in their encounters (Lenz Taguchi forthcoming). Bearing this in mind, the Baradian concepts of intra-action and spacetimematterings as well as the Deleuzio-Guattarian concept of the assemblage have been crucial in relation to producing knowledge on the phenomenon of school absenteeism within this study. If the cutting together of these theoretical concepts evokes ontological ruptures and dissonances, these should be seen as productive of new ways of knowing (Colebrook 2014b; Lenz Taguchi forthcoming) rather than as a theoretical and methodological problem. My focus has been on how the concepts work and what they produce together. This brings us to the concluding remarks on concepts, where the 'what' and the 'how' that were cut apart are cut together.

\section{Cutting together what was cut apart: entangling what and how}

As has been stressed above, an ontoepistemology entangles 'what' is studied with 'how' it is studied. These entanglements are what produce a phenomenon; in this study the phenomenon of school absenteeism is simultaneously produced by those concepts I have assigned the task of describing the 'what' of the study, and those I have assigned the task of asking 'how'. What I want to stress in these final words is that the concepts outlined above are nevertheless inseparable; they have only been cut apart to enable me to describe the work they have done - what 
they have helped me with and what they have produced - within the apparatuses of knowing when researching school absenteeism. What was momentarily cut apart, is never really separate at all, and needs to be cut back together because all theorizing of the phenomenon of school absenteeism as produced in practices is simultaneously a theorizing of how: in intra-actions, of spacetimematterings and within assemblages.

\section{In conclusion: entanglements as a queer twist of time?}

By focusing on school absenteeism as a phenomenon, produced in practices of intra-actions and spacetimematterings - like an assemblage in which technologies, affect and everyday encounters become equally important components - the complexity of school absenteeism can be theorized and analysed. Thus, and as has been discussed above, different aspects of entanglements have become important to explore different aspects of the phenomenon. The outlining of a posthumanist approach and the temporary focusing on a certain concept has been a way to try to accentuate the contradictions and the complexities of school absenteeism. The different concepts engaged with are multiple and diverse, and not always coherent. As entanglements, cut together and apart, the concepts discussed have created a jumbled effect of relations and connections, but also displayed diversities and cracks. What becomes important has thus been to follow the entanglements as they twist, twirl and queer assemblages, space, time and matterings, and intra-actions, "given that queer is a radical questioning of identity and binaries" (Barad 2012a, 29).

The entanglements discussed in this section further emphasize the importance of the relations between theories and methodologies. The upcoming part, Engagements, explores the methodologies put to work in the study. 


\section{Engagements}

Up and over we go through the wave and undertow.

King of Carrot Flowers, Pt. 2-3 - Neutral Milk Hotel $^{27}$

...knowing is a direct material engagement, a cutting together-apart...

(Barad interviewed in Dolphijn \& van der Tuin 2012, 52).

How the ambition to produce theoretically as well as empirically grounded knowledge has materialized into methodological and empirical engagements is the focus of this section. Hird $(2009,342)$ claims that engagement requires an ontology and epistemology that does not reproduce dichotomies. To rephrase this, I would claim that ontoepistemologies require engagements; the phenomenon of school absenteeism, as it is produced in this study, is an "ongoing intra-active engagement" (Barad 2007, 376). Engagement thus becomes a way to underline the inescapable and sometimes overwhelmingly intense relations between myself as researcher, the theories and methodologies put to work, and the humans and nonhumans within the practices that produce school absenteeism.

${ }^{27}$ Lyrics: Mangum et al. (1998) 
Engagements starts with a discussion of how ethical engagements are played out within a posthumanist approach. Subsequently, I outline how the empirical engagements within this study have emerged in a continuation of qualitative methodologies, evolving into post-qualitative methodologies. I discuss the specific methodologies put to work, as well as what has been produced in these engagements. Rather than referring to this as 'data', I introduce the concept of empirical productions. Following this, the enactments of theories and empirical productions are explained; that is, how the process of analysis was organized. The research papers - that in different ways weave (or wave) together the entrances, entanglements and engagements discussed in the 'kappa', and that acknowledge the aims and questions of the study - are introduced and summarized, before the section concludes with some words on engagements through 'wave and undertow'.

\section{Ethical engagements in research}

As Barad (2007) explains, ethical concerns can never be a supplement to processes of research but are always an integral part of it, because values are an integral part of knowing, being, choosing and producing research. This study was approved by the Regional Ethical Review Board in Linköping (www.epn.se), (Dnr 2012/110-31). As part of the application, questions were asked about how the research project would affect the participants, how the participants would be introduced to the purpose of the project, whether the research would in any way violate the participants' privacy, how the collected data would be stored and how the information letters and consent forms to the participants would be worded.

Individual students' absences are not a main focus of this study and neither are individual teachers' work or parent's relations to the children's presences or absences; this was emphasized in the application to the Ethical Review Board. Nevertheless, knowledge of individual absences sometimes reached me through the registrations in the digital systems. The project thus entails a certain risk of privacy violation because the information about students' school absenteeism may be sensitive, for students as well as parents. However, this information does not provide the basis for the analysis, but should be primarily understood as 'extra material', as a consequence of the focus on the digital registration. Despite this, it is of importance that this information is treated with the same requirements - in terms of confidentiality and storage - as the study's main material. Consequently, all the names of places and people within the study are pseudonyms. Because I visited several different classes at three different schools, the empirical engagements can be varied in the presentation of results, making the identification of research participants more difficult. Furthermore, all participants gave their informed consent. They were informed about the possibility of withdrawing their engagement at any time from the project and how 
this could be achieved. The project follows the Swedish Research Council's ethical principles (www.vr.se).

According to the ethical principles of research that involve humans as presented by the Ethical Review Board, the application was approved and the research presented in the thesis was accepted as ethically reliable. However, the participants discussed in the application refer exclusively to human participants. In line with a posthumanist approach it thus becomes necessary to extend the ethical discussion to include other relevant aspects of the phenomenon. Consequently, to be ethical in relation to my research project or the participants I engage with can never be reduced merely to my own consciousness of how to treat the participants or the empirical engagements, but has to be stretched to include what phenomenon the research and the researching produce. Barad (2007) calls this an ethico-onto-epistem-ology, to stress the importance of the intertwining of ethics, knowing and being. To engage ethically in relation to researching school absenteeism in this study is to be aware of how the agential cuts produce a specific version of the phenomenon and to take responsibility for the fact that the world is materialized differently through different practices (Barad 2007). In line with the feminist imperative to acknowledge what has previously been understood as non-agentic and unimportant in the production of realties, ethical engagement thus invites a close examination of how the methodological, theoretical and empirical approaches include/exclude both human and nonhuman agency. Being ethical is thus about enabling cuts that open up, rather than close down, unexpected entanglements, cuts that produce new realties, new questions and new versions of school absenteeism. This highlights the ethical responsibility of putting to work apparatuses of knowing that challenge notions of both the neutral digital technologies and the autonomous blameable students. For me, this is closely connected to a feminist responsibility for producing more affirmative and more inclusive realities and possibilities.

\section{Engagements with post-qualitative methodologies}

With these ethical responsibilities as the starting point, this section discusses the methodologies put to work in this study, in a continuum of qualitative methodologies and what comes after.

MacLure (2013a, 664) describes how "[q]ualitative research is heavily invested in language practices: interviews, fieldnotes, focus groups, conversations, seminars, monographs, scholarly papers, etc." Methodologically, language and linguistic representations has been used as a mediating function with the focus on a correspondence between descriptions and reality (that is, do the representations reflect nature/culture in a satisfying way?) (Barad 2007, 135). Accordingly, what is produced in this line of thinking when engaging in empirical work is the reality as ontologically separated into materialities on the one hand, and language, words, 
reflections and discourses performatively enacting the reality on the other. Within a representationalist ontology, the researcher thus reflects on the known from the outside, at a distance from what is studied (Barad 2007, 88). This is challenged within a posthumanist approach.

Barad (2003, 829, italics in original) claims that "we do not obtain knowledge by standing outside the world; we know because "we' are of the world". Accordingly, a posthumanist questioning of representations has radical implications for qualitative methodology and has been described as important for opening up explorations that problematize the humanist notions of 'conventional' qualitative methodologies (MacLure 2013a; St. Pierre 2011; 2013). Post-qualitative inquiry (Lather 2013; Lather \& St. Pierre 2013; St. Pierre 2011; 2014) becomes a way of challenging the binaries between the researcher and what is researched, and between linguistic representations and materialities. It also enables experimentation with qualitative methodological concepts like data, interviews, observations and analysis (Gunnarsson 2015, 66). As such, the postqualitative methodologies put to work in this study are not a rejection of qualitative methodologies. Rather, they are on a continuum that takes important insights from qualitative methodologies but slightly shifts the focus to include both human and nonhuman agency in the production of the phenomenon of school absenteeism. In putting other things forward, there is a refocusing and a restaging of qualitative methodologies. And as the focus of this study is to explore how the phenomenon of school absenteeism is produced in practices of humans and nonhumans when absences and presences are digitally registered, both Skolwebben and Dexter are inevitably part of these methodologies.

In the following section, I outline how I have worked with the software and the schools of this study through empirical engagements and interviews/intraviews.

\section{Empirical engagements to explore practices}

Empirical engagements can be described as a continuation of the methodology often referred to as participant observation, but here the emphasis is not primarily on human participants but on the human/nonhuman practices that produce school absenteeism (see also Gunnarsson 2015, 80). Like participant observations, empirical engagements involve the study of everyday situations. By describing my participation in everyday practices as empirical engagements, rather than as participant observations, I want to highlight the role of theories and methodologies in producing the phenomenon of interest, as well as emphasizing that the focus has changed from human participants to a focus on human/nonhuman entanglements. Through examining the conditions and possibilities of the seemingly ordinary and mundane, I aim with empirical engagements to produce knowledge on the practices produced and performed in relation to school absenteeism. In participant observation, the researcher is 
understood not as a neutral observer, but as a participant that in various ways explores and navigates through an environment that s/he initially had not mastered (Emerson, Fretz \& Shaw 2011; Hammersley \& Atkinson 2007). This is also my starting point for the empirical engagements, where my involvement as a researcher is viewed as crucial to how the phenomenon is produced. However, in participant observation, the researcher has been described as being always at a distance from full involvement, since engagements often become interesting research occasions which may be selected and written down, rather than 'real life' happenings (Emerson, Fretz \& Shaw 2011). From a posthumanist approach though, it becomes impossible to describe the researcher as being at a distance from the phenomenon, which is yet another reason for choosing the term empirical engagements. When studying a specific practice and a specific phenomenon like school absenteeism, the researcher and the theories are also involved in (the production of) those practices and phenomena.

\section{The empirical engagements at three schools}

My first empirical engagement lasted only a day, with Skolwebben at Kardinal School. In December 2010, I joined two classes (Grades 5 and 6) and interviewed their teacher, but more importantly I met with the practices surrounding the digital registration, as the teacher of the class showed me how absences and presences were registered in Skolwebben. This visit could best be described as a pilot study and a first engagement to explore the practices surrounding the work with school absenteeism that eventually directed my interest to the digital registration. Our collaboration ended after this day.

To further explore the phenomenon of school absenteeism in relation to digital registration, I chose to engage with the software Dexter. Since Dexter is one of the most widespread forms of software for the digital registration of absences and presences in Sweden, I contacted a municipality (City 2) that worked with Dexter. Through a meeting with representatives at the education office of City 2 I learned that Sandö School and Björnäng School had been working with Dexter for a while, and both schools were interested in participating in the study to learn more about the digital registration. That was how our collaboration started. Teachers at the schools were informed verbally and in writing and filled in consent forms, agreeing to be part of the project. At two separate parent meetings I informed the parents that I, in consultation with school management and teachers, would perform parts of my study at the schools. I informed them about the purpose of the project and parents had the opportunity to ask questions. Written information about the project and consent forms were handed out, together with postage-paid envelopes. The classroom teachers mediated the written information for the parents who did not attend the meeting. The students at both schools were informed about the project during 
the first days I started working with the schools. Written information about the project and consent forms were handed out, and filled in by the students. ${ }^{28}$

Between May 2012 and December 2013, I spent a total of 70 hours at Sandö School. I spent five full days joining in lessons and other activities, and an additional six days at interviews or meetings. Altogether, I followed 54 students and nine teachers at Sandö School. I engaged mainly with the team who worked with students in Grade 8. Between April 2012 and September 2013, I spent 30 hours, participating in various school activities at Björnäng School. At this school, I spent two full days, and an additional four days at interviews or meetings. Altogether, I followed 45 students - mostly in Grade 7 - and six teachers at Björnäng School. The time spent at each school differs (as do the students, teachers and participating parents). However, since my focus was neither to compare the schools nor to highlight what distinguished them from each other, spending the same amount of time or engaging with the same number of participants at each school did not seem important. This also meant that, rather than participating in the school setting for a long period of time, the aim of the engagements was to pay close attention to practices in which the digital registration of absences and presences was actualized.

Sørensen $(2009,22)^{29}$ argues that it is only when various practices are carefully studied that knowledge can be produced on what materialities are important, and on how they become important in entanglements with other materials and with humans. Inspired by this, I focused on the human as well as nonhuman agents related to school absenteeism, and on what was performed in the material-discursive entanglements among them. Focusing on the phenomenon of school absenteeism during the time I spent in the schools might be described as a "shadowing" (Czarniawska-Joerges 2007) of practices related to school absences and presences, including their digital registration. This meant that the practices in which, in different ways, absences and presences were actualized guided me and confronted me with other performative agents, both human and nonhuman (see Bruni 2005 for a further discussion on the shadowing of nonhuman agents). Accordingly, Dexter was almost always part of the engagements.

In my shadowing of practices, I some days followed a teacher and other days a group of students. It may sound contradictory, especially in a posthumanist

28 All consent forms were approved by the Regional Ethical Review Board in Linköping (www.epn.se), (Dnr 2012/110-31).

${ }^{29}$ Sørensen (2009) departs from an actor-network perspective in her methodological descriptions. Even though I am not working with ANT in my study, the ontological and epistemological underpinnings of ANT are similar to those I depart from, which makes it possible for me to take 'bits and pieces' of an ANT-inspired methodology and incorporate them in my empirical engagements. 
approach, to organize my days around the actions of the human participants. However, this was a way of trying to be part of many different practices in relation to absences and presences, including digital registration. The teachers and the students became the organizational structure for achieving this. The days I followed a teacher, I participated in teaching and in registrations in Dexter, accompanied the teacher between lessons and joined him or her for coffee breaks, as well as for meetings and during planning time after the school day. Particular interest was directed at the beginning of class when the teacher checked the numbers of absent/present students, registered whether anyone had arrived too late or had been reported as sick, and so on. This was done either directly into the software, on paper, or in the app on the smartphones. I asked the teachers if I could stand beside them in front of the class when they did the registration on a laptop, look at the notes on their written papers, and if I could 'hang over the shoulder' of the teachers when they used the smartphones. A special focus was also directed to the times between lessons because teachers often did the registration during the break, on their computers in the teachers' office. I was often invited to sit together with Dexter and the teachers as they did the registration. The days I joined the students, I took part in their lessons and breaks during the day, as well as joining meetings with the school council and so on. I spent time with students waiting for teachers in hallways (I sometimes arrived late as well), caught the same buses as the students to and from the school, and so on. On the days I spent at the schools I always had lunch with the students and the teachers in the school canteen.

\section{Engagements at meetings in the municipality of City 2}

Before, as well as during the engagements in the schools, I was a participant at three meetings at either the education office or the IT centre of the municipality where the schools were located. The first meeting was a gathering to discuss, together with representatives - both teachers and social workers - from other municipalities within the province, various aspects of school absenteeism within the municipality. The second meeting was an information meeting about the procurement of different software - the registration of absences and presences was one of the features of the software - to be used in the schools of the municipality. Representatives from schools and from the IT unit were present at the meeting. The third meeting, at the IT unit of the municipality, was an information meeting about the new features, related to the registration of school absences and presences, of Dexter. Teachers and headmasters from different schools participated in the meeting. These meetings had various effects: they became a way of introducing my research to the officials in the municipalities and as a consequence of this, to get in touch with different schools, as well as a way of including aspects within the study that on a political level affected the 
phenomenon of school absenteeism, for example the procurement of software where it eventually (but not at the meeting I participated in) was decided that Dexter was the 'winner'. During these meetings I collected written information and made notes; the second meeting was also recorded.

During the time of the empirical engagements I also had a temporary login to Dexter. Through this, I had access to a Dexter 'test school' where some fabricated students were listed, for example Erik Dextersson and Cindy Birdsong. In this test environment I could try some of the different features in Dexter, without accessing information on any 'real students'. This was helpful in getting to know Dexter better.

\section{Human and nonhuman conversations}

Just as the times I spent at the three schools and at different meetings can be named empirical engagements, so can the more formalized conversations with teachers, students, parents and with computers and computer software. Nonetheless, I have chosen to describe the more formalized conversations as interviews/intraviews.

\section{Interviews with teachers, students and parents}

To produce knowledge on opinions and notions about school absenteeism and its digital registration, the interviews with teachers, students and parents involved discussions on absenteeism, late arrival, the formal school rules concerning the registration (of absences and late arrivals), Dexter, the text messages sent through the system, and so on. Prior to the interviews, interview guides were prepared (see Appendices II-IV), but they were used more as an aid than a schedule. Some of the themes were 'absence and presence', 'relations between home and school', 'text messages' and 'the computer system'.

Interviews have been theorized in terms of a co-construction of meaning between interviewer and respondent (Holstein \& Gubrium 1995; Silverman 2006). It is a social interaction in which the participants, together with the interviewer, constantly produce and performatively construct themselves in various ways by telling and re-telling their self-narratives (Rapley 2001; Halkier 2010). Interview methodologies are thus mainly focused on the spoken words of human participants, often departing from a humanist ontology (Mazzei 2013). Hence, "the interview apparatus has sought to make visible the enclosed, complete humanist subject" (Kuntz \& Presnall 2012, 735, italics in original). Accordingly, in interviews a specific form of knowledge on the phenomenon of school absenteeism was produced: perspectives and thoughts from teachers, parents and students about school absenteeism, about the practices produced in relation to the registration of absences and presences, and about Skolwebben and Dexter. Still, materialities in different ways slipped into the interviews. When 
talking to the parents about the text messages they received, their mobile phones became part of the conversation, as the parents both looked at the phones and showed the messages to me. Erik, one of the parents in the group interview at Sandö School, had been quiet in the early part of the interview. But when he began looking at the text messages on his phone, he became engaged in the conversation and started contributing much more. A similar thing happened in the conversation with Malin, a teacher at Björnäng School. When I asked her about different alternatives when registering absences, Malin immediately asked "May I look?", with her glance directed toward her closed laptop, "Because I don't know that by heart". In relation to the students, other materialities made it into the conversations. It was $13^{\text {th }}$ of December and Lucia [St. Lucy's Day] on one of the interview days, so I brought some candy. The students' focus on getting as much candy as possible and the chewing mouths made the conversation a bit difficult. Together with my constant glances at the candy, worrying whether it would be enough for the next group (it was not), these materialities clearly affected the situation and afterwards I wondered if the conversations had ended when the candy was finished. These examples show how interviews, even if centred on social interaction, can be described as situations where materialities are central to knowledge production (Gunnarsson 2015, 86; see also Nordstrom 2013).

The conversations with teachers took place individually, except on one occasion where two teachers were interviewed together (because of organizational reasons at the school). In total, interviews (and intraviews, discussed below) were performed with nine teachers and one student assistant. A group interview was held with four parents of students from Sandö School. ${ }^{30}$ Rather than wanting the parents to reach a consensus on the themes discussed, I was interested in "a range of responses which provide a greater understanding of the attitudes, behaviour, opinions or perceptions of participants on the research issues" (Hennink 2007, 6; see also Barbour 2007; Krueger \& Casey 2009; Liamputtong 2011). In addition to the group interview, I met one parent of a student from Björnäng School alone, as the other three parents for the group interview were indisposed on the day of the interview. The interviews with students, took place in four groups, of four or five students each, from Grade 9 at Sandö School. ${ }^{31}$ The reason for choosing to talk to the students in groups was an interest in how they discussed school absenteeism and Dexter among themselves. An additional reason for choosing to talk to the students in groups was to make the conversations a bit less 'intimidating' or 'scary' (Madriz 2003), on

\footnotetext{
${ }^{30}$ Before the group interview with parents, a pilot interview was conducted with six parents from other schools.

${ }^{31}$ When the empirical engagements began, in 2012, they were in Grade 8.
} 
the assumption that $\mathrm{I}$, as researcher and adult, am always in a hierarchal relation to the students. In total, eighteen students participated in the group interviews.

Even though materialities inevitably were part of all the conversations described above, questions on how for example the digital technologies intra-act with humans in the production of school absenteeism were sometimes difficult to address. Some aspects of the phenomenon seemed to go unnoticed in the interviews, where the focus was mainly on the notions, actions, and feelings of teachers, parents and students. As a way of challenging the anthropocentric ontology that has been described as being an inevitable part of qualitative methodologies (MacLure 2013a; Lather \& St. Pierre 2013; St. Pierre 2011; 2013; St. Pierre \& Jackson 2014), introducing the concept of intraviews became a way to zoom in on the material-discursive intra-actions taking place in the processes of registration. It also became a way to continue, and extend, a thinking in which the entanglements of human and nonhuman agents are central to the knowledge produced in interviews (compare with Gunnarsson 2015; see also Lindén 2016, 74).

\section{Intraviews in entanglements of humans and nonhumans}

By weaving together the concept of the interview and the Baradian concept of intra-action (Barad 2007; 2003), Kuntz and Presnall (2012; see also Stender Petersen 2014; Bodén 2015) introduce intraviews ${ }^{32}$ as an interruption of the traditional structure of the interview. When researching the phenomenon of school absenteeism, the intraviews became a way of inviting the computer software to be a part of the conversation on absences and presences and to try to open up possibilities for more than human agents to 'speak'. Spontaneous, as well as more organized, conversations about specific practices or happenings are common in qualitative research. Researchers have emphasized that the firm distinctions between conducting an interview and participant observation can be challenged, by, for example, obser-views (Kragelund 2013) and think-aloud-protocols (Charters 2003). The intraviews can be seen as in line with these methodologies, but at the same time take them a step further. Rather than focusing on how materialities in the interview situation become tools or mediators - or "secondary, ancillary data sources about people" (Nordstrom 2013, 243, italics in original) - my interest was directed to the entanglements of humans and nonhumans and how this was enacted in the intraview situation.

I engaged in intraviews with six teachers (three from Sandö School and three from Björnäng school). I met with the teachers one at a time, and the teachers were asked to bring their laptops to the conversation or to choose a location where they had access to their computer. In the intraview they were asked to log

\footnotetext{
${ }^{32}$ Intraviews as a methodology to research school absenteeism are explored in Research paper II.
} 
in to the computer software and we then talked about different themes while simultaneously engaging with the computer. This meant the intraviews transformed the conversations from a talk about the teachers' thoughts about the software, to conversations with the software and the practices of doing the registrations. Sometimes the software made it into the conversation without me asking for it, as described above in relation to the conversation with the teacher Malin. And sometimes it refused to participate; on several occasions the computer did not start or it was not possible to log in to Dexter. During one week when I had planned on engaging in intraviews with three teachers a fire in the master server at the education office of the municipality shut down the computer software for that entire week, making the intraviews impossible to perform. Nevertheless, this incident shed light on how entangled the teachers were with the computer software: "This week, you're just lost, I log in, I do not know how many times a day..." as the teacher Agneta at Sandö School described the shutdown.

The intraviews brought attention to the agency of materialities and the active engagements of myself as researcher, the teachers, the computer and the software. However, the material-discursive methodology of the intraviews, turned 'doing research' into a much messier affair. It can be claimed that a new materialdiscursive reality was produced through the intraviews, which highlighted how things that at first seemed unimportant were vital to understanding the processes of registering school absences and presences. Questions arose on what to count as the 'data' to be included in the knowledge production of this study. These are discussed further in the following section on empirical productions.

\section{Emerging empirical productions}

I have theorized as empirical productions all that emerged through the empirical engagement in the shape of notes, photos, interview transcripts and so on produced in the engagements with the many and various performative agents that I have described above, not the least Dexter. This becomes a way to rethink the concept of 'data'. Rather than focusing on transcripts or notes as representations of what has been 'collected out there' from interviews or observations, this rethinking emphasizes the way empirical material is always produced in close entanglements of theories and methodologies (for discussions challenging the concept of 'data', see further Lather \& St. Pierre 2013; St. Pierre 2013; St. Pierre \& Jackson 2014). Focusing on productions does not mean that just any aspect of the phenomenon of school absenteeism can be studied but rather that it cannot be decided beforehand what should be studied. This stands in contrast to a thinking that, even before the engagements have begun, the researcher is able to determine what is worth 'collecting' (St. Pierre \& Jackson 2014). 
During the time I spent at the schools I wrote notes on paper and on an iPad that were then rewritten on a computer. The rewritten notes consist of about 90 pages of text. In the writing and rewriting of notes it was a constant challenge to not decide in advance the role of humans or nonhumans, nor what affected the understanding and management of school absenteeism. It was "a continuous struggle against [my] own tendencies to lapse into realist or objectifying modes of description that see only what is already assumed to be "there"' (Jones et al. 2010, 479). What guided me in deciding what engagements to get further involved in, and what to disengage from - what empirical productions to cut into the phenomenon of school absenteeism and what to cut out - was the premise of the study to explore school absenteeism as a phenomenon of the entanglements of humans and nonhumans. The focus when writing notes was practices that actualized school absences and presences, in human and nonhuman entanglements. In the notes I tried to describe what happened, the humans and nonhumans that participated, and statements and responses by both humans and nonhumans; for example, what happened in Dexter or in Skolwebben on the screen or on the smartphones of the teachers. I made notes of what I saw, heard, felt (heating/cooling, etc.), and smelled as well as thoughts, feelings and theoretical or analytical comments that emerged in these material-discursive engagements. In addition to this, I took a few photos (twelve in total) of the school environment, of the teachers collaborating with the software during registration, of teachers working on reorganizing the school schedule, and during my travels to and from the schools. I also collected documents from the schools, such as schedules, class lists, hand-outs and tests.

With the exceptions of the pilot study with caregivers and the interview with the system administrator/project manager at the education office in City 1, all interviews/intraviews was transcribed in full. In total, the transcriptions consist of ca. 210 pages of 'data'. The focus when transcribing the interviews/intraviews was both human and nonhuman 'voices'. This meant I tried to listen carefully to what was immediately heard, but also to what at first appeared as background noise such as the fan of the computer, or the footsteps outside the room where the interview was taking place, as well as what happened in Dexter if Dexter was part of the situated engagement. Sometimes expected happenings were part of the empirical productions: students talking about Dexter in interviews, teachers counting students to register them, or parents describing the control the text messages offer in both positive and negative terms. But also less expected happenings became possible to acknowledge: the bright red lights on a computer screen that affected what was registered, the 'silences' between human voices in the intraviews, the darkness of a gymnasium, teachers dreaming about ski trips, doors that were locked or unlocked, how the process of writing evoked memories of my son and I encountering digital registration for the first time at my home, 
and parents' affective and intense encounters with text messages on smartphones. Opening up to unexpected empirical productions became yet another way to acknowledge the imperative to produce different versions of school absenteeism, as this inevitably affects what can be known about the phenomenon. What became increasingly obvious was that 'new' things emerged in the processes of rewriting the field notes and transcribing the interviews/intraviews. New empirical productions were continuously created and engaged with during writing (compare with St. Pierre 2011). The proliferation of empirical productions did not end when I left the schools nor when the recording device was shut off, but continued and intensified through the writing and the processes of analysis. ${ }^{33}$

\section{(Re)presenting the engagements}

The aim of the following tables is to visually (re)present the empirical engagements. Table 1 summarizes the engagements that took place 'inside' the three schools (Kardinal School, City 1; Sandö School and Björnäng School, City 2): namely, the days spent at the three schools and the interviews, group interviews and intraviews with teachers, parents and students. Table 2 summarizes the engagements that took place in City 1 and City 2, 'outside' the schools: empirical engagements at IT offices and education offices, interviews with a system administrator and a product owner, and a pilot interview with parents.

${ }^{33}$ This is developed further in Research paper II (Bodén 2015). 
Table 1: Engagements at the three schools
City 1
City 2

KARDINAL SCHOOL SANDÖ SCHOOL

BJÖRNÄNG SCHOOL

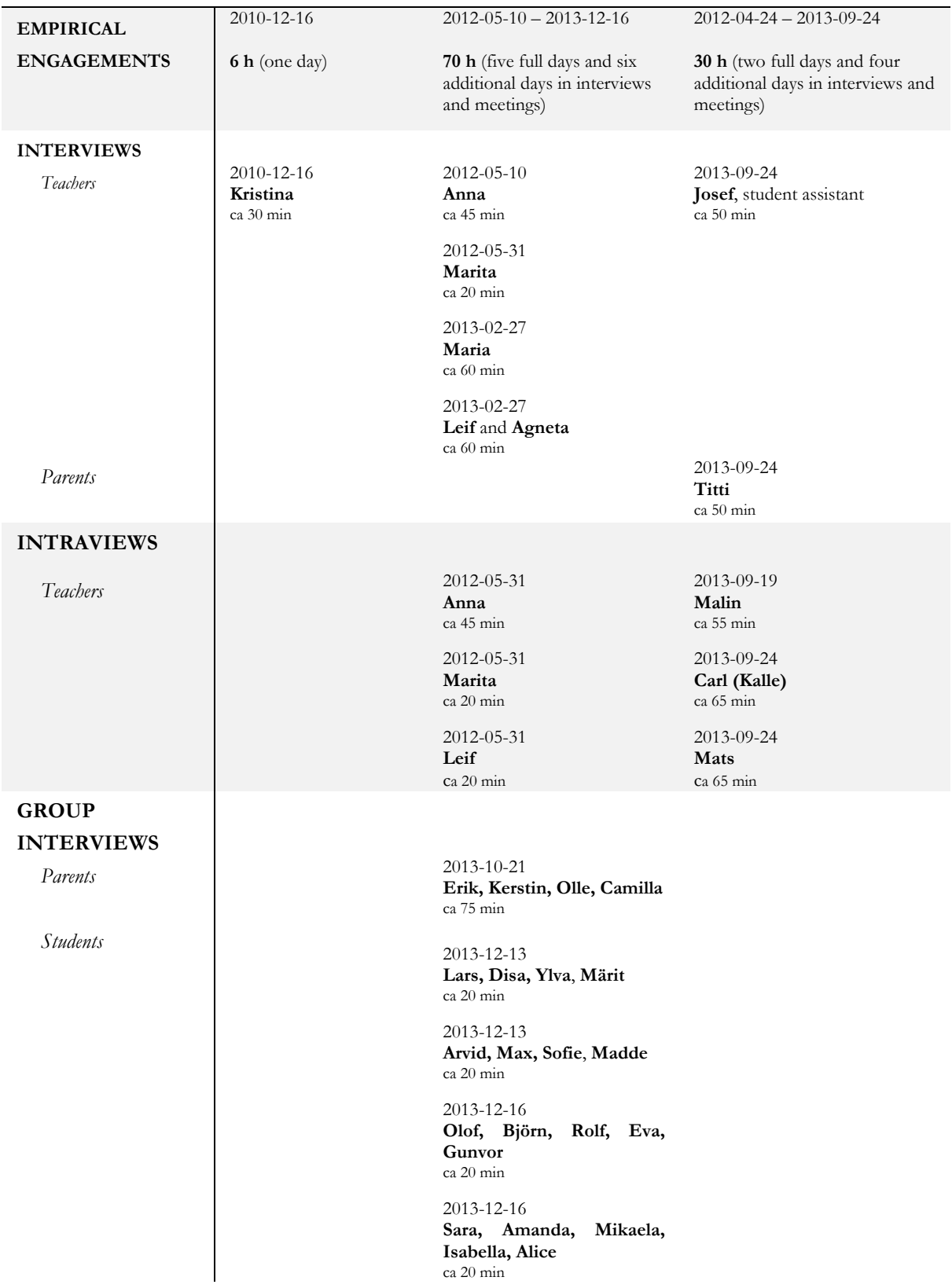


Table 2: Engagements in City 1 and City 2

City 1

City2

\begin{tabular}{|c|c|c|}
\hline \multirow[t]{3}{*}{$\begin{array}{l}\text { EMPIRICAL } \\
\text { ENGAGEMENTS }\end{array}$} & & $\begin{array}{l}2012-02-13 \\
\text { Education office. Participation in meeting on } \\
\text { school absences, with representatives from } \\
\text { different municipalities. } \\
\text { ca } 2 \text { hours }\end{array}$ \\
\hline & & $\begin{array}{l}2012-02-16 \\
\text { Education office. Participation in meeting on } \\
\text { digital tools for presence/absence registration, } \\
\text { with representatives from the different schools in } \\
\text { the municipality. } \\
\text { ca } 2 \text { hours }\end{array}$ \\
\hline & & $\begin{array}{l}2012-08-27 \\
\text { IT unit. Participation in information meeting } \\
\text { about Dexter, with representatives from the } \\
\text { different schools in the municipality. } \\
\text { ca } 60 \mathrm{~min}\end{array}$ \\
\hline INTERVIEWS & $\begin{array}{l}2011-09-27 \\
\text { Johan, system administrator/ } \\
\text { project manager in the education office } \\
\text { ca } 90 \mathrm{~min}\end{array}$ & \\
\hline & $\begin{array}{l}2015-12-15 \\
\text { Thomas, former product owner of an } \\
\text { absence/presence function within a } \\
\text { learning management platform. } \\
\text { Interview conducted through e-mail. }\end{array}$ & \\
\hline $\begin{array}{l}\text { GROUP } \\
\text { INTERVIEWS }\end{array}$ & & $\begin{array}{l}2013-09-17 \\
\text { Pilot interview with six parents from various } \\
\text { schools in the municipality. } \\
\text { ca } 90 \mathrm{~min}\end{array}$ \\
\hline
\end{tabular}

\section{Processes of analysis}

When the myriad of entanglements is the starting point for the research, "data cannot be seen as an inert and indifferent mass waiting to be in/formed and calibrated by our analytic acumen or our coding systems" (MacLure 2013a, 660). And furthermore, in the process of analysis and writing - "in the thinking that writing produced" (St. Pierre 2011, 621, italics in original) - new things might appear as necessary to engage with (Bodén 2015). This calls for explorations of strategies on how to account for the analytical processes that question the researcher as one who is able to choose, make visible and represent the empirical productions analysed. In the section that follows, I discuss how and why the things that are explored in the study were chosen. Or rather, how these things were simultaneously produced, producing, and choosing me. I also discuss how the concepts central to the study have been put to work as questions in the processes of analysis. 


\section{Engagements with shimmery and gloomy glows}

Discussions of the processes of analysis need to be "tuned to the particularities of the entanglements at hand" (Barad 2007, 74), as "a long, slow, familiarisation with the details" (MacLure 2013b, 174). In relation to this, Allendyke (2014, 124f.) emphasizes that

the task becomes to hold elements or empirical materials in productive tension. Or perhaps more precisely, rather than hold, provide the conditions whereby they might spin together and produce a peculiar whistle.

This is what I have tried to accomplish in the process of analysis: to provide conditions where the different pieces of the phenomenon of school absenteeism are allowed to together produce a peculiar whistle. That they in different ways made school absenteeism whistle at me is what unites the engagements focused upon in my study.

Eloquently described by MacLure (2010) as things that in the processes of doing research suddenly start to glow, what glowed at me, whistled at me, affected me, were the occasions when the phenomenon of school absenteeism was played out in all its complexity: simultaneously extraordinary, dense, messy, familiar and mundane. I have engaged closely with practices that stand out - all glowing in their uniqueness - like the times when a student was both present and absent at the same time, or when text messages arrived with information about absent students in the middle of the night. And at other times I have engaged with the gloomy glows of recurring and ordinary practices - like the repeated question 'Who is absent?', the regular discussions of whether late arrivals under five minutes should be registered, or the opening and closing of doors. Hence, in the processes of analysis I have put effort into being attentive to both the unique and the ordinary, and was sometimes surprised, sometimes happy, sometimes amused, sometimes worried, sometimes angry, sometimes bored, but always moved. What chose me was thus what moved me. Affects and emotions performed their way into the processes of analysis, entangling things in ways that were sometimes odd and strange and making research a truly affective and messy affair (Hohti 2016).

What made certain things whistle and glow were also the occasions when the research interests of the study, the research questions and the premises of the theories and methodologies put to work temporarily collided, making school absenteeism impossible to ignore. And both extraordinary and mundane practices were crucial in this. 


\section{Engagements with questions}

It cannot be claimed that the processes of analysis described above is an autonomous procedure, staged by me as a researcher. Rather, it is a mutual process of choosing/being chosen by the material-discursive becomings of the phenomenon of school absenteeism. However, as asked by Lather and St. Pierre $(2013,630)$

Can we disconnect ourselves from the mangle somehow (Self) and then carefully disconnect some other small piece of the mangle (Other) long enough to study it?

Questions have become my answer. I have posed questions to the phenomenon of school absenteeism, and these questions have temporarily cut apart the entanglements long enough to be able to produce knowledge on school absenteeism. The concepts central to the study - the inseparability of practices, production and phenomenon - have helped me to formulate these questions: Is something related to school absences or presences in these practices? If so, what? What are the material-discursive entanglements that produce these practices? What happenings/actions/agencies/entanglements/engagements do these practices produce? What is produced as absences? Presences? Which humans and nonhumans are (allowed to be) productive of the phenomenon? In turn, these questions formed new questions that directed interest to 'how' the phenomenon of school absenteeism is produced: How are intra-actions produced in, as well as producing, this practice? Do some intra-actions produce absences, while others produce presences? How are the entanglements of spacetimematterings enacted in this practice? What spaces, materialities or times 'stand out' as consequences of these entanglements? What desires, energies and flows become part of these practices? How do these desires, energies and flows affect school absenteeism?

Allowing questions to be an answer to how the phenomenon of school absenteeism can temporarily be cut apart has been something I have come back to throughout the study, The questions can be described as both very (too?) broad and very (too?) specific, but have nevertheless been important companions especially in the processes of analysis. Something that links them is that the answers cannot be described as either empirical or theoretical findings or results. It can thus be claimed that what these questions have helped me produce are analytical findings, in the meeting of theories, methodologies and empirical engagements. This is something to keep in mind as the next part introduces how the empirical engagements, methodologies and theories have merged into four research papers. 


\section{Summaries of the research papers}

In the following four sections, the research papers that are part of the thesis are summarized. Instead of introducing them in a separate chapter, I have chosen to make them part of Engagements. There are two reasons for this. Firstly, even though the papers were written over a period of several years (2010-2016), and even though the ways in which the phenomenon of school absenteeism is produced differs in each of the papers, what connects them are engagements: the engagements with empirical productions from two software and three different schools, various post-qualitative methodologies and entangled posthumanist concepts. And secondly, by placing the summary of papers within instead of outside the three main sections of the thesis, I want to emphasize that I do not view this thesis as divided into one general text that describes the research, and one part that contains the research papers where the 'actual' study was performed. Rather, they presuppose each other.

The research papers are presented in chronological order. This order invites the reader to follow the research journey in which one paper opened up new questions that reached into the next paper.

\section{I. 'Seeing red?' The agency of computer software in the production and management of students' school absences}

In this paper, the Deleuzio-Guattarian concept of the assemblage (Deleuze \& Guattari 1987) is put to work within a posthumanist framework to explore an event in a classroom of 11-year-olds. The event took place at Kardinal School, where I took part in classroom activities, spoke to teachers and students and performed an interview with a teacher. In one of those conversations, I sat down with a teacher and a student, and the teacher showed me the student's web pages in Skolwebben. One of the fields for a lesson was red, indicating that the student sitting next to us had a registered unexcused absence. After the student sitting with us had left, the teacher wanted to show me the page of another student she claimed she knew had a lot of unexcused absences. Several fields were filled with red on this student's page.

Within the paper, the concept of assemblage becomes a way of producing knowledge on how the red field/s produced school absenteeism in different ways, depending on the relations and forces of diverse components. The paper concludes by claiming that the concept of the assemblage is a way of theorizing how materialities - like the software - are entangled with the social and gendered discursive components within the production of school absenteeism. Thus, seeing red fields on a computer screen does not only invoke fear of, anger at, or trouble with a student's absences. Seeing red can also enable a reconsidering of 
school absenteeism and actually seeing the materialities of the educational setting - to see red - as a part of how the phenomenon is produced.

In relation to the aims and questions of the study, this paper became a first way of opening up to the powerful agency of the materialities of the computer screen and the software. The focus on the color red and the following of this color as it flows within the assemblage highlighted the necessity of attuning to both the specificities of the phenomenon and how the phenomenon is produced in ordinary and mundane events. The paper put to work several concepts associated with conventional humanist qualitative methodologies - like data collection, observation, interviews and field notes. However, as discussed in the paper, these methodologies and descriptions of 'data' risk separating humans from nonhumans as well as 'data' from researcher, making the complexities of school absenteeism difficult to address. In the paper, the concept of the assemblage is emphasized as a way of challenging these dualisms. To further elaborate the deconstruction of these dualisms - and to underline the entanglements of ontology and epistemology in the production of phenomena - I chose to focus the next research paper on an exploration of methodologies.

\section{The presence of school absenteeism. Exploring methodologies for researching the material-discursive practice of school absence registration}

To be able to produce knowledge on how a phenomenon can be researched to include both human and nonhuman entanglements, the paper explores postqualitative methodologies and relations of posthumanist theorizing and methodology. The questions that underpin the paper are: How can I as researcher connect to the material-discursive production of absences and presences? Can this be done in interviews?

As discussed in the paper, a conventional qualitative interview and the engagements produced can be discussed, post-interview, in posthumanist terms, as various materialities will always be part of the conversation. However, posthumanist approaches invite us to engage with more than the human agents in the interview situation itself. I thus decided to experiment with intraviewing where the expressions and actions of materialities are acknowledged and the subjectcentrism of conventional humanist qualitative interviewing is questioned. I invited the computer and the software Dexter to be part of the conversation to explore school absenteeism. The bringing of the computer and Dexter to the conversation seemed to make it possible to emphasize how humans and nonhumans together produce material-discursive knowledge on the registration of school absences. This became important in relation to how the phenomenon of school absenteeism is produced within this study, as it affects both the answers to some of the queries within the study as well as the ways in which questions - 
and which questions - can be asked. The knowledge produced on the registration of school absences and presences as an embodied, material, affective, and intraactive practice produces school absenteeism as a reality in which the computer software was always already part of the phenomenon. The paper concludes by stating that the software thus needs to be an agential part of the methodologies for researching registration.

How practices of registration affect the phenomenon of school absenteeism is also manifest in the third research paper, focusing on the spacetimematterings of the digital registration of absences and presences.

\section{Dexter time. The space, time and matterings of school absence registration}

With the aim of researching how students' absences/presences and on time/late arrivals are shaped and reshaped, the third research paper explores how the computer software Dexter is part of producing different practices of time, place, space, and matter. By engaging in the seemingly mundane practices of the ordinary school day, the paper shows how the combination of posthumanist theorizing and empirical engagements (interviews/intraviews with teachers, students and parents from Sandö School and Björnäng School as well as memory notes from both schools) produced new knowledge on how spatial, temporal, material, and technological events continuously affect education. The paper argues that practices in educational settings do not happen in space and time but can instead be theorized as of spacetimematters (Barad 2007).

The examples - focusing on clocks, opened and closed doors, handwritten papers with the names of present students, gymnasiums and craft lessons highlight how students' 'bodily' presences are continually (de)stabilized in relation to digital registration, how time and presence become detached from the present, and how materialities affect what is produced as absences or late arrivals. Together these examples show the phenomenon of school absenteeism as always dependent on intra-actions of spacetimematterings; what becomes important enough to register or not - what is produced as a 'real' absence or late arrival - is fully dependent on these entanglements. The software is a powerful performative agent that in entanglements produces presences, unexcused absences, and late arrivals. Absences or presences of the students do not exist solely in the classroom, but are a becoming that changes directions and significations and is produced in different places at different times in relation to the registration.

Related to the registration are the text messages sent to parents when a student has been absent. The flows of these messages are discussed in the fourth research paper. 


\section{Going with the affective flows of digital school absence text messages}

The fourth paper investigates the way school absenteeism is produced within affective assemblages by focusing on digital text messages that contain information about students' absences and are sent to parents. Within the paper, a theoretical and methodological approach of 'going with' the text messages is unfolded, as they flow between different spaces, places and times. Since the text messages are theorized as entangled with flows of affect, the analysis shows that the text messages flow in all kinds of directions, and against notions of linearity. The empirical engagements, produced together with multiple performative agents at Sandö and Björnäng Schools, show that within the affective assemblages of human and nonhuman bodies, school absenteeism is expanded to include the homes of students as well as the homes of teachers, and guilt as well as control. The analysis shows that depending on the entanglements within the assemblage, the assemblage can work in both affirmative and destructive ways, and thus become productive of various forms of emotions and practices connected to school absenteeism. Accordingly, the text messages can become 'stirrers' that evoke nervousness and anxiety, but also excitement and feelings of control that affect the production and conception of absenteeism. The conclusion emphasizes how the text messages, as affective materialities, are an inextricable part of the production of school absenteeism in multiple and sometimes unexpected ways.

\section{Summary of the summaries}

What has been described in the summaries of the research papers is their links to the way the phenomenon is produced in this study. At a first glance it may appear that the aim is to focus on different human agents in each of these engagements: the first paper focuses on two students and a teacher in the process of registration; the second mainly on teachers' work with the software; the third on the practices students are involved in; and the fourth on the relations between parents and school absenteeism. However, the reason for choosing to enhance the engagements in the four papers has not been to show how students, teachers and parents encounter the software, school absences and presences. Instead, I would argue that, depending on which performative agents are part of the engagement - human or nonhuman, the practices they are involved in will always differ. Such differences evoked the questions arising in the processes of analysis, described above. Thus, the four papers could be theorized as an exposure to different practices: practices that involve intense relations with colors on computer screens, disclosing flows and desires within assemblages that inevitably affect what is registered (Research Paper I); embodied and affective practices of doing the registration that question the neutrality of registering absences (Research 
Paper II); practices of spacetimematterings that invoke questions of what it means to be 'bodily' present in the classroom (Research Paper III); and affective flows of text messages that influence the relations between parents and schools (Research Paper IV). To relate this to the aims and questions of the study, the four papers explore practices - among humans and nonhumans - related to the digital registration of absences and presences that in a variety of ways produces the phenomenon of school absenteeism. Rather than focusing on whether theses practices are part of the production of absences and presences, the papers approach how this occurs.

\section{In conclusion: engagements through the waves and undertow?}

What has been important when discussing engagements within this study is to stress the intertwining of empirical and theoretical work. As described above, a challenge has been to figure out productive ways of engaging with methodologies in which both humans and nonhumans are allowed to be agential. The thesis has thus explored methodologies in a continuation of insights from 'conventional humanist qualitative methodologies', but where a restaging temporarily zooms in on new things. The act of producing productive alternatives could be described as an 'up and over' the waves, but also tussles with undertows. Sometimes, when ideas popped up on how to enable the software to participate in conversations or in unexpected encounters in the processes of analysis, I have felt as if I have been surfing the waves; and the times when these waves met obstacles were productive diffractions. But at other times, I have felt the humanistic and anthropocentric undertows of the methodologies dragging me under, making the complexities of digital registration difficult to address.

The fact that different methodological concepts were put to work at different stages of the study highlights the ontoepistemological process of research: how the phenomenon of school absenteeism is produced differently and that different practices become the focus depending on how the apparatuses of knowing are cut out. The four research papers discussed above show that the practices of school absences and presences are far from 'human only', but are entangled engagements of humans and nonhumans. Focusing on practices that have pushed the phenomenon of school absenteeism in - at least for me - unexpected directions as discussed in the summaries of the research papers shows how engagements always emerge both up and over the waves and in the undertows. This takes us to the final section of the thesis. 


\section{Discussing present absences}

When I was fifteen, late arrivals and unexcused absences in my school were recorded in the green book and to be late or absent from class was referred to as 'getting a dot'. In this study absences - and presences - are digitally registered and teachers, students and parents refer to late arrivals and unexcused absences as 'getting a Dexter'. Both 'dots' and 'Dexters' shed light on how the recording and management of school absenteeism often turns into the punishment of individual students, even if removing chewing gum has transformed into text messages sent to parents. But 'dots' and 'Dexters' also shed light on how practices connected to the registration of absences and presences become an essential part of how school absenteeism is understood, articulated and produced.

As this study shows, there are multiple performative agents intra-acting in these practices of producing school absenteeism. By putting a posthumanist approach to work, what this study has emphasized is that the various entanglements related to the registration of absences and presences produce the phenomenon of school absenteeism differently. Digital registration produces other practices than the entries in the late 19th century 'examenskatalogen', the 1950s student book or the 'dots' in the 1990s green book: it expands the phenomenon to include other spaces and places, the past, the present and the future, and more human and nonhuman performative agents. An example of how the phenomenon is produced differently is that my parents were never aware of my three 'dots' (until they read this thesis), whereas a 'Dexter' reaches parents 
sometimes within 30 minutes, and sometimes in the middle of the night. Another example is that I was well aware of what was written (or rather dotted) about me in the green book (the book was kept on a lecturn for anyone to see) but the students in this study usually get the information about their 'Dexters' from the parent who received the text message. And furthermore, the production of the phenomenon in relation to technological studies highlighting the necessity for automatizing registration (see for Ervasti, Isomursu \& Kinnula 2009; Isomursu et al. 2011; Patel \& Priya 2014) points to a future yet to come - that is always already part of the phenomenon - where even more technologies get involved and become entangled, but maybe fewer humans.

Previous research has emphasized that school absenteeism and attendance problems "may seriously hamper psychological, social and academic development" (Havik et al. 2014, 131; see also Kearney 2008; Maynard 2014; Strand 2013; Thambirajah, Grandison \& De-Hayes 2008). This it may seem like a paradox when claiming to explore the complex and opaque phenomenon of school absenteeism through digital registration. Why in a study cut together something so difficult, vulnerable, emotive and affective as school absenteeism with the (so-called) neutrality and objectivity of digital technologies? Could this even be a violation and a simplification of the complexities of school absenteeism? Beginning to answer these questions - or rather to offer new questions and new ways of asking them - guides this final part of the thesis, making it both a conclusion and an entrance into new possibilities.

In the following section, I highlight the knowledge that has been produced in relation to the aim and questions of the study. I take the opportunity to extend the complexities of school absenteeism a bit further by recapping, intertwining and orchestrating the analytical findings of the four research papers. This evolves into an argument on how digital registration makes what is absent present. Finally, I propose the concept of school absenteeing as a productive way to open up new possibilities and new questions in relation to school absences and presences.

\section{What becomes of the phenomenon of school absenteeism...}

The posthumanist approach put to work in this study opens up a thinking in which the software for the registration of absences and presences is no longer a neutral autonomous tool that can be used by equally autonomous students, teachers or parents. As emphasized throughout the study, the challenge is therefore not to examine whether the software is important for the phenomenon of school absenteeism, but rather how it becomes important in entanglements with parents, teachers, school management, students, school facilities, schedules, and so on. And furthermore, it is also important to explore how the phenomenon 
emerges when both humans and nonhumans are included in the apparatuses of knowing. In the following section I return to the two research questions of the study to engage with this.

\section{...in entanglements with digital technologies?}

Students' presences in schools - and more precisely, being in the right classroom on time - might be viewed as the normal state of affairs, something that is taken for granted until the opposite occurs. This is unfolded when the first question of the study is engaged with: how is the phenomenon of school absenteeism produced when absences and presences are registered digitally?

Whereas school absenteeism used to be associated with a few students and concepts such as school phobia, learning disabilities, poor school performance (Sutphen, Ford \& Flaherty 2010), socioeconomically exposed regions or problematic family relations (Arthur 2015), deviant behaviour or abuse problems (Jönsson 1990), or hallway ramblers and home sitters (Strandell 2009), digital registration includes all students, whether or not they are absent. These practices produce absences not only for the absent students but for all students, every day. Thus, the knowledge produced in this study demonstrates that school absenteeism is already cut together with the digital technologies, which both reduces the complexities of school absenteeism - either a student is 'bodily' present or not - and makes it even more complex as the practices surrounding the digital registration expand the phenomenon. What might be thought of as the neutral and everyday practices of registering students' school absences and presences have real material consequences. Doors are closed. Text messages are sent. Names on the screen come alive. Schedules are rearranged. Meetings at municipalities are arranged. Anxieties and affects are aroused. Contracts and procurements are signed. Laughter and emotions are acted out. Doors are opened. And closed again. Numerous registrations are performed, of absent students, and of those present.

The extensive registration is inevitably related to the control and surveillance of students. In this study it becomes particularly noticeable in relation to the text messages as all late arrivals and unexcused absences result in messages to parents, whether or not a particular student has so-called 'attendance problems'. As put forward in media debate in Sweden, the text messages are supposed to reduce school absenteeism (see for example Helmersson 2014; Sundén Jelmini 2014). Real-time information to parents on children's attendance has been described as one of the benefits of the software (Ervasti, Isomursu \& Kinnula 2009; Isomursu et al. 2011), while other studies have shown that the digital registration have little impact on students' absence behaviours (Visscher \& Bos 1993; Enarsson 2016). As shown in the fourth research paper of this study (Bodén forthcoming), if too many messages are sent, their effect as 'stirrers' disappear. And furthermore, as one mother describes it, getting a text message every day because your daughter is 
always late in the morning is not that funny, especially since this means that you don't know what is happening during the rest of the day - is she at school at all? - as only one message is sent per day. Moreover, in cases where students have many registrations, the red fields on the computer screen become a new way of pointing out the problematic behaviour of individual students. Rather than enabling means to handle far-reaching absenteeism, the visualisation of the absences the computer screen offer seems to reinforce notions of these particular students. Hence, I assert that what is produced in entanglements with digital technologies is school absenteeism for students that do not have a problem with school absenteeism: absences for those students who are present most of the time.

When school absenteeism is multiplied and expanded, it inevitably includes more places, more spaces, more humans and more nonhumans. On the days I spent at the schools, almost every lesson started with the question: 'Who is absent?' Usually, this question was easily - or rather sophisticatedly and complexly - solved in the entanglement with the computer screen showing a list of the students who should be in the classroom, empty or taken chairs, open or closed doors, timepieces on walls and on arms, the teacher's and the students' knowledge or discursive notions of who was usually late, who was on vacation, or who was doing other school activities. The material-discursive entanglements were necessary to enable understandings of who was absent or present. And when the entanglements of the everyday routines were broken - when a replacement teacher did not have access to the software or when the names on the screen were confused - the 'bodily' presence of students suddenly became fluid. In other words, practices surrounding the digital registration produce a phenomenon of school absenteeism where students at the same time seem to be absent and present: sometimes 'bodily' present but registered as absent, sometimes 'bodily' present but absent in class (Jonasson 2011), sometimes 'bodily' absent but registered as present and thus regarded as 'digitally present'.

However, this fluidity is produced in close connection with the 'rigidity' and binary of the software: rows of students' names; boxes that are either ticked or not; minutes that should be rounded up to the nearest five; the impossibility of writing comments or thoughts related to the absences; fields that are either red, green, yellow, blue or grey (no in-betweens, no purple, orange or pink options). Usually, what is focused on are just the green or the red fields, which points to the complexities of digital registration; simultaneously while questioning the 'bodily' presence of students in both time and space, the registration transforms the absences and presences into something stable and invariable since what (and who) is finally counted as absent or present is what is digitally registered. The rigidity, precision and the lack of complexity within the software thus produce new complexities in the educational setting. 
To summarize the knowledge produced in relation to the first question of the study, practices surrounding digital registration continuously blur the dichotomous crack between absences and presences, and queer what is absent and what is present. These analytical findings are crucial in questioning dominant understandings of school absenteeism. Even though school absenteeism, non-attendance and truancy have been described as a multi-faceted problem (Reid 1999; 2014; 2015; Corville-Smith et al. 1998; Weinberg \& Weinberg 1992), the focus on individual characteristics and individually related factors in many of the published studies I have reviewed highlights absenteeism as an exception connected to risk-groups (Karlberg \& Sundell 2004; Maynard et al. 2012; Sundell, El-Khouri \& Månsson 2005) or to individual behaviours such as over-anxiety, psychosocial problems and so on (Witts \& Houlihan 2007). When the responsibility for absences is understood as located within the individual, the complexities of the phenomenon become difficult to address, as shown in this study. When absenteeism is reduced to something individualistic and easily distinguishable both explanations and actions can fail to engage in-depth with students' absences as difficult, vulnerable, emotive and affective. This study shows that responsibility for absences is always located in the entanglements of students and material-discursive practices. The software is an agentic and strong co-producer of these practices. To acknowledge both the difficulties and the unexpected sensations of the phenomenon of school absenteeism, what thus need to be considered are the practices that have the potential to produce and reproduce, but also to challenge and change the phenomenon of school absenteeism. The cutting together of school absenteeism and digital technologies could be described as necessary to acknowledge practices that are already present in the majority of Swedish schools, as well as in a number of other countries. And as it becomes a way of challenging discourses of the autonomous and responsible student and of technologies as neutral, the cutting together could be formulated in terms of possibilities, rather than described as a violation.

\section{...in the apparatuses of knowing?}

As has been emphasized throughout the study, the phenomenon of school absenteeism does not exist in itself, but becomes momentarily manifest through the processes of research and the apparatuses of knowing, consisting of entanglements of theories, methodologies, concepts and empirical engagements. This brings us to the second question of the study: how does the phenomenon of school absenteeism emerge when both human and nonhuman entanglements are included in the apparatuses of knowing?

In the study, this question became a way of exploring strategies that challenge notions about the 'nature' of the software and of the phenomenon of school absenteeism as individualistic and a 'human only' activity. In cutting out/in an 
apparatus of knowing that enables a close connection between empirical engagements, theoretical explorations and methodological experimentations, it becomes necessary to include both human and nonhuman entanglements. The concepts central to the study have been crucial to accomplish this: the concept of assemblage was put to work as a methodological strategy to unfold the desires, affects and energies surrounding digital registration and to investigate the foldings and becomings of the affective flows of text messages; the methodology of intraviews and the concept of intra-action were explored to acknowledge the expressions and actions of materialities in the interview situation; and the concept of spacetimematterings was followed through in various empirical engagements to create knowledge on how absences and presences are shaped and reshaped. Within the engagements with the everyday events of three schools, these concepts, together with the concepts of phenomenon, practices, and production, have highlighted as well as entangled different premises of school absenteeism: students become entangled with software, teachers with clocks, doors with schedules, hallways with a news quiz, affects with text messages, toothbrushes with late arrivals, colors with computer screens and so on. Through the apparatuses of knowing that have been put to work, what might have appeared as unimportant thus emerged as vital co-producers of school absenteeism.

The second question of the study became crucial to acknowledge the potential of producing new versions of school absenteeism that do not consolidate human agency but open up the potential of other realities to come to life. Furthermore, when school absenteeism is researched to include both human and nonhuman relations " $[\mathrm{w}]$ hat often appears as separate entities (and separate sets of concerns) with sharp edges does not actually entail a relation of absolute exteriority at all" to quote Barad (2007, 93). This highlights the importance of being attentive to how the apparatuses of knowing are always crucial to what properties of the phenomenon come to matter, and what is excluded from mattering (Barad 2007, 148). Even if the phenomenon of school absenteeism is closely entangled with humanistic and anthropocentric notions of the autonomous and responsible student, this study shows that school absenteeism emerges as a phenomenon in which material practices inside as well as outside schools are agentially part of producing school absenteeism. When materialities and humans are given equal importance, it became apparent that only because students' absences and presences derive from human activities (that is, are anthropogen) is school absenteeism not a human-alone phenomenon (compare with Pedersen 2014). This is developed further in the following section, where the phenomenon of school absenteeism is related to the educational setting more broadly. 


\section{What is absent becomes present}

Since the analytical findings of the study have been outlined, I cannot resist asking: what enables the computer software to become such a powerful material co-producer in relation to school absenteeism, despite the fact that digital registration makes it more difficult to define absences and presences, makes the 'bodily' presence of students unreliable, works mainly for the students that are usually present, and queers both time and space?

The Swedish Education Act states that all children must attend school the year they turn seven; this is accompanied by a demand for compulsory school attendance (SFS 2010:800, Chapter 7, 25, 10\$, 17\$). It could thus be argued that school absenteeism becomes a disruption of the very foundations of the educational system. In line with the notions about how schools with fewer absences are more likely to contribute to improved educational results (Jonasson 2011), the absences become a problem not only for the individual student but also for the whole school. The digital registration that produces the students as absent until registered as present turns school absenteeism into a ghost haunting the school, always ready to reveal itself, always present in its absence. ${ }^{34}$ But, the software, the text messages and the colors of the schedule on the computer screen makes this ghostlike and haunting absence visible, touchable and controllable. It materializes absences, in every sense of the word. Through the collaborations of humans and nonhumans what is absent becomes present. I would claim that this is central to understanding how both the digital registration and the text messages have become such widespread companions in the management and handling of absences.

To keep controlling and to keep visualizing the absences - to chase the ghost away - the practices of registration need to be performatively repeated. They are repeated in classrooms, in teachers' offices, in the application on teachers' smartphones, at teachers' kitchen tables in their own homes, when replacement teachers write names on lists and carry pieces of paper through the school, when parents receive text messages, when students receive text messages from their parents about the absence messages. They are repeated at the start of lessons, at the end of lessons, between lessons, and sometimes in the middle of the night. In her review of research on absence prevention and school attendance Ekstrand $(2015,474)$ suggests that "if a study of real-life interventions in schools nowadays had been conducted, it would have resulted in a picture of counting, more regulations and disciplinary restrictions". The analytical findings of this study

34 The theorization of school absenteeism as a ghost haunting the school is inspired by the way Barad (2010) puts Derrida's concept of an bauntology to work, to enable analyses of practices as haunted and constituted by the absent, by the future and the past, by other space and times, by other stories and other ideas (see also Sauzet 2015, 104). 
support this and show how the digital registration of absences and presences plugs into discursive and material notions of both schooling and students as crucially needing control, in time and space. As shown in this study, a close collaboration of humans and nonhumans is necessary for this to continue to work, pointing to the performative agency of both humans and nonhumans. What at first might have appeared as an obscure cutting together of difficult, emotive and affective aspects of school absenteeism with neutral digital technologies emerges rather as a phenomenon at the very centre of education today. But, what happens with schools when 'not being absent' occupies such a big place in classrooms? Is being on time and at the right place what the school is all about? Could this be otherwise?

\section{Present absences and the potential of school absenteeing}

Do we miss anyone? Does anyone usually sit here?

If something is going on, a chair is empty then you'll see...he is absent or she is absent.

Why are you late? You just had a lesson, help me, who's absent?

You don't know if he was two minutes or twenty minutes too late.

It would have been a nice thing to be on time today, you know.

Doesn't it say two minutes, doesn't it?

Dig har jag sett. I've seen you.

The lesson was not registered, it is red.

The lesson cannot start before each name is read and called out.

Click ok.

Yes, this is how you do it; you check the ones who are usually absent.

Well, that's good, now everyone who should be here is here.

This poem cuts together bits and pieces from my notes and from interviews and intraviews with students, parents, teachers and the software. It embraces the affects, efforts and time involved in the practices around school absences and presences. The study has opened up possibilities for reformulations of the question of whether it is possible to cut together school absenteeism with digital technologies. As such, it becomes productive to ask: What does the registration do with the phenomenon of school absenteeism? What practices have been enacted as an effect of this? What this study shows is school absenteeism in the making, or what I have come to theorize as school absenteeing. In this final part of the thesis I engage with this concept.

Within the posthumanist approach that has been put to work in this study, the potential of producing other or new realities is always present. Being ethically 
responsible is being aware of how realities are produced - what is cut out of or cut in to phenomenon. But a posthumanist ethicality also allows for the unexpected and multiple to take place as it "entails hospitality to the stranger threaded through oneself and through all being and non/being" (Barad 2012b, 217). This allows for "new configurations, new subjectivities, new possibilities" (Barad interviewed in Dolphijn \& van der Tuin 2012, 69). These new possibilities are always ontoepistemologically produced; the research apparatus is crucial for how the emergence of new realities is enabled. Through the entanglements of a posthumanist approach and empirical engagements, the concept of school absenteeing has arisen as a new possibility to shift the focus from individuals, to the on-going doings and makings of the phenomenon. By not letting the concept of school absenteeing become merely a description or a critique of the findings of this study, I put it to work to highlight how school absenteeism might be produced in new ways that question the dominant anthropocentric and individualist understandings of school absences and presences.

When the phenomenon of school absenteeism is understood as a production rather than as something someone is or has (that is, as a verb rather than a noun) new ways of understanding students' absences and presences become possible. This small exchange of letters (from an -ism to an -ing) has the potential to open up other possibilities when engaging with the phenomenon. In line with the feminist invitation running through the thesis to include what has been understood as peripheral or of less/no importance in the production of knowledge, this concept acknowledges an engagement in which all participants humans as well as nonhumans - are taken seriously and seen as equally important to processes of school absenteeing. It thus becomes important to ask who or what is part of, and who or what is allowed to be part of, producing students' school absences and presences.

The concept of school absenteeing opens to a production of realities that questions whether it is ever possible to 'check the ones who are usually absent' without also acknowledging the empty chairs, the red lessons, the clicks, the repetitive questions on absences and so on, that this study has come to know. This is not to seek computerized attendance systems that eliminate human involvement or data entry mistakes as described by Patel and Priya (2014), as this would just strengthen notions of neutral technologies that enhance, improve and extend human capabilities and intensifies anthropocentric ideas of a future 'posthuman condition', emphasized by theorists like Fukuyama (2002). Rather, what the concept of school absenteeing enables is a focus on how 'real' absences or presences are fully dependent on the entanglements of humans, empty chairs, clicks and practices of registrations.

Ekstrand (2015) suggests that more counting, regulations and discipline contrast with what research and recommendations on school absenteeism have 
pointed out for decades and stresses the need for studies focusing on the role of the educational system. Through the concept of school absenteeing, I consider it possible not only to produce an understanding of students' absences and presences as always dependent on the educational system (Ekstrand 2015; Strand 2013) but to zoom in on the mundane (and forgotten?) materialities and practices that endlessly (re)produce the structures of school absenteeism. And furthermore, as described above, the concept enables a production of realities in which school absenteeism is not only affected by the educational system but absenteeism in turn affects the structure of the educational system. The concept thus becomes a way of acknowledging both what is already going on, as well as opening up to what is yet to be known.

School absenteeing invites a state of uncertainty, necessary to shake habitual ways of engaging with absences and presences. The emphasis on humans and nonhuman entanglements highlights the productive nature of registration in which control and regulation sometimes turn against themselves, enabling multiple versions of absences and presences. The concept thus emphasizes that practices that might be easy to dismiss as involving only control and regulation, are always already otherwise. This evokes questions like: What absences and presences would be registered if the registration were always thought of in terms of an absenteeing? What practices would emerge through this? How could the software be designed to acknowledge this? What would a 'Dexter' become? And, is it any longer possible to ask, 'who is absent'? Could we (and with we I mean the entangled humans and nonhumans) instead ask ourselves, "who are we absenteeing'? How would the $56 \%$ of late arriving Swedish students (OECD 2013) be perceived if these questions were asked?

Situating the phenomenon in this state of uncertainty makes it possibly to recognize realities in which absences and presences are no longer ascribed to autonomous individual students registered and represented by an autonomous and neutral digital tool. Instead the phenomenon of school absenteeing can be seen as continuously produced in entanglements of the ordinary practices of everyday schooling. This phenomenon challenges the on-going production of absences and becomes a new way of exploring the haunting ghost of the absent that is always already present in schools today: the present absences. 


\section{Svensk sammanfattning}

Under de senaste tio åren har en förändring skett i den svenska hanteringen av skolelevers frånvaro: från att papperslistor eller i olika typer av anteckningsböcker använts för frånvaroregistrering, till att både frånvaro och närvaro registreras digitalt. En översikt över Sveriges 290 kommuner visar att de kommunala skolorna i alla kommuner använder, eller är i startgroparna för att börja använda, olika digitala system för närvaro- och frånvaroregistrering så som Dexter, edWise, Fronter, InfoMentor, Hypernet, Ping Pong, SchoolSoft, Skola24, Skolwebben, Unikum eller Vklass (se Appendix 1). De praktiker och materialiteter ${ }^{\mathrm{i}}$ som omger registreringen har således transformerats från anteckningar i böcker eller på listor, till kryss på datorskärmar, appar, automatiska sms till föräldrar etcetera. Skolfrånvaron har digitaliserats. Men hur påverkar detta olika praktiker som i utbildningssammanhang omger registreringen? Vilka relationer eller sammanvävningar av människor, icke-människor, diskurser och materialiteter skapas genom detta och blir del av fenomenet skolfrånvaro? Utgångspunkten för denna studie är att skolfrånvaro blir till i relationer som innefattar både människor och icke-människor och att dessa relationer hela tiden formulerar,

\footnotetext{
'Materialiteter kan vara både ting och miljöer. I studien används också begreppet "icke-människa" synonymt med materialitet. Digitala system beskrivs i studien som en materialitet, som ting, eftersom dessa "ting" - $\mathrm{i}$ likhet med andra ting - förstås som passiva material som finns till för att användas av människor i de praktiker som omgärdar hanteringen av skolfrånvaro. Dock problematiseras denna förståelse av materialiteter och ting i studien.
} 
producerar och omskapar fenomenet skolfrånvaro. Utmaningen är således inte att undersöka om de digitala systemen blir betydelsefulla, utan bur de blir betydelsefulla i relationer med lärare, elever, föräldrar, scheman, skolmiljöer och så vidare. I fokus är ett utforskande av hur skolfrånvaro skapas - eller produceras - i relationer bland människor och icke-människor, när närvaro- och frånvaroregistreringen sker digitalt. I studien genomförs ett empiriskt arbete tillsammans med två olika system: Skolwebben som används på Kardinalskolan samt Dexter som används på Sandöskolan och Björnängsskolan. I båda dessa system registrerar lärare elevers närvaro och frånvaro. I Skolwebben kan föräldrar logga in för att ta del av det som finns registrerat och $\mathrm{i}$ Dexter skickas automatiska sms så snart en registrering gjorts om att en elev kommit försent eller varit ogiltigt frånvarande.

\section{Bakgrund och teoretisk situering}

Elevers närvaro - att vara på plats, på rätt lektion, på utsatt tid - kan beskrivas som en av hörnstenarna i det svenska utbildningssystemet. Barn som är bosatta i Sverige har skolplikt som inträder det år barnet fyller sju år (SFS 2010:800, 7 kap. $\left.\int 2 ; \int 10\right)$ och med skolplikten följer en närvaroplikt som innebär att eleven ska delta i utbildningen då hen inte är sjuk eller har beviljats ledigt (SFS 2010:800, 7 kap. \17). Den 1 juli 2012 infördes en bestämmelse om att ogiltig frånvaro ska registreras i terminsbetyget (SFS 2011:506) ${ }^{\text {ii }}$ och ogiltig frånvaro skall komma vårdnadshavare/föräldrar till kännedom samma dag som frånvaron ägt rum (SFS 2010:800, 7 kap. 17 )). Detta har skapat en efterfrågan på exakta, effektiva och snabba sätt att hantera registreringen av elevers närvaro och frånvaro. Den utbredda användningen av digitala system och de automatiserade sms som ofta är kopplade till systemen kan förstås i ljuset av dessa skrivelser. Trots den spridda användningen av digitala system samt att ett stort fokus läggs på hur skolfrånvaro ska hanteras och registreras, har skolfrånvaro sällan relaterats till denna omfattande digitalisering. Detta synliggör ett nästintill obeforskat område inom pedagogisk forskning kring skolfrånvaro: de faktiska verktyg som tusentals svenska iii skolor använder i sin dagliga verksamhet.

Två olika, men relaterade, diskurser kan teoretiseras som bidragande till detta: föreställningar om den individuelle och autonome eleven som är ensamt ansvarig för frånvaron samt föreställningar om digitala system som neutrala och effektiva verktyg för att minska frånvaron. Båda dessa diskurser kan förstås som tätt

\footnotetext{
ii Denna skrivelse (SFS 2010:800, Kap. 6, \12) har nyligen tagits bort ur skollagen. Vid tiden för studiens empiriska engagemang (2012-2013) påverkade dock formulering i skollagen praktiker kring skolfrånvaro på olika sätt.

iii Liknande system används exempelvis i Australien, Brasilien, Danmark, England, Finland, Norge och USA.
} 
sammankopplade med humanistiska och antropocentriska (människocentrerade) föreställningar, där autonomi och självständighet från den materiella omgivningen har blivit synonymt med definitioner av mänsklighet. Genom att i denna studie fokusera på de praktiker som produceras kring den digitala registreringen av närvaro och frånvaro, utmanas föreställningar om de ensamt ansvariga eleverna och de neutrala verktygen. Istället teoretiseras de digitala systemen som kraftfulla och agentiska i relationer med människor och andra materialiteter. För att undersöka hur skolfrånvaro kan förstås och skapas på nya sätt, som ifrågasätter några av de dominerande föreställningarna kring elevers närvaro och frånvaro, introduceras ett posthumanistiskt perspektiv. Ett posthumanistiskt perspektiv kan öppna upp för en mer nyanserad bild av skolfrånvaron i den svenska skolan. Perspektivet möjliggör en kunskapsproduktion där eleven inte förstås som isolerad från sin omgivning och där produktionen av skolfrånvaro som fenomen förstås som sammanvävd med de olika sätt som används för att hantera frånvaron och registreringen av densamma. Det posthumanistiska perspektiv som sätts i arbete i denna studie är influerat av en feministisk ansats som synliggör det som betraktats som icke-agentiskt (jämför med Barad 2007; Braidotti 2013; Haraway 1997). Perspektivet lyfter således fram det som tidigare har förståtts som perifert eller mindre relevant i formandet av olika skeenden.

När materialiteter förstås intra-agera ${ }^{\text {iv }}$ med människor och som lika viktiga $i$ producerandet av olika praktiker, kan de digitala systemen inte längre betraktas som neutrala verktyg och den individuella elevens frånvaro måste relateras till den materiella omgivning hen befinner sig i. Två huvudsakliga områden är satta i fokus för studien: skolfrånvaro som fenomen samt de praktiker relaterade till närvaro och frånvaro som produceras när digitala system användas för att registrera närvaro/frånvaro. Ett fenomen brukar i dagligt tal beskrivas som en företeelse, något allmänt iakttagbart, något märkligt eller ovanligt (Nationalencyklopedin 2013). Dessa beskrivningar skulle förvissa kunna passa in på beskrivningar av skolfrånvaro. Det är dock inte denna mer allmänna beskrivning av fenomen som sätts $i$ arbete i denna studie. Med referens till kvantfysikern Bohr beskriver Barad (2007) ett fenomen som det som uppstår som en följd av omöjligheten att skilja "the object" (i denna studie skolfrånvaro och digitala system) från "the measuring agencies" (i denna studie systemen för registrering av närvaro/frånvaro, men också studiens teoretiska och metodologiska utgångspunkter). Barad (2007) utvidgar Bohrs teori och hävdar att det som studeras inte kan avskiljas från de aktiva agenter som intra-agerar med det studerade, lika lite som det studerade kan

\footnotetext{
${ }^{\text {iv }}$ Begreppet intra-agera/intra-aktion (intra-action) används av Barad (2007) som en kontrast till det mer vanligt förkommande interaktion. Enligt Barad (2007, 139) förutsätter begreppet interaktion en på förhand given uppdelning mellan olika komponenter, något som intra-aktion inte gör.
} 
avskiljas från hur och med vilka verktyg det studeras. Ett fenomen skapas inte i ett tomrum utan i konkreta materiella praktiker. Med begreppet praktik avses de händelser (eller de intra-aktioner) som gör att ett fenomen som exempelvis skolfrånvaro görs meningsfullt och/eller problematiskt, men också de särskilda sätt att agera som uppstår som en följd av vissa fenomen. Praktiker kan alltså beskrivas som konkreta handlingar som har potentialen att förändra, men också skapa - eller producera - ett fenomen såsom skolfrånvaro. Eftersom skolfrånvaro förstås som något som blir till eller skapas i praktiker, teoretiseras skolfrånvaro i studien som ett fenomen som produceras (snarare än som är eller finns) i olika praktiker. Med utgångspunkt i det posthumanistiska teoretiska perspektiv som underbygger denna studie kan det fenomen som studeras aldrig skiljas från de (vetenskapliga såväl som pedagogiska) praktiker i vilket det produceras. Detta innebär att skolfrånvaro alltid kommer att vara sammanvävd med de praktiker i vilka skolfrånvaro på olika sätt produceras och manifesteras. Skolfrånvaro förstås således både som ett diskursivt och ett materiellt fenomen - ett materielltdiskursivt fenomen (Barad 2007). Studien har två sammanvävda intresseområden som blir omöjliga att separera från varandra: de praktiker som skapas kring användandet av digitala system för närvaro- och frånvaroregistrering samt hur dessa praktiker producerar fenomenet skolfrånvaro. För att undersöka hur skolfrånvaro som ett materiellt-diskursivt fenomen produceras, är de posthumanistiska begreppen assemblage (Deleuze \& Guattari 1983; 1987), intraaction (Barad 2003; 2007) samt spacetimematterings (Barad 2007) centrala i denna studie.

\section{Syfte och frågeställningar}

Syftet med studien är att undersöka hur skolfrånvaro som materiellt-diskursivt fenomen produceras i mänskliga/icke-mänskliga praktiker när frånvaro och närvaro hanteras och registreras med hjälp av digitala system.

För att möjliggöra kunskap som är teoretiskt såväl som empiriskt grundad har följande frågeställningar formulerats:

- Hur produceras fenomenet skolfrånvaro när elevers frånvaro och närvaro registreras digitalt?

- Hur framträder fenomenet skolfrånvaro när människor såväl som ickemänniskor inkluderas i kunskapsproduktionen? 


\section{Empiriska engagemang}

I studien genomförs ett empiriskt arbete - empiriska engagemang - tillsammans med Skolwebben på Kardinalskolan (i en femte- och en sjätteklass) samt tillsammans med Dexter på Sandöskolan (framförallt med åttondeklassare och deras lärare) och på Björnängsskolan (med sjundeklassare och deras lärare). Ungefär 100 timmar tillbringades på de olika skolorna samt ytterligare några timmar på olika möten på utbildningskontor och IT-enheter. Tiden som tillbringades på skolorna kan beskrivas som ett "skuggande" (CzarniawskaJoerges 2007) av praktiker relaterade till elevers frånvaro/närvaro, samt registreringen av densamma. Detta innebär att de olika digitala systemen nästan alltid var del av de empiriska engagemangen. Tillsammans med de olika deltagarna på skolorna - mänskliga såväl som icke-mänskliga - genomfördes intervjuer och intravjuer. ${ }^{v}$ Intervjuer/intravjuer genomfördes med nio lärare och en elevassistent från de tre skolorna; fyra gruppintervjuer genomfördes med sammanlagt 18 elever från Sandöskolan och en gruppintervju genomfördes med fyra föräldrar från Sandöskolan. En enskild intervju genomfördes också med en förälder från Björnängsskolan. Sammanlagt producerade de empiriska engagemangen ungefär 90 sidor dataskrivna minnesanteckningar och 210 sidor transkriberade intervjuer.

I den analytiska processen fokuseras både det som sticker ut (som exempelvis tillfällen där elever verkade vara både närvarande och frånvarande på samma gång), samt vardagliga och återkommande händelser (som den återkommande frågan "Vem är borta?", ställd av en mängd olika lärare). Det som förenar de händelser, praktiker eller berättelser som fokuseras i analysen är att i dessa olika skeenden förenas studiens syfte och frågeställningar med studiens teoretiska och metodologiska ansatser, i tillfälliga möten där fenomenet skolfrånvaro blir omöjligt att ignorera.

Att teoretisera det metodologiska och empiriska arbete som genomförs i studien som engagemang möjliggör en förståelse av de intensiva relationer som uppstår i arbetet: mellan forskaren, andra mänskliga och icke-mänskliga deltagare, teorier och metodologier. Genom detta synliggörs nödvändigheten i att förstå dessa engagemang som kopplat till en mängd olika etiska aspekter. Från ett posthumanistiskt perspektiv rör dessa etiska aspekter dock inte enbart de deltagande eleverna, föräldrarna eller lärarna. Inte heller rör det enbart frågor kring hur det producerade empiriska materialet ska hanteras eller förvaras. Istället

\footnotetext{
${ }^{\mathrm{v}}$ Intravjuer kan beskrivas som en metodologi som utmanar den antropocentrism som ofta uppstår i intervjuer. Istället inkluderades Dexter som en viktig "röst" i intervjuerna. Denna metodologiska ansats utforskas i studiens andra forskningsartikel (Bodén 2015).
} 
lyfter studien fram att ett etiskt engagemang alltid måste innefatta ett omsorgsfullt granskande av vad den forskningsapparatur som sätts i arbete producerar och hur forskningen kan möjliggöra en produktion av nya frågor och alternativa versioner av skolfrånvaro.

\section{Resultat och diskussion}

Genom att sätta i arbete ett posthumanistiskt perspektiv visar studien att de olika relationer som uppstår kring den digitala registreringen skapar nya praktiker, nya engagemang och nya sätt att förstå skolfrånvaro. Studien lyfter fram att den digitala registreringen av närvaro och frånvaro skapar ett annat skolfrånvarofenomenen än då frånvaro registrerades på papperslistor eller i anteckningsböcker. Fler människor blir involverade, både i och utanför skolan. Fler icke-människor sammanvävs med registreringen, så som smartphones och appar. Medan en ogiltig frånvaro tidigare kom en förälder till kännedom långt efter att den ägt rum, kan föräldern nu få reda på om en elev skolkat eller kommit försent inom en halvtimme, eller till och med mitt i natten.

Ett huvudresultat $i$ studien är att den digitala registreringen av elevers frånvaro och närvaro sammanväver alla elever med fenomenet skolfrånvaro. Om skolfrånvaro tidigare associerades med avvikande beteenden och enbart med vissa elever (se exempelvis Arthur 2015; Ekstrand 2015; Jönsson 1990; Reid 2015; Strandell 2009; Sutphen, Ford \& Flaherty 2010) producerar den digitala registreringen skolfrånvaro inte bara för de frånvarande eleverna, utan för alla elever, varje dag. Samtidigt verkar den digitala registreringen fungera bäst för vissa elever. Eftersom det enbart skickas ett sms per dag blir registreringen av omfattande skolfrånvaro svår att hantera. Vidare verkar diskursiva föreställningar om "problemelever" snarast förstärkas av den visualisering av frånvaron som dataskärmen erbjuder. Vad som produceras i sammanvävningen av digital registrering och skolfrånvaro är således skolfrånvaro för de som inte har några problem med skolfrånvaro; skolfrånvaro för de elever som till största delen är närvarande. Studien visar hur den digitala registreringen gör det komplexa fenomenet skolfrånvaro ännu mer komplext. Elever framstår ibland som på samma gång närvarande och frånvarande; "kroppsligt" närvarande, men registrerade som frånvarande, ibland "kroppsligt" närvarande men ickedeltagande i lektionsarbetet (jämför med Jonasson 2011) och ibland som "kroppsligt" frånvarande men registrerade som närvarande och således "digitalt närvarande". Samtidigt gör den digitala registreringen att frånvarons komplexitet reduceras, genom att elever enbart kan registreras som frånvarande eller närvarande.

I studien framhålls att en förklaring till att den digitala registreringen av elevers frånvaro och närvaro blivit så allomfattande är att registreringen gör vad som är osynligt - det frånvarande - synligt. Genom den visualisering som 
färgkodade scheman på dataskärmar erbjuder och den tillgänglighet som sms öppnar upp för, blir det frånvarande närvarande. Samtidigt krävs ett performativt upprepande av registreringen - i klassrum, i lärarrum, i appar, när föräldrar får sms, när elever får sms av föräldrar som har fătt sms - för att det frånvarande skall fortsätta vara närvarande.

I sammankopplingar och sammanvävningar med människor och andra materialiteter kan de digitala systemen sägas sudda ut gränserna mellan frånvaro och närvaro och ifrågasätta vad fenomenet skolfrånvaro är. För trots att skolfrånvaro är ett fenomen som är nära sammankopplat med antropocentriska och humanistiska diskurser som separerar människor och icke-människor, visar denna studie att när det skapas möjligheter och potential för nya sammanvävningar och relationer, skapas också nya förståelser av skolfrånvaro. Andra berättelser och verkligheter blir möjliga. Begreppet school absenteeing [ungefär skolfrånvarogöra] föreslås därför som ett alternativ till begreppet school absenteeism/skolfrånvaro. Detta begrepp möjliggör en förståelse av skolfrånvaro som ett verb, en pågående produktion i mänskliga/icke-mänskliga relationer, snarare än som något elever har eller är och öppnar upp för andra sätt att engagera sig i den alltid närvarande frånvaron. 


\section{References}

Alaimo, S., \& Hekman, S. (2008). Material Feminisms. Bloomington, IN: Indiana University Press.

Allendyke, S.P. (2014). Edibale Assamblages and the Deleurian Event. Rethinking

'Anorexia'. PhD diss., Manchester Metropolitan University.

Andersen, C. (2015). Mot en mindre profesjonalitet. 'Rase', tidlig barndom og Deleureoguattariske blivelser. PhD diss., Stockholm University.

Arthur, R. (2015). Troubling times for young people and families with troubles. Responding to truancy, rioting and families struggling with adversity. Social \& Legal Studies, 24(3): 443-464.

Assarson, I. (2007). Talet om en skola för alla. Pedagogers meningskonstruktion i ett politiskt uppdrag. PhD diss., Malmö University.

Attwood, G. \& Croll, P. (2015). Truancy and well-being among secondary school pupils in England, Educational Studies, 41(1-2): 14-28.

Auerbach, S. (2012). “The law has no feeling for poor folks like us!” Everyday responses to legal compulsion in England's working-class communities, 1871 1904. Journal Of Social History, 45(3): 686-708.

Badmington, N. (2004). Mapping posthumanism. Environment and Planning A, 36(8): 1344-1351.

Barad, K. (1999). Agential realism. Feminist interventions in understanding scientific practices. In M. Biagioli (Ed.), The Science Studies Reader (pp. 1-11). London/New York: Routledge.

Barad, K. (2003). Posthumanist performativity. Toward an understanding of how matter comes to matter. Signs: Journal of Women in Culture and Society, 28(3): 801831.

Barad, K. (2007). Meeting the Universe Halfway. Quantum physics and the entanglement ofmatter and meaning. Durham: Duke University Press.

Barad, K. (2010). Quantum entanglements and hauntological relations of inheritance. Dis/continuities, spacetime enfoldings, and justice-to-come. Derrida Today 3(2): 240-268.

Barad, K. (2012a). Nature's queer performativity. Kvinder, Koen og Forskning, 1-2: 2554.

Barad, K. (2012b). On touching. The inhuman that therefore I am. Differences: $A$ Journal of Feminist Cultural Studies, 23(3): 206-223.

Barbour, R. (2007). Doing Focus Groups. London: Sage.

Bhalla, V., Singla, T., Gahlot, A. \& Gupta, V. (2013). Bluetooth based attendance management system. International Journal of Innovations in Engineering and Technology, 3(1): 227-233.

Bodén, L. (2013). 'Seeing red?' The agency of computer software in the production and management of students' school absences. International Journal of Qualitative 
Studies in Education, 26(9): 1117-1131.

Bodén, L. (2015). The presence of school absenteeism. Exploring methodologies for researching the material-discursive practice of school absence registration. Cultural Studies $\Leftrightarrow$ Critical Methodologies, 15(3): 192-202.

Bodén, L. (2016). Dexter time. The space, time and matterings of school absence registration. Discourse: Studies in the Cultural Politics of Education, 37(2): 245-255.

Bodén, L. (forthcoming). Going with the affective flows of digital school absence text messages.

Bohr, N. (1963). The Philosophical Writings of Niels Bohr. Vol I-III. Woodridge: Ox Box Press.

Bohr, N. (1998). The Philosophical Writings of Niels Bohr. Vol VI. J. Faye \& H.J. Folse (Eds.). Woodridge: Ox Box Press.

Bowker, G.C. \& Star, S.L. (2015). Science and technology, social study of: Computers and information technology ( $2^{\text {nd }}$ ed.). International Encyclopedia of the Social \& Behavioral Sciences, 21: 186-191.

Braidotti, R. (2000). Teratologies. In I. Buchanan \& C. Colebrook (Eds.), Deleuze and Feminist Theory (pp. 156-172). Edinburgh: Edinburgh University Press.

Braidotti, R. (2013). The Posthuman. Cambridge/Malden: Polity Press.

Braun, B. (2004). Modalities of posthumanism. Environment and Planning A, 36(8): 1352-1355.

Bruni, A. (2005). Shadowing software and clinical records. On the ethnography of non-humans and heterogeneous contexts. Organization, 12(3): 357-378.

Brøgger, K. (2015). The Faceless Masters of Higher Education. Governing Through Standards. The Bologna Process and the New Realities of Higher Education. PhD diss., Aarhus University.

Butler, J. (1990). Gender Trouble. Feminism and the Subversion of Identity. London/New York: Routledge.

Butler, J. (1993). Bodies that Matters. On the Discursive Limits of Sex. London/New York: Routledge.

Carroll, H.C.M. 1986. Parental factors in primary school pupil absenteeism and their possible implications for educational psychologists. Educational and Child Psychology, 3(3): 202-212.

Cave, N. (1994). I let love in. On I Let Love In [CD]. London: Mute Records.

Ceder, S. (2015). Cutting Through Water. Towards a Posthuman theory of Educational Relationality. PhD diss., Lund University.

Charters, E. (2003). The use of think-aloud methods in qualitative research. An introduction to think-aloud methods. Brock Education, 12(2): 68-82.

Childers, S.M. (2013). The materiality of fieldwork. An ontology of feminist becoming. International Journal of Qualitative Studies in Education, 26(5): 599-609.

Chitiyo, M. \& Wheeler, J. (2006). School phobia. Understanding a complex behavioural response. Journal of Research in Special Educational Needs, 6(2): 87-91. 
Clough, P.T. (2009). The new empiricism. Affect and sociological method. European Journal of Social Theory, 12(1): 43-61.

Colebrook, C. (2014a). Sex After Life. Essays on Extinction, Vol. 2. Ann Arbor, MI: Open Humanities Press.

Colebrook, C. (2014b). Death of the PostHuman. Essays on Extinction, Vol. 1. Ann Arbor, MI: Open Humanities Press.

Coleman, R. \& Ringrose, J. (2013). Introduction. Deleuze and research methodologies. In R. Coleman \& J. Ringrose (Eds.), Deleuze and Research Methodologies (pp. 1-22). Edinburgh, UK: Edinburgh University Press.

Coole, D.H. \& Frost, S. (Eds.) (2010). New Materialisms. Ontology, Agency, and Politics. Durham, N.C.: Duke University Press.

Corville-Smith, J., Ryan, B.A., Adams, G.R. \& Dalicandro, T. (1998). Distinguishing absentee students from regular attenders. The combined influence of personal, family and school factors. Journal of Youth and Adolescence, 27(5): 629-640.

Czarniawska-Joerges, B. (2007). Shadowing and Other Techniques for Doing Fieldwork in Modern Societies. Malmö: Liber.

Dahl, P. (2016). Factors associated with truancy. Emerging adults' recollections of skipping school. Journal Of Adolescent Research, 31(1): 119-138.

Dahlstedt, M. (2007). I val(o)frihetens spår. Segregation, differentiering och två decennier av skolreformer. Pedagogisk Forskning i Sverige, 12(1): 20-38.

Dahyabhai, D. \& Mehta, B. (2014). Directive access control system. Oriental Journal Of Computer Science And Technology, 7(3): 406-410.

Deleuze, G., \& Guattari, F. (1983). Anti-Oedipus. Capitalism and Schizophrenia. Minneapolis, MN: University of Minnesota Press.

Deleuze, G., \& Guattari, F. (1987). A Thousand Plateaus. Minneapolis, MN: University of Minnesota Press.

Dijstelbloem, H., \& Broeders, D. (2015). Border surveillance, mobility management and the shaping of non-publics in Europe. European Journal Of Social Theory, 18(1): 21-38.

Dolphijn, R. \& van der Tuin, I. (2012). New Materialism. Interviews \& Cartographies. Ann Arbor, MI: Open Humanities Press.

Dovemark, M. (2004). Ansvar-flexibilitet-valfribet. En etnografisk studie om en skola i förändring. $\mathrm{PhD}$ diss., Göteborg University.

Edwards, R. (2010). The end of lifelong learning. A post-human condition. Studies in the Education of Adults, 42(1): 5-17.

edWise (n.d). About edWise. Retrieved 17 February, 2015 from https://www.edwise.se/NewCookieInformation.aspx?UICulture=en-GB

Ekstrand, B. (2015). What it takes to keep children in school. A research review. Educational Review, 67(4): 459-482.

Emerson, R.M., Fretz, R.I. \& Shaw. L.L. (2011). Writing Ethnographic Fieldnotes (2nd ed.). Chicago: University of Chicago Press. 
Enarsson, L. (2016). En enkätstudie av läraresanvändande av digitala fränvarorapporteringssystem ur ett infrastrukturellt perspektiv. Master diss., University of Gothenburg.

Englund, T. (1993). Utbildning som "public good" eller "private good". Svensk skola $i$ omvandling? Uppsala: Pedagogiska institutionen.

Englund, T. (1995). Utbildningspolitiskt systemskifte? Stockholm: HLS.

Ervasti, M., Isomursu, M. \& Kinnula, M. (2009). Bringing Technology into School-NFCenabled School Attendance Supervision. The $8^{\text {th }}$ International Conference on Mobile and Ubiquitous Multimedia (MUM09), Cambridge, UK, 22-25 November 2009.

Fenomen (n.d.). In Nationalencyklopedin. Retrived 4 April, 2013, from http://www.ne.se.lt.ltag.bibl.liu.se/lang/fenomen Nedladdad 2013-05-04

Foucault, M. (1981). The order of discourse. In R. Young (Ed.), Untying the Text. A Post-Structuralist Reader (pp. 52-64). London: Routledge

Foucault, M. (1995). Discipline and Punish. The birth of the prison. New York: Vintage Books.

Foucault, M. (2000). The subject and power. In J.D. Faubion (Ed.), Power (pp. 326348). New York: The New Press.

Fraser, B.J. (1987). Identifying the salient facets of a model of student learning. A synthesis of meta-analyses. International Journal of Educational Research, 11(2): 187212.

Fukuyama, F. (2002). Our Posthuman Future. Consequences of the Biotechnology Revolution. New York: Farrar, Straus and Giroux.

Gavade, S., Atwal, P., Khan, Z., Pillai, V. R. \& Chandargi, B. (2015). Automated bluetooth attendance management system. International Journal of Computer Science Engineering and Information Technology Research, 5(2): 7-14.

Gentle-Genitty, C., Karikari, I., Chen, H., Wilka, E., \& Kim, J. (2015). Truancy. A look at definitions in the USA and other territories. Educational Studies, 41(1-2): 62-90.

Gillie, A. (2008). Identifying the poor in the 1870s and 1880s. Economic History Review, 61(2): 302-325.

Gottfried, M.A. (2009). Excused versus unexcused. How student absences in elementary school affect academic achievement. Educational Evaluation and Policy Analysis, 31(4): 392-415.

Griffith, A., \& André-Bechley, L. (2008). Institutional technologies. In M. DeVault (Ed.), People at work (pp. 40-55). New York: New York University Press.

Gross, R.N. (2014). Public regulation and the origins of modern school-choice policies in the progressive era. Journal Of Policy History, 26(4): 509-533.

Gulson, N.K., \& Symes, C. (2007). Knowing one’s place. Space, theory, education. Critical Studies in Education, 46(1), 97-110.

Gunnarsson, K. (2015). Med önskan om kontroll. Figurationer av hälsa i skolors bälsofrämjande arbete. $\mathrm{PhD}$ diss., Stockholm University. 
Halkier, B. (2010). Focus groups as social enactments. Integrating interaction and content in the analysis of focus group data. Qualitative Research, 10(1): 71-89.

Halldén, K. (2008). The Swedish educational system and the ISCED-97. In S. Schneider (Ed.), The International Standard Classification of Education (ISCED-97). An evaluation of content and criterion validity in 15 European countries (pp. 253-267). Mannheim: MZES.

Hammersley, M. \& Atkinson, P. (2007). Ethnography. Principles in Practice (3rd ed.). London/New York: Routledge.

Hansson, A. (2013). Arbete med skolutveckling. En potentiell gränszon mellan verksambeter? Ett verksambetsteoretiskt perspektiv på en svensk skolas arbete över tid med att verksambetsintegrera IT. PhD diss., Mid Sweden University.

Harakeh, Z., de Looze M.E., Schrijvers C.T., van Dorsselaer S.A., \& Vollebergh W.A. (2012). Individual and environmental predictors of health risk behaviours among dutch adolescents. The HBSC Study. Public Health, 126(7): 566-573.

Haraway, D. (1988). Situated knowledges. The science question in feminism and the privilege of partial perspective. Feminist studies, 14(3): 575-599.

Haraway, D. (1989). Primate Visions. Gender, Race and Nature in the World of Modern Science London/New York: Routledge.

Haraway, D. (1991). Simians, Cyborgs, and Women. The Reinvention of Nature. London/New York: Routledge.

Haraway, D. (1997).Modest_Witness@Second_Millenium.FemaleMan@_Meets_ OntoMouse_TM Feminism and Technoscience. London/New York: Routledge.

Havik, T., Bru, E., \& Ertesvåg, S. K. (2014). Caregiveral perspectives of the role of school factors in school refusal. Emotional and Behavioural Difficulties, 19(2): 131153.

Havik, T., Bru, E., \& Ertesvåg, S. K. (2015). School factors associated with school refusal- and truancy-related reasons for school non-attendance. Social Psychology of Education, 18(2): 221-240.

Hayles, K.N. (1999). How we Became Posthuman. Virtual Bodies in Cybernetics, Literature, and Informatics. Chicago, Ill.: Univ. of Chicago Press.

Hayles, K.N. (2003). Afterword. The human in the posthuman. Cultural Critique, 53 : 134-137.

Hein, S.F. (2016). The new materialism in qualitative inquiry. How compatible are the philosophies of Barad and Deleuze? Cultural Studies $\Leftrightarrow$ Critical Methodologies, 16(2): 132-140.

Hekman, S. (2010). The Material of Knowledge. Feminist Disclosures. Bloomington, IN: Indiana University Press.

Helmersson, E. (2014). Hårdare tag fungerade mot skolket. Dagens Nyheter, November 17. Retrieved from http://www.dn.se/ledare/signerat/hardare-tagfungerade-mot-skolket/

Hennel, L. (2013). ’Lås dörren för sena elever". Svenska Dagbladet, December 10. 
Retrieved from http://www.svd.se/las-dorren-for-sena-elever Hennink, M.M. (2007). International Focus Group Research. A Handbook for the Health and Social Sciences. Cambridge university Press: Cambridge.

Hickey-Moody, A. (2013). Affect as method. Feelings, aesthetics and affective pedagogy. In R. Coleman \& J. Ringrose (Eds.), Deleuze and Research Methodologies (pp. 79-95). Edinburgh: Edinburgh University Press.

Hird, M.J. (2009). Material feminist engagements. Feminist Studies, 35(2): 329-346.

Hohti, R. (2016). Classroom Matters. Research with Children as Entanglement. PhD diss., University of Helsinki.

Holstein, J. \& Gubrium, J. (1995). The Active Interview. Thousand Oaks: Sage. Huck, J.L. (2011). Truancy programs. Are the effects too easily washed away? Education \& Urban Society, 43(4): 499-516.

Hultman, K. (2011). Barn, linjaler och andra aktörer. Posthumanistiska pespektiv på subjektskapande och materialitet i förskola/skola. PhD diss., Stockholm University.

Hyvönen, F. (2005). Valerie. On Until Death Comes [CD]. Stockholm: Licking Fingers. IST (n.d.). Dexter. IT-lösningen för kommuner längst fram. Retrieved 18 February, 2015 from http://www.iktbuf.com/projekt_dur/filer/dexter_extens.pdf

Isomursu, M., Ervasti, M., Kinnula, M. \& Isomursu, P. (2011). Understanding human values in adopting new technology. A case study and methodological discussion. International Journal of Human-Computer Studies, 69: 183-200.

Jackson, A.Y. \& Mazzei, L.A. (2012). Thinking with Theory in Qualitative Research. Viewing Data Across Multiple Perspectives. London/New York: Routledge.

Jonasson, C. (2011). The dynamics of absence behaviour. Interrelations between absences from class and absences in class. Educational Research, 53(1): 17-32.

Jones, L. Holmes, R., Macrae C. \& MacLure, M. (2010). Documenting classroom life. How can I write about what I am seeing? Qualitative Research, 10 (4): 479-491.

Jones, A. \& Jenkins, K. (2008). Indigenous discourse and 'the material'. A postinterpretivist argument. International Review of Qualitative Research, 1(2): 125-144.

Juelskjær, M. (2013). Gendered subjectivities of space time matter. Gender and Education, 25(6): 754-768.

Jönsson, A. (1990). Skolk i grundskolan. En meta-studie. Pedagogisk-psykologiska problem. Nr 538. Lärarhögskolan i Malmö, Lunds universitet.

Kallstenius, J. (2010). De mångkulturella innerstadsskolorna. Om skolval, segregation och utbildningsstrategier i Stockholm. PhD diss., Stockholm University.

Karlberg, M. \& Sundell, K. (2004). Skolk. Sund protest eller riskbeteende? Stockholm: Fou-enheten.

Kearney, C.A. (2003). Bridging the gap among professionals who address youths with school absenteeism. Overview and suggestions for consensus. Professional Psychology-Research and Practice, 34(1): 57-65.

Kearney, C.A. (2008). An interdisciplinary model of school sbsenteeism in youth to inform professional practice and public policy. Education Psychology Review, 20(3): 
257-282.

Kearney, C.A. \& Bensaheb, A. (2006). School absenteeism and school refusal behaviour. A review and suggestions for school-based health professionals. Journal of School Health, 76(1): 3-7.

Kofoed, J. \& Ringrose, J. (2012). Travelling and sticky affects. Exploring teens and sexualized cyberbullying through a Butlerian-Deleuzian-Guattarian lens. Discourse: Studies in the Cultural Politics of Education, 33 (1): 5-20.

Kozina. A. (2015). Aggression in primary schools. The predictive power of the school and home environment. Educational Studies, 41(1-2): 109-121.

Kragelund, L. (2013). The obser-view. A method of generating data and learning. Nurse Researcher, 20(5): 6-10.

Krueger, R.A. \& Casey, M.A. (2009). Focus Groups. A practical guide for Applied Research (4th ed.).Thousand Oaks, CA: Sage Publications.

Kuntz, M. A. \& Presnall, M. M. (2012). Wandering the tactical. From interview to intraview. Qualitative Inquiry, 18(9): 732-744.

Landahl, J. (2006). Auktoritet och ansvar. Lärares fostrans- och omsorgsarbete $i$ historisk belysning. PhD diss., Stockholm University.

Larsson, H.A. (2011). Mot bättre vetande. En svensk skolhistoria. Stockholm: SNS Förlag.

Larsson, J., Löfdahl, A., \& Pérez Prieto, H. (2010). Rerouting. Discipline, assessment and performativity in contemporary Swedish educational discourse. Education Inquiry, 1(3): 177-195.

Larsson, J.K. (2015). Integrationen och arbetets marknad: hur jämställdhet, arbete och annat "svenskt" görs av arbetsförmedlare och privata aktörer. $\mathrm{PhD}$ diss., Linköping University.

Lather, P. (2013). Methodology-21. What do we do in the afterward? International Journal of Qualitative Studies in Education, 26(6): 634-645.

Lather, P. \& St. Pierre, E.A. (2013). Post-qualitative research. International Journal of Qualitative Studies in Education, 26(6): 629-633.

Lauchlan, F. (2003). Responding to chronic non-attendance. A review of intervention approaches. Educational Psychology in Practice, 19(2): 133-146.

Law, J. (1999). After ANT. Complexity, naming and topology. In J. Law \& J. Hassard (Eds.), Actor Network Theory and After (pp. 1-14). Oxford: Blackwell

Lee, F. (2009). Letters and Bytes. Sociotechnical Studies of Distance Education. PhD diss., Linköping University.

Lenz Taguchi, H. (2010). Going Beyond the Theory/Practice Divide in Early Childhood Education. Introducing an Intra-active Pedagogy. London/New York: Routledge.

Lenz Taguchi, H. (2012). A diffractive and Deleuzian approach to analysing interview data. Feminist Theory 13(3): 265-281.

Lenz Taguchi, H. (2013). Images of thinking in feminist materialisms. Ontological divergences and the production of researcher subjectivities. International Journal of Qualitative Studies in Education, 26(6): 706-716.

Lenz Taguchi, H. (forthcoming). Concept as method. Posthumanism as a feminist 
figuration for contemporary micro-political research. Qualitative Inquiry.

Lenz Taguchi, H. \& Palmer, A. (2013). A more 'livable' school? A diffractive analysis of the performative enactments of girls' ill-/well-being with(in) school environments. Gender and Education, 25(6): 671-687.

Lewis, C.J. (2009). Schools Aim to Achieve Maximum Attendance Rates for All Pupils. Does Electronic Registration make a Valuable Contribution? Master diss., Cardiff

Metropolitan University.

Lgr -80, Läroplan för grundskolan. Allmän del. Stockholm: Skolöverstyrelsen och

Utbildningsförlaget.

Liamputtong, P. (2011). Focus Group Methodology. Principles and Practice. London: Sage. Lindblad, S., Lundahl, L., Lindgren, J. \& Zackari, G. (2002). Educating for the New Sweden? Scandinavian Journal of Educational Research, 46(3): 283-303.

Lindén, L. (2016). Communicating Care. The Contradictions of HPV Vaccination Campaigns. PhD diss., Linköping University.

Lodha, R., Gupta, S., Jain, H. \& Narula, H. (2015). Bluetooth smart based attendance management system. Procedia Computer Science 45: 524-527.

López Fernández, M.J., Fernández, J.G., Aguilar, S.R., Selvi, B.S. \& González Crespo, R. (2013). Control of attendance applied in higher education through mobile NFC technologies. Journal of Future Generation Computer Systems, 29(10): 4478-4489.

Lykke, N. (2010a). Feminist Studies. A Guide to Intersectional Theory, Methodology and Writing. London/New York: Routledge.

Lykke, N. (2010b). The timeliness of post-constructionism. NORA: Nordic Journal of Feminist and Gender Research, 18(2): 131-136.

Lynch, T.L. (2015) The Hidden Role of Software in Education. Policy to Practice. London: Routledge.

MacLure, M. (2010). The offence of theory. Journal of Education Policy, 25(2): 277-286.

MacLure, M. (2013a). Researching without representation? Language and materiality in post-qualitative methodology. International Journal of Qualitative Studies in Education, 26(6): 658-667.

MacLure, M. (2013b). Classification or wonder? Coding as an analytic practice in qualitative research. In B. Coleman \& J. Ringrose (Eds.), Deleuze and Research Methodologies (pp. 164-183). Edinburgh: Edinburgh University Press.

Madriz, E. (2003). Focus groups in feminist research. In N. Denzin \& Y. Lincoln (Eds.), Collecting and Interpreting Qualitative Materials (pp. 363-388). Thousand Oaks, CA: Sage.

Mangum, J., Barnes, J., Koster, J. \& Spillane, S. (1998). King of Carrot Flowers, Pt. 2-3. On In the Aeroplane over the Sea [CD]. Durham: Merge Records.

Markström, A-M. (2013). Children's perspectives on the relations between home and school. International Journal about Caregivers in Education, 7(1): 43-56.

Masalha, F. \& Hirzallah, N. (2014). A students attendance system using QR code. 
International Journal of Advanced Computer Science and Applications, 5(3): 75-79.

Massey, D. (1994). Space, Place and Gender. Cambridge, UK: Polity Press.

Massey, D. (1999). Spaces of politics. In D. Massey, J. Allen \& P. Sarre. (Eds.),

Human Geography Today (pp. 279-294). Cambridge/Oxford: Malden.

Massey, D. (2005). For Space. London: Sage.

Maynard, B.R. (2014). School truancy. Poor school attenders' perceptions of the impact regarding dysfunctional teacher-learner relationships on truant behaviour. Mediterranean Journal of Social Sciences, 5(23): 1056-1063.

Maynard, B.R., Salas-Wright, C.P., Vaughn M.G., \& Peters, K.E. (2012). Who are truant youth? Examining distinctive profiles of truant youth using latent profile analysis. Journal of Youth and Adolescence, 41(12): 1671-1684.

Mazzei, L.A. (2013). A voice without organs. Interviewing in posthumanist research. International Journal of Qualitative Studies in Education, 26(6): 732-740.

McGregor, J. (2003). Spatiality and teacher workplace cultures. The department as nexus. In: R.U. Edwards, R (Ed.) Space, Curriculum and learning (pp. 45-59).

Greenwich, Conneticut: Information Age Publishing.

Morawski, J. (2010). Mellan frihet och kontroll. PhD diss., Örebro University.

More, V. \& Nayak, S. (2013). Attendance automation using near field communication (NFC) technology. International Journal of Scientific \& Engineering Research, 4(12): 572-575.

Mulcahy, D. (2012). Affective assemblages. Body matters in the pedagogic practices of contemporary school classrooms. Pedagogy, Culture \& Society, 20(1): 9-27.

Nordstrom, S. (2013). Object-interviews. Folding, unfolding, and refolding perceptions of objects. International Journal of Qualitative Methods, 12: 237-257.

OECD (2013). PIS A 2012 Results: Ready to Learn: Students' Engagement, Drive and SelfBeliefs (Volume III). PISA, OECD Publishing.

Ozga, J. (2016). Trust in numbers? Digital education governance and the inspection process. European Educational Research Journal, 15(1): 69-81.

Patel, U.A. \& Priya, R.S. (2014). Development of a student attendance management system using RFID and face recognition. A review. International Journal of Advance Research in Computer Science and Management Studies, 2(8): 109-119.

Pedersen, H. (2014). Posthumanistisk pedagogisk forskning. Några ingångar. Pedagogisk forskning i Sverige, 19(2-3): 83-89.

Phenonomena (n.d.). In Oxford Dictonary of English ( $3^{\text {rd }}$ edition). Retrived 20 November, 2014, from

http://www.oxfordreference.com.e.bibl.liu.se/view/10.1093/acref/9780199571 123.001.0001/m_en_gb0625690

Qvarsebo, J. (2006). Skolbarnets fostran. Enhetsskolan, agan och politiken om barnet 1946 1962. PhD diss., Linköping University.

Rao, V.R. (2013). A framework for unified digital government. A case of India. Journal Of E-Governance, 36(1): 35-55. 
Rapley, T.J. (2001). The (art)fullness of open-ended interviewing. Some considerations on analyzing interviews. Qualitative Research, 1(3): 303-323.

Rauscher, E. (2014). Hidden gains. Effects of early U.S. compulsory schooling laws on attendance and attainment by social background. Educational Evaluation \& Policy Analysis, 36(4): 501-518.

Reid, K. (1999). Tackling Truancy in Schools. London: Routledge Falmer.

Reid, K. (2005). The causes, views and traits of school absenteeism and truancy. Research In Education, 74: 59-82.

Reid, K. (2006). An evaluation of the views of secondary staff towards school attendance issues. Oxford Review of Education, 32(3): 303-324.

Reid, K. (2010). Finding strategic solutions to reduce truancy. Research in Education, 84(1): 1-18.

Reid, K. (2014). Managing school attendance. Successful intervention strategies for reducing truancy. London/New York: Routledge.

Reid, K. (2015). Introduction to special edition. Educational Studies, 41(1-2), 4-13.

Renold, E. \& Ivinson, G. (2014). Horse-girl assemblages. Towards a post-human cartography of girls' desire in an ex-mining valleys community. Discourse: Studies In The Cultural Politics Of Education, 35(3): 361-376.

Richardson, G. (2010). Svensk utbildningshistoria. Skola och sambälle förr och nu. Lund: Studentlitteratur.

Ringrose, J. (2011). Beyond discourse? Using Deleuze and Guattari's schizoanalysis to explore affective assemblages, heterosexually striated space, and lines of flight online and at school. Educational Philosophy and Theory, 43(6): 598-618.

Sandin, B. (1986). Hemmet, gatan, fabriken eller skolan. Folkundervisning och barnuppfostran $i$ svenska städer 1600-1850. PhD diss., Linköping University.

Sauzet, S. (2015). Versioner. Diffraktive analyser af tvarprofessionalismens tilblivelse som fanomen i Professionshojskolen. PhD diss., Aarhus University.

Selwyn, N. (2011). 'It's all about standardisation'. Exploring the digital (re)configuration of school management and administration. Cambridge Journal of Education, 41(4): 473-488.

Selwyn, N. (2016). 'There's so much data'. Exploring the realities of data-based school governance. European Educational Research Journal, 15(1): 54-68.

SFS [Swedish statutes]. (1985:1100). Skollag [Education Act].

SFS [Swedish statutes]. (2011:506). Förordning om ändring $i$ skolförordningen (2011:185).

SFS [Swedish statutes]. (2010:800). Skollag [Education Act].

Sheppard, A. (2007). An approach to understanding school attendance difficulties. Pupils' perceptions of caregiveral behaviour in response to their requests to be absent from school. Emotional \& Behavioural Difficulties, 12(4): 349-363.

Silverman, D. (2006). Interpretating Qualitative Data. London: Sage.

Sjöberg, M. (1996). Att säkra framtidens skördar. Barndom, skola och arbete i agrar miljö: Bolstad pastorat 1860-1930. PhD diss., Linköping University. 
Sjögren, H. (2016). Sustainability for Whom? The Politics of Imagining Environmental Change in Education. PhD diss., Linköping University.

Skolverket (2008). Rätten till utbildning. Om elever som inte går i skolan. Rapport 309. Stockholm: Fritzes.

Skolverket (2010). Skolfrånvaro och vägen tillbaka. Långvarig ogiltig frånvaro i grundskolan. Rapport 341. Stockholm: Fritzes.

Snaza, N. \& Weaver, J.A. (2015). Posthumanism and Educational Research. London/New York: Routledge.

Sommer, B. (1985). What's different about truants? Journal of Youth and Adolescence, 14(5): 411-422.

Sospeter, J., Sinde, R.S. \& Kaijage, S. (2015). A review on development of RFID and mobile application based attendance management system. Computer Engineering and Intelligent Systems, 6(8): 27-32.

SOU 1974:53. Skolans arbetsmiljö. Betänkande angivet av utredningen om skolans inre arbeteSLA. Stockholm: Utbildningsdepartementet.

Southwell, N. (2006). Truants on truancy. A badness or a valuable indicator of unmet special educational needs? British Journal of Special Education, 33(2): 91-97.

St. Pierre, E.A. (2004). Deleuzian concepts for education. The subject undone. Educational Philosophy and Theory, 36(3): 283-296.

St. Pierre, E.A. (2011). Post qualitative research. The critique and the coming after. In N.K. Denzin \& Y.S. Lincoln (Eds.), Sage Handbook of Qualitative Inquiry (4th ed.) (pp. 611-635). Los Angeles, CA: Sage.

St. Pierre, E.A. (2013). The appearance of data. Cultural Studies $\Leftrightarrow$ Critical Methodologies, 13(4): 223-227.

St. Pierre, E.A. (2014). A brief and personal history of post qualitative research.

Toward "post inquiry". Journal of Curriculum Theorizing 30(2): 2-19.

St. Pierre, E.A. \& Jackson, A.Y. (2014). Qualitative data analysis after coding. Qualitative Inquiry, 20(6): 715-719.

St. Pierre, E.A., Mazzei, L.A \& Jackson, A.Y. (Eds.) (2016). Special Issue. New empiricisms and new materialisms. Cultural Studies $\Leftrightarrow$ Critical Methodologies, 16(2): 99-234.

Star, S.L. (Ed.) (1995). The Cultures of Computing. Oxford: Blackwell.

Stender Petersen, K. (2014). Interviews as intraviews. A hand puppet approach to studying processes of inclusion and exclusion among children in kindergarten. Reconceptualizing Educational Research Methodology, 5(1): 32-45.

Stenliden, L. (2014). Visual Storytelling Interacting in School. Learning Conditions in the Social Science Classroom. PhD diss., Linköping University.

Stigsdotter Ekberg, M. (2010). Dom kallar oss värstingar. Om ungas lärande i mötet med skola, socialtjänst och polis. $\mathrm{PhD}$ diss., Linnaeus University.

Strand, A-S. (2013). Skolk ur elevernas och skolans perspektiv. En intervju- och dokumentstudie. PhD diss., Högskolan i Jönköping. 
Strand, A-S. \& Granlund, M. (2014). The school situation for students with a high level of absenteeism in compulsory school. Is there a pattern in documented support? Scandinavian Journal Of Educational Research, 58(5): 551-569.

Strandell, A. (Ed.) (2009). Otillaten franvaro. Om hemmasittare, korridorvandrare och skolkare. Stockholm: Gothia.

Sundell, K., El-Khouri, B.M. \& Månsson, J. (2005). Elever på vift. Vilka är skolkearna? Stockholm: Fou-enheten.

Sundén Jelmini, M. (2014). Nytt projekt minskar skolk. Svenska Dagbladet, November 17. Retrieved from http://www.svd.se/nyheter/inrikes/nytt-projekt-minskarskolk_4106395.svd

Sutphen, R., Ford, J. \& Flaherty, C. (2010). Truancy interventions. A review of the research literature. Research on Social Work Practice, 20(2): 161-171.

Sälzer, C., Trautwein, U., Lütke, O. \& Stamm, M. (2012). Predicting adolescent truancy. The importance of distinguishing between different aspects of instructional quality. Learning and Instruction, 22(5): 311-319.

Sørensen, E. (2009). The Materiality of Learning. Technology and Knowledge in Educational Practices. Cambridge: Cambridge University Press.

Tamboukou, M. (2008). Machinic assemblages. Women, art education and space. Discourse: Studies in the Cultural Politics of Education, 29 (3): 359-375.

Taylor, C.A. \& Hughes, C. (Ed.) (2016). Posthuman Research Practices in Education. New York, NY: Palgrave Macmillan.

Taylor, C.A. \& Ivinson, G. (2013). Material feminisms. New directions for education. Gender and Education, 25(6): 665-670.

Thakare, V. \& Khire, G. (2014). Role of emerging technology for building smart hospital information system. Procedia Economics And Finance, 11: 583-588.

Thambirajah, M. S., Grandison, K. J., \& De-Hayes, L. (2008). Understanding School Refusal. A Handbook for Professionals in Education, Health and Social Care. London: Jessica Kingsley Publishers.

Tieto (n.d.). Lärportal som öppnar för nya arbetssätt. Retrieved 17 February, 2015 from http://www.tieto.se/branscher/offentlig-sektor/skola-kommunal-ochprivat-tieto/larportal-edwise-edu-tieto

Tuana, N. (2008). Viscous porosity. Witnessing Katrina. In S. Alamio \& S. Hekman (Eds.), Material Feminisms (pp. 188-213). Bloomington: Indiana University Press.

Tyerman, M. (1968). Truancy. London: University of London Press.

Veenstra, R., Lindenberg, S., Tinga, F. \& Ormel, J. (2010). Truancy in late elementary and early secondary education. The influence of social bonds and self-control The TRAILS study. International Journal of Behavioral Development, 34(4): 302-310.

Visscher, A.J. \& Bos, K.T. (1993). Combating truancy. Can the computer help schools? Studies in Educational Evaluation, 19(3): 297-309.

Weaver, J.A. (2010). Educating the Posthuman. Biosciences, Fiction, and Curriculum Studies. Rotterdam: Sense Publishers. 
Weinberg, C. \& Weinberg, L. (1992). Multiple perspectives on the labeling, treatment, and disciplining of at-risk students. Journal of Humanistic Education and Development, 30(4): 146-156.

Whatmore, S. (2004). Humanism's excess. Some thought on the 'post-human/ist' agenda. Environment and Planning A, 36(8): 1360-1363.

Williamson, B. (2016). Digital education governance. An introduction. European Educational Research Journal, 15(1): 3-13.

Winthereik, B.R., van der Ploeg, I., \& Berg, M. (2007). The electronic patient record as a meaningful audit tool. Accountability and autonomy in general practitioner work. Science, Technology, \& Human Values, 32(1): 6-25.

Witts, B. \& Houlihan, D. (2007). Recent perspectives concerning school refusal behavior. Electronic Journal of Research in Educational Psychology, 5(2): 381-398.

Wolfe, C. (2010). What is Posthumanism? Minneapolis, Minn.: University of Minnesota Press.

Youdell, D. (2011). School Trouble. Identity, Power, and Politics in Education. London/New York: Routledge.

Åsberg, C., Koobak, R., \& Johnson, E. (2011a). Beyond the humanist imagination. NORA: Nordic Journal Of Women's Studies, 19(4): 218-230.

Åsberg, C., Koobak, R., \& Johnson, E. (2011b). Post-humanities is a feminist issue. NORA: Nordic Journal Of Women's Studies, 19(4): 213-216.

Åsberg, C., Hultman, M., \& Lee, F. (Eds.) (2012). Posthumanistiska nyckeltexter. Lund: Studentlitteratur. 



\section{Research papers included in the thesis}

I. Bodén, L. (2013). Seeing red? The agency of computer software in the production and management of students' school absences. International Journal of Qualitative Studies in Education, 26(9): 11171131.

II. Bodén, L. (2015). The presence of school absenteeism. Exploring methodologies for researching the material-discursive practice of school absence registration. Cultural Studies $\Leftrightarrow$ Critical Methodologies, 15(3): 192-202.

III. Bodén, L. (2016). Dexter time. The space, time and matterings of school absence registration. Discourse: Studies in the Cultural Politics of Education, 37(2): 245-255.

IV. Bodén, L. (forthcoming). Going with the affective flows of digital school absence text messages. Submitted to Learning, Media \& Technology. 



\section{Papers}

The articles associated with this thesis have been removed for copyright reasons. For more details about these see:

http://urn.kb.se/resolve?urn=urn:nbn:se:liu:diva-130460 



\section{Appendix I}

\section{Digital software for the registration of absences in the municipalities of Sweden}

\begin{tabular}{|c|c|c|}
\hline MUNICIPALITY & 2013 & 2016 \\
\hline ALE & Skola24 & Skola24 \\
\hline ALINGSÅS & - & Skola24 \\
\hline ALVESTA & - & Starts working with a software $2016^{*}$ \\
\hline ANEBY & - & SchoolSoft \\
\hline ARBOGA & edWise (upper secondary) & edWise \\
\hline ARJEPLOG & - & Dexter* \\
\hline ARVIDSJAUR & - & Fronter \\
\hline ARVIKA & edWise & edWise \\
\hline ASKERSUND & - & InfoMentor* \\
\hline AVESTA & Dexter & Dexter \\
\hline BENGTSFORS & Skola24/edWise & edWise \\
\hline BERG & - & Skola24 \& SchoolSoft* \\
\hline BJURHOLM & SchoolSoft (grade 6-9) & SchoolSoft (all students) \\
\hline BJUV & Fronter & Fronter \\
\hline BODEN & - & Dexter \\
\hline BOLLEBYGD & - & SchoolSoft \\
\hline BOLLNÄS & Dexter & Dexter \\
\hline BORGHOLM & edWise & edWise \\
\hline BORLÄNGE & edWise & Skola24 \\
\hline BORÅS & Dexter & Dexter \\
\hline BOTKYRKA & MinSkola & Vklass \\
\hline BOXHOLM & Dexter & InfoMentor \\
\hline BROMÖLLA & InfoMentor & InfoMentor \\
\hline BRÄCKE & - & InfoMentor \\
\hline BURLÖV & Dexter & Vklass \\
\hline BÅSTAD & - & edWise \\
\hline DALS-ED & Rexnet & Vklass \\
\hline DANDERYD & SchoolSoft & Danderyd24 \\
\hline DEGERFORS & - & edWise \\
\hline DOROTEA & Skola24 & InfoMentor \\
\hline EDA & edWise (previously Skola24) & edWise \\
\hline EKERÖ & InfoMentor & InfoMentor \\
\hline EKSJÖ & Unikum & edWise (only for teachers)* \\
\hline EMMABODA & edWise & edWise \\
\hline ENKÖPING & - & InfoMentor \\
\hline ESKILSTUNA & - & Dexter \\
\hline ESLÖV & edWise & edWise \\
\hline ESSUNGA & edWise & edWise \\
\hline FAGERSTA & Dexter (not all schools) & InfoMentor \\
\hline FALKENBERG & - & Skola24* \\
\hline FALKÖPING & Skola24 & Skola24 \\
\hline FALUN & Skola24 & Skola24 \\
\hline FILIPSTAD & InfoMentor & InfoMentor \\
\hline FINSPÅNG & Fronter & Fronter \\
\hline FLEN & edWise & edWise \\
\hline FORSHAGA & - & Fronter \\
\hline FÄRGELANDA & - & Dexter (soon to be introduced) \\
\hline GAGNEF & SchoolSoft & SchoolSoft \\
\hline GISLAVED & Fronter & Dexter \\
\hline GNESTA & InfoMentor & InfoMentor \\
\hline GNOSJÖ & Hypernet & Hypernet \\
\hline GOTLAND & SchoolSoft & SchoolSoft \\
\hline
\end{tabular}




\begin{tabular}{|c|c|c|}
\hline GRUM & Fronter & Skola24 \\
\hline GRÄSTORP & edWise & edWise \\
\hline GULLSPÅNG & Unikum & Skola24 \\
\hline GÄLLIVARE & Skola24 & SchoolSoft \\
\hline GÄVLE & Skola24 & Skola24 \\
\hline GÖTEBORG & Skola24 & Hjärntorget \\
\hline GÖTENE & Ping Pong (called Delta) & Ping Pong (called Delta) \\
\hline НАBO & InfoMentor & InfoMentor \\
\hline HAGFORS & - & edWise \\
\hline HALLSBERG & edWise & edWise (called Skolwebben) \\
\hline HALLSTAHAMMAR & - & InfoMentor \\
\hline HALMSTAD & Portal035 & Dexter \\
\hline HAMMARÖ & Fronter & Fronter \\
\hline HANINGE & Dexter & Dexter \\
\hline HAPARANDA & InfoMentor & InfoMentor \\
\hline HEBY & - & Dexter \& Hypernet* \\
\hline HEDEMORA & Skola24 & Vklass \\
\hline HELSINGBORG & Ticket & Skola24 \\
\hline HERRLJUNGA & - & Vklass \& Skola24 \\
\hline HJO & edWise & edWise \\
\hline HOFORS & edWise (upper secondary) & edWise \\
\hline HUDDINGE & Skola24 & Skola24 \\
\hline HUDIKSVALL & edWise \& Skola24 & Skola24 \\
\hline HULTSFRED & Dexter & InfoMentor \\
\hline HYLTE & - & Dexter (will change to Hypernet)* \\
\hline HÅBO & InfoMentor & Hypernet \\
\hline HÄLLEFORS & InfoMentor (previously PODB) & InfoMentor \\
\hline HÄRJEDALEN & SchoolSoft & SchoolSoft \\
\hline HÄRNÖSAND & Dexter & Dexter \\
\hline HÄRRYDA & Skola24 & Skola24 \\
\hline HÄSSLEHOLM & SchoolSoft & SchoolSoft \\
\hline HÖGANÄS & - & Fronter \\
\hline HÖGSBY & - & InfoMentor \\
\hline HÖRBY & SchoolSoft & Vklass \& SchoolSoft \\
\hline HÖÖR & - & Vklass \\
\hline JOKKMOKK & SchoolSoft & SchoolSoft \\
\hline JÄRFÄLLA & Skolwebben & Skolwebben \\
\hline JÖNKÖPING & Skol-Kompassen \& Skola24 & Vklass \\
\hline KALIX & SchoolSoft \& Fronter & SchoolSoft \\
\hline KALMAR & edWise & edWise \\
\hline KARLSBORG & Dexter & Dexter \\
\hline KARLSHAMN & Dexter & Dexter \\
\hline KARLSKOGA & edWise (called Skolan) & edWise (called Skolan) \\
\hline KARLSKRONA & SchoolSoft & edWise (called Skolportalen) \\
\hline KARLSTAD & Dexter & Dexter \\
\hline KATRINEHOLM & Dexter & Lärknuten \\
\hline KIL & - & Fronter \\
\hline KINDA & Dexter & Dexter \\
\hline KIRUNA & Gymnasiet: Skola24 & Dexter \\
\hline KLIPPAN & - & Ping Pong (called Skolportalen) \\
\hline KNIVSTA & Skola24 & Skolportalen Grundskola \\
\hline KRAMFORS & - & It's Learning \\
\hline KRISTIANSTAD & edWise & edWise \\
\hline KRISTINEHAMN & Procapita web & Skola24 \\
\hline KROKOM & InfoMentor & InfoMentor \\
\hline KUMLA & Dexter (upper secondary) & Skolportalen \\
\hline KUNGSBACKA & Skola24 & Skola24 \\
\hline KUNGSÖR & - & InfoMentor \\
\hline KUNGÄLV & Fronter & Skola24 \\
\hline KÄVLINGE & InfoMentor (called IS@K) & InfoMentor (called IS@K) \\
\hline KÖPING & $\begin{array}{l}\text { Dexter (called Grundskola på } \\
\text { webben) }\end{array}$ & Dexter (called Grundskola på webben) \\
\hline LAHOLM & Dexter & Dexter \\
\hline LANDSKRONA & Dexter (called Familjeportalen) & Dexter (called Familjeportalen) \\
\hline
\end{tabular}




\begin{tabular}{|c|c|c|}
\hline LAXÅ & edWise & edWise (called Skolwebben) \\
\hline LEKEBERG & - & InfoMentor \\
\hline LEKSAND & InfoMentor & InfoMentor \\
\hline LERUM & Skola24 & Skola24* \\
\hline LESSEBO & - & Schoolsoft \\
\hline LIDINGÖ & Dexter & Dexter \\
\hline LIDKÖPING & Skola24 & Ping Pong (called Tango) \\
\hline LILLA EDET & - & Skola24* \\
\hline LINDESBERG & Dexter & Dexter \\
\hline LINKÖPING & Skola24 (upper secondary) & Fronter \\
\hline LJUNGBY & Skola24 (upper secondary) & Fronter \\
\hline LJUSDAL & Dexter (upper secondary) & Skolplatsen (from March 2016) \\
\hline LJUSNARSBERG & - & Implementing It's Learning \\
\hline LOMMA & InfoMentor & InfoMentor \\
\hline LUDVIKA & edWise & Procapita web \\
\hline LULEÅ & edWise & edWise \\
\hline LUND & Skola24 (upper secondary) & Skola24 \\
\hline LYCKSELE & Dexter (upper secondary) & InfoMentor \\
\hline LYSEKIL & Dexter (vuxenutbildning) & Vklass \\
\hline MALMÖ & Skola24 & Skola24 \\
\hline MALUNG-SÄLEN & Dexter & Dexter \\
\hline MALÅ & SchoolSoft & SchoolSoft \\
\hline MARIESTAD & Skola24 & InfoMentor \\
\hline MARKARYD & Skola24 & Skola24 \\
\hline MARK & SchoolSoft & SchoolSoft \\
\hline MELLERUD & Skola24 & Skola24 \\
\hline MJÖLBY & edWise & Skola24 \\
\hline MORA & Dexter & Dexter \\
\hline MOTALA & Fronter & Dexter \\
\hline MULLSJÖ & InfoMentor & InfoMentor \\
\hline MUNKEDAL & Skola24 & Procapita web* \\
\hline MUNKFORS & - & InfoMentor (called Familjewebben) \\
\hline MÖLNDAL & Skola24 & Fronter \& Skola24 \\
\hline MÖNSTERÅS & Skola24 & InfoMentor \\
\hline MÖRBYLÅNGA & edWise & edWise \\
\hline NACKA & Skola24 & SchoolSoft \\
\hline NORA & Dexter & Dexter \\
\hline NORBERG & - & InfoMentor \\
\hline NORDANSTIG & - & Unikum* \\
\hline NORDMALING & Dexter & Hypernet \\
\hline NORRKÖPING & Dexter & Dexter \\
\hline NORRTÄLJE & Skola24 & Fronter \\
\hline NORSJÖ & - & Dexter* \\
\hline NYBRO & Skola24 & Dexter \\
\hline NYKVARN & InfoMentor & InfoMentor \\
\hline NYKÖPING & edWise & edWise \\
\hline NYNÄSHAMN & Dexter & Dexter \\
\hline NÄSSJÖ & Dexter & Dexter \\
\hline OCKELBO & SchoolSoft & SchoolSoft \\
\hline OLOFSTRÖM & Dexter & InfoMentor \& Dexter \\
\hline ORSA & Skola24 & SchoolSoft \\
\hline ORUST & - & Skola24 \\
\hline OSBY & - & InfoMentor \\
\hline OSKARSHAMN & Skola24 (upper secondary) & Dexter \\
\hline OVANÅKER & edWise \& Skola24 & edWise \\
\hline OXELÖSUND & Dexter & Dexter \\
\hline PAJALA & Skola24 & Skola24 \\
\hline PARTILLE & Skola på webben & Skola på webben \\
\hline PERSTORP & InfoMentor & InfoMentor \\
\hline PITEÅ & Skola24 & edWise \\
\hline RAGUNDA & - & InfoMentor \\
\hline ROBERTSFORS & SchoolSoft & SchoolSoft \\
\hline RONNEBY & InfoMentor & InfoMentor \\
\hline
\end{tabular}




\begin{tabular}{|c|c|c|}
\hline RÄTTVIK & Fronter & Fronter \\
\hline SALA & SchoolSoft & SchoolSoft \\
\hline SALEM & SchoolSoft & SchoolSoft \\
\hline SANDVIKEN & edWise & edWise \\
\hline SIGTUNA & Dexter & Dexter \\
\hline SIMRISHAMN & Dexter & Dexter \\
\hline SJÖBO & edWise & edWise \\
\hline SKARA & Dexter & Dexter \\
\hline SKELLEFTEÅ & Skola24 & InfoMentor \\
\hline SKINNSKATTEBERG & InfoMentor (upper secondary) & InfoMentor \\
\hline SKURUP & Dexter & Dexter \\
\hline SKÖVDE & Fronter & Fronter \\
\hline SMEDJEBACKEN & Will introduce a software. & Fronter \\
\hline SOLLEFTEÅ & edWise & edWise \\
\hline SOLLENTUNA & Dexter & Dexter \& Skola24 \\
\hline SOLNA & Skola24 & InfoMentor \\
\hline SORSELE & - & SchoolSoft \\
\hline SOTENÄS & edWise & edWise \\
\hline STAFFANSTORP & Dexter (preschools) & Vklass \\
\hline STENUNGSSUND & Skola24 & Skola24 \\
\hline STOCKHOLM & edWise (called Skolwebben) & edWise (called Skolwebben) \\
\hline STORFORS & - & Procapita web* \\
\hline STORUMAN & Dexter & SchoolSoft \\
\hline STRÄNGNÄS & Fronter & Fronter \\
\hline STRÖMSTAD & Hypernet (upper secondary) & Dexter \\
\hline STRÖMSUND & - & Skola24 \\
\hline SUNDBYBERG & InfoMentor (called Skolwebben) & InfoMentor (called Skolwebben) \\
\hline SUNDSVALL & Skolan på webben & Skolan på webben \\
\hline SUNNE & Dexter & Dexter \\
\hline SURAHAMMAR & SchoolSoft & SchoolSoft \\
\hline SVALÖV & edWise & edWise \\
\hline SVEDALA & Dexter & InfoMentor \\
\hline SVENLJUNGA & edWise & edWise \\
\hline SÄFFLE & Skola24 & edWise \\
\hline SÄTER & - & InfoMentor \\
\hline SÄVSJÖ & edWise & edWise \\
\hline SÖDERHAMN & Skola24 (upper secondary) & Skola24 \\
\hline SÖDERKÖPING & - & edWise \\
\hline SÖDERTÄLJE & Skola24 & Ping Pong (called Lärplattformen) \\
\hline SÖLVESBORG & - & Dexter \\
\hline TANUM & Skola24 & Fronter \\
\hline TIBRO & edWise & edWise \\
\hline TIDAHOLM & Skola24 & Skola24 \\
\hline TIERP & Unikum & Dexter \\
\hline TIMRÅ & edWise & edWise \\
\hline TINGSRYD & Skola24 & Skola24 \\
\hline TJÖRN & Skolwebben & Skolwebben \\
\hline TOMELILLA & Skola24 & InfoMentor \\
\hline TORSBY & Dexter & Dexter \\
\hline TORSÅS & - & Dexter (only for teachers)* \\
\hline TRANEMO & - & InfoMentor \\
\hline TRANÅS & Skola24 & SchoolSoft \\
\hline TRELLEBORG & Dexter & Dexter \\
\hline TROLLHÄTTAN & FirstClass & Skola24 \\
\hline TROSA & - & InfoMentor \\
\hline TYRESÖ & Skolportalen & Hypernet \\
\hline TÄBY & Unikum & Vklass \\
\hline TÖREBODA & - & SchoolSoft \\
\hline UDDEVALLA & Dexter & Dexter \\
\hline ULRICEHAMN & Skola24 & InfoMentor \\
\hline UMEÅ & Skola24 & Lärum \\
\hline UPPLANDS VÄSBY & Skola24 & InfoMentor \\
\hline UPPLANDS-BRO & Skola24 & Skola24 \\
\hline UPPSALA & edWise & Skola24 \\
\hline UPPVIDINGE & - & Implementing Skola24* \\
\hline
\end{tabular}




\begin{tabular}{|c|c|c|}
\hline VADSTENA & SchoolSoft & SchoolSoft \\
\hline VAGGERYD & Unclear what system is in use & Dexter \\
\hline VALDEMARSVIK & - & InfoMentor* \\
\hline VALLENTUNA & Skola24 & Skola24 \\
\hline VANSBRO & Dexter & Dexter \\
\hline VARA & Skola24 & Dexter \\
\hline VARBERG & - & Tempus \\
\hline VAXHOLM & Dexter & Skola24 \\
\hline VELLINGE & edWise & Vklass \\
\hline VETLANDA & Dexter & Dexter \\
\hline VILHELMINA & Skola24 & Skola24 \\
\hline VIMMERBY & Dexter & InfoMentor \\
\hline VINDELN & SchoolSoft & Schoolsoft \\
\hline VINGÅKER & SchoolSoft & Dexter \\
\hline VÅRGÅRDA & - & SchoolSoft \\
\hline VÄNERSBORG & Skola24 & edWise (called LÄR) \\
\hline VÄNNÄS & InfoMentor & InfoMentor \\
\hline VÄRMDÖ & Skola24 & SchoolSoft \\
\hline VÄRNAMO & Dexter \& Fronter & Dexter \& Fronter \\
\hline VÄSTERVIK & Dexter & Dexter \\
\hline VÄSTERÅS & - & Vklass \\
\hline VÄXJÖ & - & Ticket \\
\hline YDRE & InfoMentor & InfoMentor \\
\hline YSTAD & Dexter & Vklass \\
\hline ÅMÅL & Skola24 & Skola24 \\
\hline ÅNGE & edWise & edWise (called Skolportalen) \\
\hline ÅRE & Dexter & Skola24 \\
\hline ÅRJÄNG & - & edWise* \\
\hline ÅSELE & - & Extens (not for absence registration)* \\
\hline ÅSTORP & edWise & edWise \\
\hline ÅTVIDABERG & Dexter & InfoMentor \\
\hline ÄLMHULT & SchoolSoft & Dexter* \\
\hline ÄLVDALEN & - & Fronter \\
\hline ÄLVKARLEBY & - & Dexter* \\
\hline ÄLVSBYN & Dexter & Dexter \\
\hline ÄNGELHOLM & Fronter & Fronter \\
\hline ÖCKERÖ & Unikum & Skola24 \\
\hline ÖDESHÖG & - & Dexter \\
\hline ÖREBRO & Unclear what system is in use & E-skola \\
\hline ÖRKELLJUNGA & - & InfoMentor \\
\hline ÖRNSKÖLDSVIK & Skola24 & Vklass \\
\hline ÖSTERSUND & Dexter & Hypernet \\
\hline ÖSTERÅKER & Skola24 & Dexter \\
\hline ÖSTHAMMAR & Skola24 & Skola24* \\
\hline ÖSTRA GÖINGE & Dexter & Dexter \\
\hline ÖVERKALIX & SchoolSoft & SchoolSoft \\
\hline ÖVERTORNEÅ & SchoolSoft & SchoolSoft \\
\hline
\end{tabular}

* No information on webpage. Information received via e-mail or phone call

The table is based on a review of the webpages of all Swedish municipalities, where I searched for information on what software were in use in elementary schools. As the review shows, all municipalities use (or are about to start using) software for the registration of absences and presences. Dexter is in use in 60 municipalities, while InfoMentor is used in 51 municipalities, Skola24 in 45 municipalities, edWise in 43 municipalities, SchoolSoft in 32 municipalities, Fronter in 19 municipalities, Vklass in 15 municipalities, Hypernet in 5 
municipalities, Ping Pong in 4 municipalities, and Procapita web in 3 municipalities, It's Learning, Unikum, and Skolwebben are used in 2 municipalities each, and 12 municipalities have a software specific for the municipality (such as Danderyd24, E-skola, Lärum and so on). As shown in the table above some municipalities use two forms of software and some software has a name 'made up' by the municipality. For example, edWise is called Skolwebben by some municipalities - as for instance by City 1 of this thesis -, and Skolan or Skolportalen by others. Skolwebben is also a nickname for InfoMentor in one municipality, and in two municipalities the name Skolwebben is connected to neither edWise nor InfoMentor.

During the spring of 2013, and again during the spring of 2016, I visited the webpages of each the municipalities. The searches were organized like this: I started by clicking the link that said 'Schools and education' (or 'Children and Childcare' or something similar to this). On some of the pages a link to the software was shown on this initial page, and this link took me to the webpage for the software, where Teachers and/or students, and/or caregivers could log in, usually using a BankID. On other webpages I had to search for the link to the software. If so, I started by searching for the word "frånvaro" [absence] on the page. Sometimes this took me to a link to the software. When the search for "frånvaro" did not result in any hits, I searched under the various software names: Dexter, edWise, Fronter, InfoMentor, Hypernet, Ping Pong, SchoolSoft, Skola24, Skolwebben, Unikum, and Vklass. Sometimes this method led me to a link; when it did not, I regarded that as a municipality without software for absence registration. This means I might have missed information on the websites of municipalities that use software unknown to me, or that name the software something unknown to me.

The review performed during 2016 showed that 20 municipalities (Alvesta, Askersund, Berg, Heby, Hylte, Lerum, Lilla Edet, Ljusnarsberg, Munkedal, Nordanstig, Norsjö, Storfors, Torsås, Uppvidinge, Valdemarsvik, Årjäng, Åsele, Älmhult, Älvkarleby and Östhammar) did not have any information about software on their websites. I chose to contact these municipalities by e-mail. Further, I contacted the three municipalities that only had information for upper secondary schools (Arjeplog, Eksjö and Falkenberg). This led to information about digital software use in elementary schools in an additional 15 municipalities. After the e-mails, I still lacked information about seven municipalities, that I phoned. They were all at the stage of discussing when to introduce a software program. This led to information about all municipalities. The municipalities that I contacted by e-mail (and phone) are marked with * in the table above.

The table must be read with certain provisos. Firstly, even if a municipality uses a software which has an absence/presence function, they may not make use of that function. The webpage does not always indicate this. Secondly, since the 
focus of the search is on municipalities, the review only includes information on public schools. In some municipalities software is not in use in all schools, which is not always indicated by the webpage. Other aspects did also appear during the research. For example, Åsele use the system Extens, which has no functions for absence registrations (but they are planning to use Dexter). Thus, the table cannot be viewed as an exact description of what software different municipalities use or how they use it. Rather it serves as a glimpse into what citizens meet when they visit the webpages; sometimes the software is in focus, highlighted at the first page, and sometimes it is very difficult to find (which can indicate the importance given to the software). The increase in software use between 2013 and 2016 could therefore be explained as either a consequence of the fact that more municipalities use software, or that the software is more visible ('searchable') on the webpages (which can indicate an increase in importance), or a combination of both of those circumstances. Some of the municipalities changed software between 2013 and 2016 as the table shows, and in those cases I have done an additional search to confirm this. What I have often found is a short note on the webpage that says that the municipality is about to change software.

To summarize: I primarily understand the table to be an indicator of the widespread use of software that could be, and most often is, used for the digital registration of absences and presences. 


\section{Appendix II}

\section{Interview guide, teachers}

\section{Skolfrånvaro}

Beskriv vad skolfrånvaro är för dig.

- Finns det olika typer av skolfrånvaro?

- Finns det riktlinjer kring detta på skolan?

- Tycker du att riktlinjerna är tillräckliga/bra/dåliga?

- När du registrerar frånvaro i Dexter, berätta om vad det är du tänker - vilka tankar som dyker upp i förhållande till olika elever eller olika typer av frånvaro när du fattar beslut om hur du skall registrera frånvaron: vad tar du hänsyn till?

- Hur bestämmer du vilken typ av frånvaro en elev haft?

Är detta lätt/svårt? Är det särskilt svårt med vissa elever och i så fall varför?

Kan du berätta om något tillfälle du varit osäker och hur du då agerat?

Händer det att du blir arg eller besviken när du registrerar frånvaro?

När och varför då?

Händer det att du blir glatt överraskad? Kan du ge exempel?

\section{Hantering av registrering av närvaro och frånvaro}

Berätta om hur ni på skolan tänker om och hanterar registreringen av elevers närvaro och frånvaro?

- Har ni alltid gjort så här?

- Hur gjorde ni tidigare och hur gör ni nu?

- Har ni några riktlinjer att jobba efter?

- Tycker du att riktlinjerna är bra och fungerar? Vad är dåligt och varför?

- Hur ser riktlinjerna ut? Finns de nedskrivna?

- Hur får du tillgång till riktlinjer?

- Hur använder du dem i ditt arbete rent konkret?

Fungerar de tillsammans/finns det motsägelser?

När är de användbara/när är de inte användbara?

- Hur hanterar du situationer där riktlinjerna inte är tillämpbara?

- Vad händer om du avviker från riktlinjerna?

Kan du beskriva en situation där du avvikit?

- Vem har beslutat om riktlinjerna?

\section{Hur tror du att eleverna uppfattar och upplever inrapporteringen av sin frånvaro $i$ Dexter? \\ - Blir det mycket diskussioner med eleverna kring inrapporteringen? \\ - Hur tänker du att eleverna upplever att frånvaron rapporteras in i Dexter? \\ - Använder elever Dexter? Hur?}




\section{Relationen hem/skola}

Hur ser du på föräldrarnas del av rapporteringen i Dexter?

- Hur används Dexter i relationen till föräldrar?

- Har detta underlättat eller försvårat relationer till hemmet?

Vid vilka tillfällen?

\section{Dexter}

- Använder föräldrar Dexter? Hur?

Kan du visa mig direkt på dator hur systemet fungerar? Berätta om själva datasystemet som ni använder för närvaro- och frånvaroregistrering.

- Kan du beskriva de olika stegen i inrapporteringen så som du brukar göra?

- Gör alla dina kollegor också på det här sättet? Finns det andra sätt?

- När på dagen gör du frånvarorapporteringen för det mesta?

- Var brukar du sitta?

- Använder du alltid denna dator?

- $\quad$ Är det nån skillnad att sitta på jobbet här och rapportera eller att sitta hemma?

- Brukar du känna dig pressad, stressad, sur, irriterad när du rapporterar in elevernas frånvaro? Eller glad, positiv? Varför?

- Tror du att du rapporterar in på ett annat sätt när du är väldigt trött eller irriterad, eller om du gör det på morgon en eller när du är pigg eller hemma...?

- Hur känns det att vara den som registrerar uppgifterna?

Känns det bra vissa gånger och mindre bra andra?

Möjlighet att påverka: positivt/negativt

Varför känns det olika?

- Känns det olika beroende på vilken elevs namn som dyker upp?

Vilka känslor? Värme, glädje, skuld, eller ilska.

Kan detta förändras? Hur?

- $\quad$ Är det svårt/lätt att lära sig Dexter: Har du gått kurser?

- Hur mycket tid har du lagt på att lära dig Dexter?

Var har du gjort detta? Hemma/på arbetet?

- Följs registreringen upp av någon annan än dig själv?

- Används Dexter till andra saker än frånvaroregistrering?

- Hur kommer det sig att ni har just Dexter?

\section{Uppgifter i Dexter}

Berätta om lite om hur du använder de uppgifter som registrerats i Dexter.

- Vid vilka tillfällen återvänder du till de registrerade uppgifterna?

- Underlättar de registrerade uppgifterna ditt arbete på nåt sätt?

När underlättare de?

När underlättare de inte?

Beskriv något tillfälle när det underlättat/inte underlättat.

\section{Diskussioner om Dexter}

Berätta något om de diskussioner som förts kring Dexter. 
- Hur diskuteras detta i lärarkollektivet?

- Hur diskuteras detta med elever?

- Hur diskuteras detta med föräldrar?

- För- och nackdelar med Dexter?

När blir dessa fördelar eller nackdelar tydliga i ditt arbete? Kan du ge något exempel?

- Tycker du att frånvaroregistrering behövs?

- Tycker du Dexter behövs?

- Vad skulle vara alternativa strategier? Om du får drömma...

Skulle programmet kunna se annorlunda ut?

Vilka känslor önskar du att registreringen skulle framkalla? 


\section{Appendix III}

\section{Interview guide, parents}

\section{Intervjuguide}

Mitt projekt handlar om hur registrering av skolnärvaro- och skolfrånvaro hanteras med hjälp av digitala system. Jag är intresserad av att undersöka vad detta skapar för handlingsmönster och sätt att agera såväl i skolan (av skolpersonal och elever) som utanför skolan (av elever och vårdnadshavare). Jag har att observerat lärare och elever, intervjuat lärare och intervjuar just nu föräldrar och elever kring hur de gör när de använder dessa digitala system. Allt du säger $\mathrm{i}$ intervjun kommer att anonymiseras. Det kommer inte framgå på vilken skola ditt barn går, i vilken kommun eller vad du heter. Presentationer av resultat från projektet kommer att formuleras så att inte enskilda deltagare skall kunna identifieras. Du kan när som helst välja att avluta ditt deltagande i forskningsprojektet utan att ange varför. Väljer du att dra dig ur, bestämmer du om du vill att den information du gett mig hittills ska användas eller inte. Säg till eller fråga om du tycker att något är oklart. Kan jag återkomma till dig om jag skull behöva följa upp något eller få något specificerat som är oklart? Jag kommer ställa några specifika frågor jag är intresserad av att undersöka, men även presentera olika fall eller händelser ni ska få diskutera. Jag tänkte dock börja med att be er berätta lite om Dexter.

\section{Fall 1.}

Du åker hemifrån tidigt på morgonen och din son/dotter ligger fortfarande kvar i sängen. Kvällen innan har hon/han känt sig lite förkyld, men när du kikar in i rummet och frågar hur hon/han mår svarar hon/han bra. Senare på förmiddagen får du ett sms från skolan där det står "NN har noterats som ogiltigt frånvarande". Vad gör du?

\section{Fall 2.}

Din son/dotter har varit sjuk $i$ två dagar och du förstår att han/hon kommer vara sjuk resten av veckan. Hur gör du för att meddela skolan detta?

\section{Fall 3.}

Er familj har planerat att åka på en utlandsresa under sportlovet. Ni kommer att komma hem när skolan redan börjat och ert barn kommer att missa tre skoldagar. Ni ansöker om ledighet, men får nej från skolledningen. Ni bestämmer för att ändå åka. Under de tre sista dagarna på resan får ni sms om att ert barn är ogiltigt frånvarande. Hur reagerar du?

\section{Fall 4.}

Du fär ett sms om att din son/dotter har kommit 10 minuter försent till en lektion. Du berättar detta för ditt barn och hon/han säger att läraren har gjort fel, att hon/han inte alls skulle fätt Dexter där. Vad gör du?

\section{Närvaro och frånvaro}

- Tycker du att det finns det olika typer av skolfrånvaro?

- Finns det tillfällen när det är svårt att om man ska ringa och sjukanmäla eller inte, eller ansöka om ledighet? 
- När anmäler ni ert barns frånvaro? På morgonen? Hur gör ni? Beskriv.

- Finns det tillfällen när du sjukanmält ditt barn fast du inte är säker på att hon eller han är sjuk?

- Har du någon gång glömt att sjukanmäla? Vad hände? Vad gjorde du då?

- Vad är en sen ankomst för dig? Efter hur många minuter ska den registreras så det går ut ett sms?

- Finns det tillfällen när du tycker att det är okej att ditt barn är frånvarande trots att hon/han inte är sjukt?

- Tycker du att det är bra om skolan enkelt kan dokumentera och informera om andra regelbrott än frånvaro, och i så fall vilka?

\section{Hem/skola}

- Hur gjorde du när du anmälde sjukfrånvaro första gången med hjälp av det digitala systemet?

- $\quad$ På vilket sätt informerades du om att frånvaron registreras digitalt? Vilken information fick du då?

- Hur har systemet påverkat kontakten mellan hem och skola? Underlättat/försvårat?

- Hur skulle du önska att kontakten mellan hem och skola gick till gällande frågor som rör skolfrånvaro?

- Har det någon gång hänt att du behövt vända dig till skolan för att de skall ändra en registrering?

- Hur gjorde du när du anmälde frånvaro på elevens tidigare skola?

\section{Eleven och digitala systemet}

- Diskuterar du någon gång inrapporteringen av frånvaro, sms osv med ditt barn?

- Hur tror du att ditt barn upplever att frånvaron registreras digitalt?

\section{SMS}

- Har du någon gång känns dig stressad för att inte hinna ringa och sjukanmäla eller orolig för att få ett sms?

- Hur brukar du reagera när du får ett sms?

- Har du någon gång fått ett sms vid ett olämpligt tillfälle?

- Har du någon gång blivit orolig när du fått ett sms?

\section{Systemet}

Vilken kontakt har du haft med systemet?

- Godkännande av användningen av ett system för närvaro/frånvaroregistrering?

- Registrering av adressuppgifter etc?

- Frånvaroanmälan till talsvar? 
- Vid utvecklingssamtal?

- Hemma, med hjälp av bankid och inloggning?

- Fått sms?

- Hur använder du oftast systemet?

- Hur fick du lära dig hur man använder Dexter? När informerades du om systemet?

- Kan du telefonnumret till Talsvaret/har du det sparat i telefonen?

- Har du någon gång fått del av den information som finns registrerad om ditt barn?

- Vilken information önskade du att du skulle kunna få genom systemet?

- Är du "nöjd" med Dexter? 


\section{Appendix IV}

\section{Interview guide, students}

\section{Intervjuguide}

Min forskning handlar om skolor jobbar med datasystem som Dexter för att registrerar när elever är på lektioner, när de inte är det eller när det kommer för sent. Jag är intresserad av se vad som händer på skolan, men också hemma hos föräldrar och elever när Dexter används. Jag har intervjuat lärare och föräldrar på Råssla och en skola till och nu intervjuar jag elever. Detta för att lära mig vad elever tycker om skolans registrering av närvaro och frånvaro. Intervjuerna jag gör kommer att spelas in för att jag ska komma ihåg vad som sagts. Det är bara jag som kommer att lyssna på inspelningarna. När jag ska berätta och skriva om vad ni tycker kommer inga riktiga namn att avslöjas, utan påhittade namn kommer att användas. Ni kan alltså vara säker på att ingen ska kunna avslöja vad just ni sagt eller på vilken skola ni går. Det är viktigt att ni inte känner er tvingad att delta utan att det är något ni själv vill göra. Tackar ni ja till att delta i undersökningen kan ni när som helst välja att inte längre vara med eller ångra att ni från början gett er tillåtelse. Jag kommer då radera allt material där ni finns med. Säg till eller fråga om det är något ni inte hänger med på.

\section{Vad har jag kommit fram till hittills?}

En del av lärarna tycker att Dexter är bra eftersom det blir tydligt och lätt att se hur mycket någon varit närvarande och frånvarande. Andra lärare tycker att det är krångligt. Några beskriver att de tror att alla göra på samma sätt, medan andra säger att det inte finns något bestämt om hur de ska göra och att alla därför gör lite olika. Några föräldrar tycker att det är viktigt att få reda på varje gång deras barn kommit försent, men andra tycker att det inte är så viktigt att veta om varje femminutare. Lärarna säger att de tror att ni tycker att de gör olika när de skriver in i Dexter och att ni ofta aktar er för Dexter eftersom ni är oroliga för vad föräldrarna ska tycka.

\section{Frånvaro}

- Vilka typer av skolfrånvaro tycker ni att det finns?

- Tycker ni att det är viktigt att registrera närvaro och frånvaro? Varför/varför inte?

- Är det ibland svårt att veta när ni ska stanna hemma från skolan?

- Finns det tillfällen när ni tycker att det är okej att vara frånvarande trots att en inte är sjuk?

- Hur skulle ni själva vilja att närvaro och frånvaron registrerades?

\section{Dexter}

- $\quad$ Är Dexter något ni ibland tänker på?

Vad tänker ni då? Oro, glädje, förvåning, irritation? 
- Pratar ni elever om Dexter med varandra?

- Brukar ni undra eller undersöka om det som är registrerat i Dexter stämmer? Kan ni få reda på det på något sätt? Prata med lärare, få utskrifter, via sms. Skulle ni vilja ha möjligheten?

- Känner ni er någon gång orättvist behandlade när Dexter registreras?

- Vad tycker ni om Dexter?

Är det något som är extra bra?

Extra dåligt?

\section{SMS}

- Hur brukar ni reagera när era föräldrar får sms?

Hur brukar de reagera?

Är det bra att det är föräldrarna som får sms?

Skulle ni vilja få sms själva?

- Vad tycker ni om sms:en?

Är det något som är extra bra?

Extra dåligt?

\section{Lärarna}

- Pratar ni om närvaro och frånvaro med era lärare?

- Pratar ni om Dexter?

- När brukar lärarna registrera närvaro och frånvaro?

- Tycker ni att alla lärare gör på samma sätt?

- Tycker ni alltid att lärarna ska skriva upp när någon kommer för sent?

- Om nej: när tycker ni inte att de ska göra det?

- Hur många minuter tycker att det är okej att ska skriva in?

- Har ni någon gång bett lärarna ändra en registrering?

- Vad tror ni lärarna tycker om Dexter?

\section{Föräldrarna}

- Pratar ni om närvaro och frånvaro i skolan med era föräldrar?

- Pratar ni om Dexter?

- Hur gör ni när ni ska sjukanmäla er? Beskriv

- Har ni någon gång glömt att sjukanmäla? Vad hände? Vad gjorde ni då?

- Vad tror ni era föräldrar tycker om Dexter? 



\section{LINKÖPING STUDIES IN PEDAGOGIC PRACTICES}

1. MARKSTRÖM, ANNE-MARIE. Förskolan som normaliseringspraktik. En etnografisk studie. 2005. ISBN 91-85297-70-4.

2. WEDIN, ANN-SOFI, Lärares arbete och kunskapsbildning. Utmaningar och inviter i den vardagliga praktiken. 2007. ISBN 978-91-85715-63-3.

3. BRÜDE SUNDIN, JOSEFIN. En riktig rektor. Om ledarskap, genus och skolkulturer. 2007. ISBN 978-91-85715-62-6.

4. HELLBERG, KRISTINA. Elever på ett anpassat individuellt gymnasieprogram: skolvardag och vändpunkter. 2007. ISBN 978-91-85831-92-0.

5. SPARRLÖF, GÖRAN. Vi manliga lärare Folkskolans lärare och lärarinnor i kamp om löner och arbetsvillkor 1920-1963. 2007. ISBN 978-91-85831-38-8.

6. KARLSSON, YVONNE. Att inte vilja vara problem. Social organisering och utvärdering av elever i en särskild undervisningsgrupp. 2008. ISBN 978-91-85895-28-1.

7. OLSON, MARIA. Från nationsbyggare till global marknadsnomad. Om medborgarskapet i svensk utbildningspolitik under 1990-talet. 2008. ISBN 978-91-7393-890-7.

8. AYTON, KATARINA. An ordinary school child. Agency and authority in children's schooling. 2008. ISBN 978-91-7393-834-1.

9. BOLANDER, EVA. Risk och bejakande. Sexualitet och genus i sexualupplysning och undervisning i TV. 2009. ISBN 978-91-7393-685-9.

10. JOHNSSON HARRIE, ANNA. Staten och läromedlen. En studie av den svenska statliga förhandsgranskningen av läromedel 1938-1991. 2009. ISBN 978-91-7393-616-3.

11. HÖGBERG, RONNY. Motstånd och konformitet. Om manliga yrkeselevers liv och identitetsskapande i relation till kärnämnena. 2009. ISBN 978-91-7393-543-2.

12. HEGENDER, HENRIK. Mellan akademi och profession. Hur lärarkunskap formuleras och bedöms i verksamhetsförlagd lärarutbildning. 2010. ISBN 978-91-7393-526-5.

13. SEVERINSSON, SUSANNE. Unga i normalitetens gränsland. Undervisning och behandling i särskilda undervisningsgrupper och hem för vård eller boende. 2010. ISBN 978-91-7393-402-2.

14. WIDÈN, PÄR. Bedömningsmakten. Berättelser om stat, lärare och elev, 1960-1995. 2010. ISBN 978-917393-372-8.

15. SANDLUND, MONICA. Lärare med utländsk bakgrund. Sju yrkeslivsberättelser om möten med nya skolsammanhang. 2010. ISBN 978-91-7393-371-1.

16. LILJA, PATRIK. Contextualizing inquiry. Negotiations of tasks, tools and actions in an upper secondary classroom. 2012. ISBN 978-91-7346-735-3

17. FREDRIKSSON, KRISTINA (Licentiatavhandling). Drama som pedagogisk möjlighet. En intervjustudie med lärare i grundskolan. 2013. ISBN 978-91-7519-613-8 
18. BENGTSSON, JENNY. Jag sa att jag älskade han men jag har redan sagt förlåt för det. Ålder, genus och sexualitet i skolans tidigare år. 2013. ISBN 978-91-7519-560-5

19. SÖDERMAN LAGO, LINA. "Mellanklass kan man kalla det". Om tid och meningsskapande vid övergången från förskoleklass till årskurs ett. 2014. ISBN 978-91-7519-349-6

20. STENLIDEN, LINNÉA. Visual Storytelling Interacting in School. Learning Conditions in the Social Science Classroom. 2014. ISBN: 978-91-7519-338-0

21. ELFSTRÖM PETTERSSON, KATARINA (Licentiatavhandling). Playing a part in preschool documentation. A study of how participation is enacted preschool documentation practices and how it is affected by material agents. 2014. ISBN: 978-91-7519-339-7

22. DALGREN, SARA (Licentiatavhandling). Förskolans pedagogiska praktik som interaktion. Frågor och svar i vardagliga förskoleaktiviteter. 2014. ISBN: 978-91-7519-262-8

23. HJORT, SIMON (Licentiatavhandling). Kritiskt tänkande i klassrummet. En studie av didaktiska val och manifesterat kritiskt tänkande i samhällskunskaps- och filosofiundervisning. 2014. ISBN: 978-917519-166-9

24. BOO, SOFIA (Licentiatavhandling). Lärares arbete med individanpassning. Strategier och dilemman i Klassrummet. 2014. ISBN: 978-91-7519-157-7

25. JOHANSSON, MARITHA. Läsa, förstå, analysera. En komparativ studie om svenska och franska gymnasieelevers reception av en narrativ text. 2015. ISBN: 978-91-7685-964-3

26. NORBURG, ULRIKA. Fängelse, skola uppfostringsanstalt eller skyddshem? Åkerbrukskolonien Hall för pojkar år 1876-1940. 2015. ISBN: 978-91-7685980-3

27. ALBINSSON, ANDERS. "De var svinhögt typ 250 kilo”. Förskolebarns mätande av längd, volym och tid i legoleken. 2016. ISBN: 978-91-7685-828-8

28. WINZELL, HELEN (Licentiatavhandling). Svensklärares skrivdidaktiska kunskapsbildning. Blivande och tidigt verksamma gymnasielärare i svenska talar om skrivundervisning. 2016. ISBN: 978-91-7685-788-5 


\section{LINKÖPING STUDIES IN EDUCATION AND SOCIAL SCIENCES}

ISSN 1653-0101

1. SUSANNE, SEVERINSSON. (2010) Unga i normalitetens gränsland: Undervisning och behandling $i$ särskilda undervisningsgrupper och hem för vård eller boende.

(Doktorsavhandling) ISBN: 978-91-7393-402-2

2. KRISTINA, FREDRIKSSON. (2013) Drama som pedagogisk möjlighet. En intervjustudie med lärare i grundskolan. (Lic) ISBN: 978-91-7519-613-8

3. JENNY, BENGTSSON. (2013) Jag sa att jag älskade han men jag har redan sagt förlåt för det. Alder, genus och sexualitet $i$ skolans tidigare år. (Doktorsavhandling) ISBN: 978-917519-560-5

4. KATARINA, ELFSTRÖM PETTERSSON. (2013) Playing a part in preschool documentation - A study of how participation is enacted in preschool documentation practices and how it is affected by material agents. (Lic) ISBN: 978-91-7519-339-7

5. LINA, LAGO. (2014) "Mellanklass kan man kalla det": Om tid och meningsskapande vid övergången från förskoleklass till årskurs ett. (Doktorsavhandling) ISBN: 978-91-7519-349-6

6. LINNEA, STENLIDEN. (2014) Visual Storytelling Interacting in School. Learning Conditions in the Social Science Classroom (Doktorsavhandling) ISBN: 978-91-7519-338-0

7. SARA, DALGREN. (2014)” Förskolans pedagogiska praktik som interaktion. Frågor och svar $i$ vardagliga förskoleaktiviteter. (Lic) ISBN: 978-91-7519-262-8

8. MATS, BEVEMYR (2014) Potentiella lärandesituationer och vardagliga matematiska begrepp. 4-5 åriga barns interaktion vid datorn under fri lek i förskolan (Lic) ISBN: 978-91$7519-259-8$

9. ANDERS, ALBINSSON (2015) "De var svinhögt typ 250 kilo” Förskolebarns mätande av längd, volym och tid i legoleken. ISBN: 978-91-7685-828-8 